\title{
Essays on International Migration and Informal Markets in Developing Countries
}

\author{
Dissertation \\ zur Erlangung des wirtschaftswissenschaftlichen Doktorgrades \\ der Wirtschaftswissenschaftlichen Fakultät \\ der Georg-August-Universität Göttingen
}

vorgelegt am 28.06.2013

von Marcus Böhme

aus Cottbus

Göttingen 2013 
Erstgutachter: Prof. Dr. Jann Lay

Zweitgutachter: Prof. Dr. Stephan Klasen 


\section{Acknowledgements}

The successful completion of this thesis would have never taken place without the unconditional love and support of my parents and my grandparents. I am deeply grateful for their support over all the years. This is why I dedicate this thesis to both my parents Ina and Ulrich.

I would also like to thank my advisor Jann Lay, Stepan Klasen who accepted to be the examiner of this dissertation and my colleagues at the Kiel Institute for their support. Especially, Rainer Thiele, who never grew weary of my countless questions and who never ceased to support me with invaluable advice. It is a real privilege to work with him. I was also incredibly lucky to have such great colleagues as Aslihan Arslan, Christiane Gebühr, Linda Kleeman, Matthias Lücke, Toman Omar Mahmoud, Tobias Stöhr, Manfred Wiebelt and Fred Goretzko.

This acknowledgement would remain incomplete without expressing my gratitude to my girlfriend Nadja König. While the constant support and encouragement of my parents has led to the opportunity to start this thesis I would not have been able to finish it without her help and understanding. 


\section{Table of Contents}

Acknowledgements

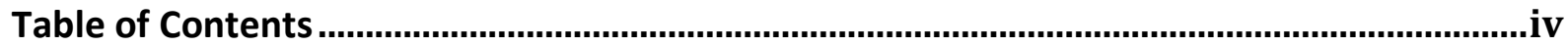

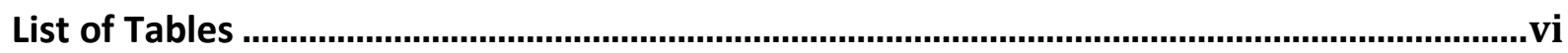

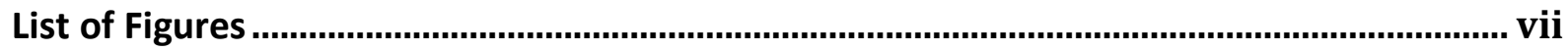

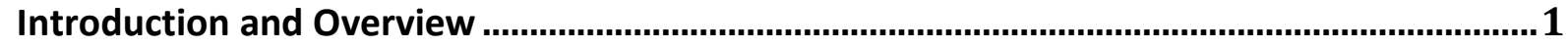

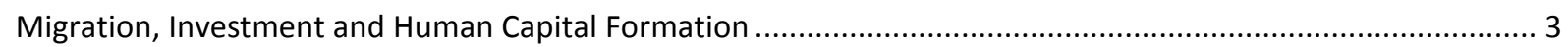

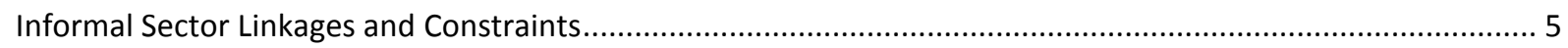

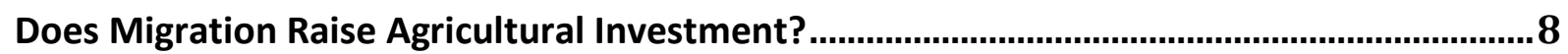

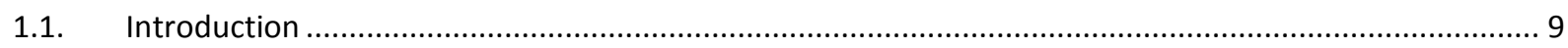

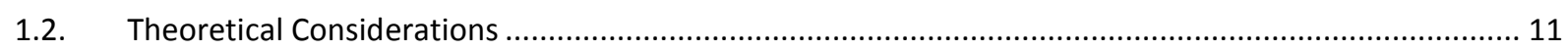

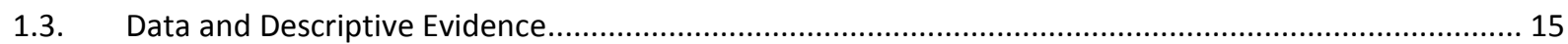

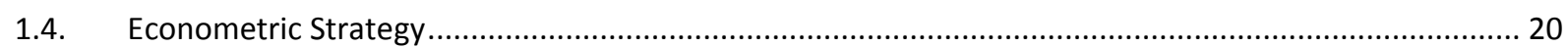

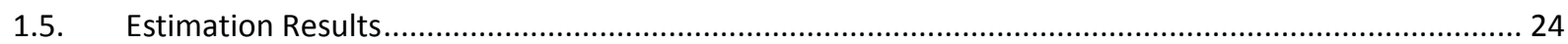

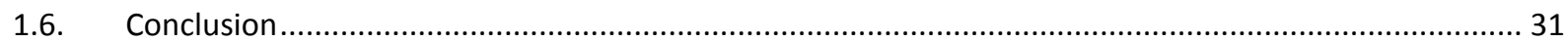

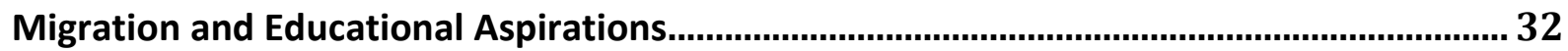

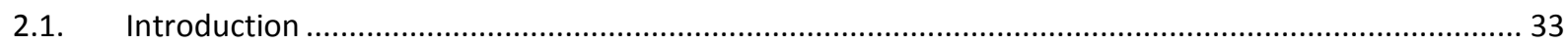

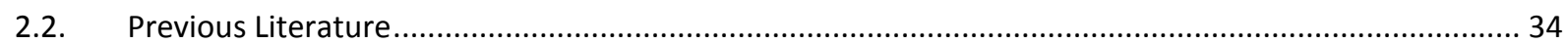

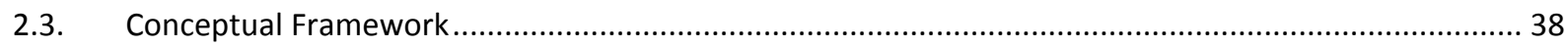

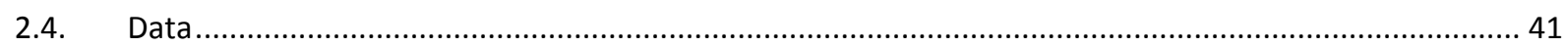

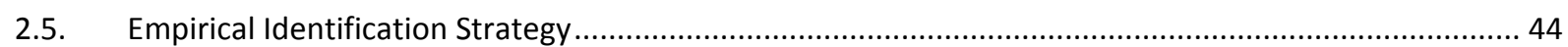

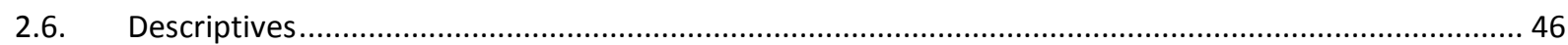

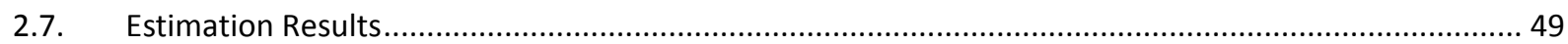

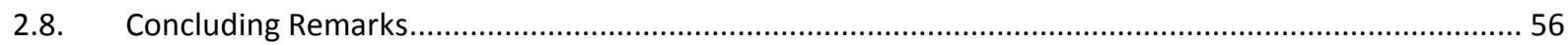


Informal-formal Linkages and Informal Enterprise Performance ............................................ 58

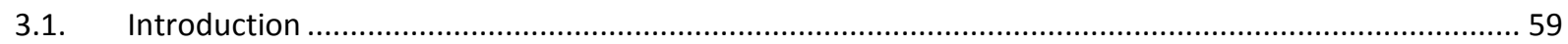

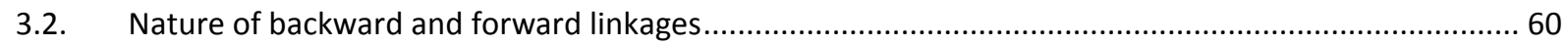

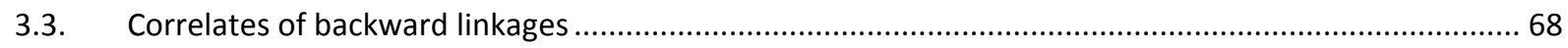

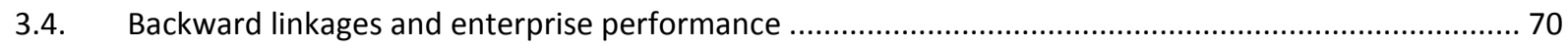

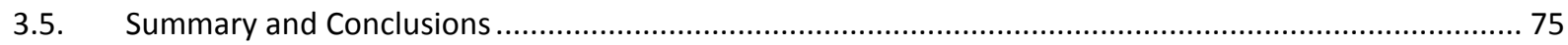

Is the Informal Sector constrained from the demand side?

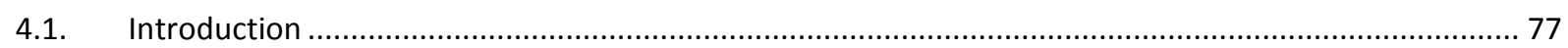

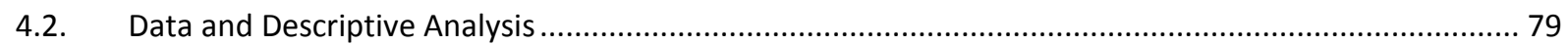

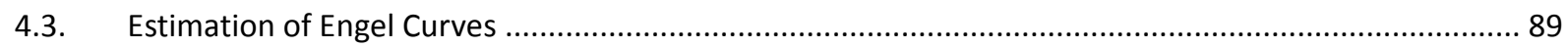

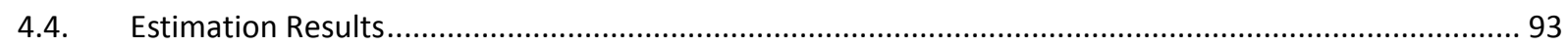

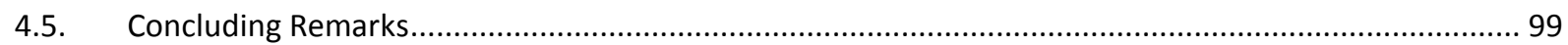

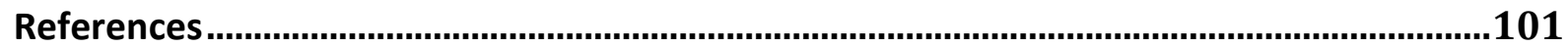




\section{List of Tables}

\section{Essay 1}

Table 1.1 - Household Characteristics. 16

Table 1.2 - Migrant Characteristics.

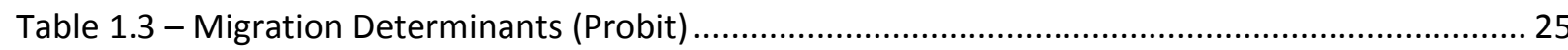

Table 1.4 - Determinants of Investment Volume and Assets (Pooled Regressions) ............................. 26

Table 1.5 - Determinants of Investment Volume and Assets (Lagged Dependent Variable) ............... 27

Table 1.6 - Determinants of Investment Volume and Assets (LDV - Split Sample).............................. 29

Table 1.7 - Determinants of Investment Volume and Assets (Fixed Effects) ....................................... 30

\section{Essay 2}

Table 2.1 - Descriptive Statistics

Table 2.2 - Effect of Aspirations on Enrollment (age 16-18) and Schooling Expenditure .................... 50

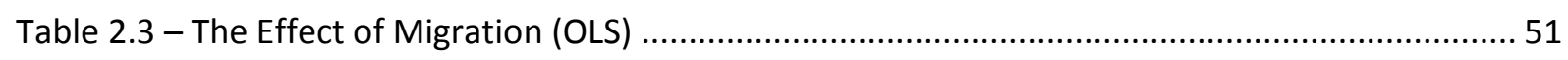

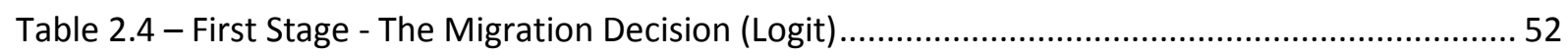

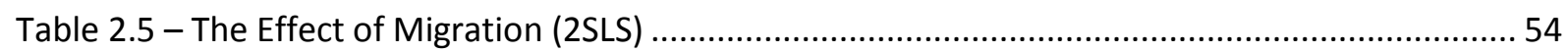

Essay 3

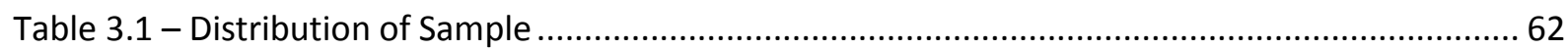

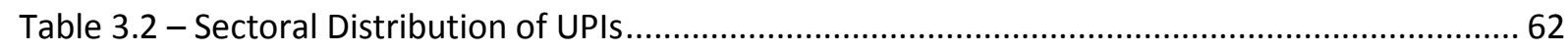

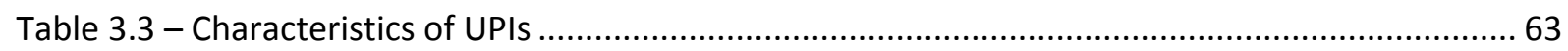

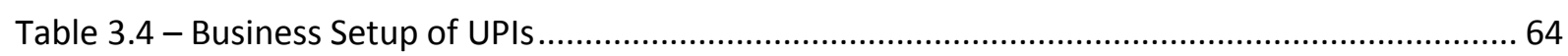

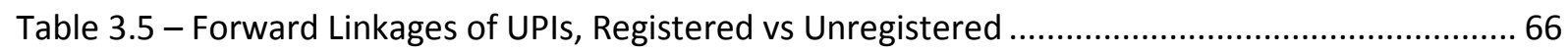

Table 3.6 - Forward Linkages of UPIs, Low Capital Informal vs High Capital Informal .........................66

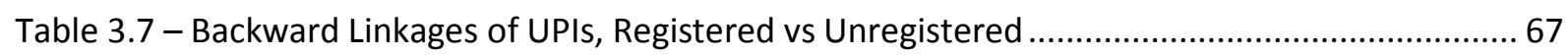

Table 3.8 - Backward Linkages of UPIs, Low Capital Informal vs High Capital Informal........................ 67

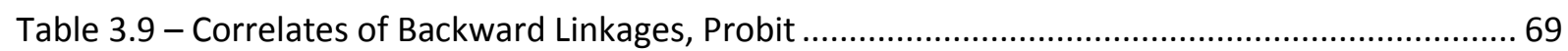

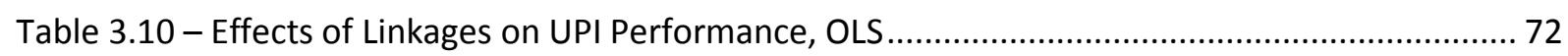

Table 3.11 - Effects of Linkages on UPI Performance, IV Using Forward Linkages as Instrument ....... 74

Table 3.12 - Effects of Linkages on UPI Performance, IV Using Informal Market Share as Instrument74

Essay 4

Table 4.1 - Summary Statistics of Sample Households by Country ................................................. 81

Table 4.2 - National Annual Household Expenditure Shares by Sector (percent) ................................. 83

Table 4.3 - Average Annual Household Expenditure Shares by Sector and Quintile (percent) ........... 84

Table 4.4 - National Annual Household Expenditure Shares by Sector and Distribution Channel (\%) 86

Table 4.5 - National Annual Household Expenditure Shares by Product Category (percent) ............... 87

Table 4.6 - National Shares of Informal Households in Overall Expenditures (percent)....................... 88

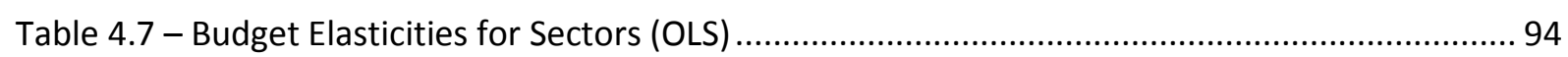

Table 4.8 - Budget Elasticities for Sectors, Quadratic Specification (OLS)........................................... 96

Table 4.9 - Budget Elasticities for Expenditure Categories (2SLS) .................................................... 97 


\section{List of Figures}

\section{Essay 1}

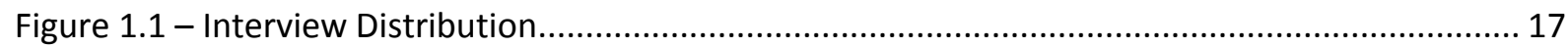

Figure 1.2 - Age Distribution of Household Heads and Spouses by Migration Status....................... 19

Figure 1.3 - Profile Plots of Agricultural Assets ......................................................................... 19

Figure 1.4 - Profile Plots of Livestock................................................................................ 19

Essay 2

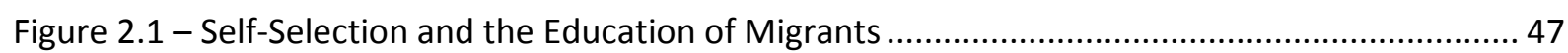

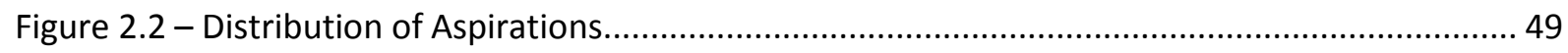

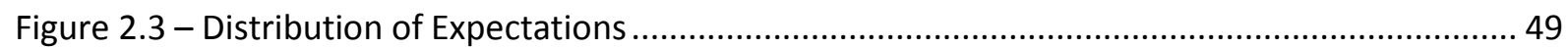

\section{Essay 4}

Figure 4.1 - Elasticities by Product Category and Distribution Channel in Benin 98 


\section{Introduction and Overview}

This thesis looks at two topics that have been prominent on the development agenda for more than five decades: migration and informal markets. These topics made a joint appearance first as core features of Lewis' (1954) dualistic model of economic development. He introduced the central idea that the development of a modern capitalist sector in urban areas of developing countries will be fueled by the inflow of labor from a traditional subsistence sector that is characterized by low wages and negligible or even zero marginal productivity. In Lewis' theory the existence of segmented labor markets implies that the increase in capital formation in the capitalist sector leads to an increasing employment of peasant farmers in industrial production. After the national labor surplus is exhausted and wages begin to rise the surplus labor from other countries will be attracted resulting in 'mass immigration'.

In the following years two strands of literature grew out of Lewis' contribution. The first started with the papers by Todaro (1969) and Harris and Todaro (1970) who emphasized the determinants of migration to understand the factors that underlie persistent rural-urban migration in the face of high unemployment rates in the urban centers. These authors identified not only wage-differentials but also employment probabilities as the main driver of migration, i.e. the expected returns from migration. The original focus of this literature, although Lewis had pointed to the importance of international migration, lay on movements from rural to urban areas within national boundaries. In the last decades this research field has extended its scope to international migration but is still strongly influenced by the classical approach in that it concentrates on wage differentials and unemployment probabilities.

The second strand of literature can be traced back to Hart (1973) who took a closer look at the persistent attraction of the urban sector despite high official unemployment rates. He argued that migrants who did not find work in the formal sector would not remain unemployed. They would rather work in what he called the 'informal' sector. He thereby extended the original labor market segmentation of subsistence and capitalist sector of Lewis (1954) and applied it to the urban labor market labeling both segments formal and informal. The prevailing perception was that the informal sector is a residual that hosts all those who are not absorbed by the formal labor market. Hence, as in Lewis' theory the informal sector was seen as a sector of low marginal productivity.

Since the discussion was initiated in the 1950s, the economic and social context in which both migration and informality take place have changed dramatically in scope and scale. Between 1960 and 2010 the population of low and middle income countries more than doubled. The population 
growth coupled with decreasing transportation costs and persistent international wage gaps resulted in an almost fivefold increase in the emigration rate of these countries. Today an estimated 3 percent of the world population lives outside their country of birth. The increased mobility of people holds an enormous potential for increasing the welfare of migrants and for economic development of sending communities due to the capital flows generated by migrants. These remittances account for almost one quarter of national GDP of some countries such as Lesotho, Moldova and Nepal. The economic importance of remittances becomes even more visible through a comparison with other flows of external capital. While the combined official development assistance (ODA) amounted to USD 135.4 billion in 2011 officially recorded remittances sent in 2011 sum up to USD 479.2 billion. Although global foreign direct investment still constitutes the largest monetary flow amounting to USD 1658.13 billion, remittances appear to close this gap soon. Since 2000 remittances grew by 253.7 percent, clearly outperforming official development assistance (25.4 percent) and foreign direct investment (172.5 percent). ${ }^{1}$

Nevertheless, there are also potential downsides to migration. Apart from concerns about economic dependency and the inequality inducing effect of migration, two aspects figure most prominently in the recent discussion (de Haas 2010). First, the outflow of skilled labor is feared to reduce the human capital stock of migrant sending countries. Although remittances have a compensating effect they cannot always offset the negative externalities of the large-scale departure of many young and talented workers. This so called brain drain could be limiting long-term growth of the migrant sending countries. A second concern is the non-productive use of remittances. More precisely various authors have argued that households spend remittances disproportionately on consumer and status goods and do not employ the received capital productively. The outflow of workers coupled with the lack of investment could lead to stagnating local economies in the long run.

The increasing population was to large extent also absorbed by the urban areas resulting in a doubling of urbanization rates to almost 50 percent. In the urban areas the informal sector has become an extensive element of the economic landscape in middle and low income countries that affects the livelihood of hundreds of millions, provides employment and contributes to economic production. Estimates indicate that for some countries such as Nigeria, Egypt and Thailand the informal sector contributes as much as two thirds of GDP (Schneider and Ernste 2000). The informal sector is the main source of employment in many countries. Xaba et al. (2002) reports that around one quarter of urban employment in many countries in Sub-Saharan Africa are provided by the informal sector. For some countries such as Thailand, Boliva and Paraguay the share of informal workers is estimated to be above 70 percent (Blunch et al. 2001, Gasparini and Tornarolli 2009).

\footnotetext{
${ }^{1}$ All figures in nominal terms and based on World Development Indicators database 2013.
} 
Despite its economic importance it is undisputed that a large informal sector also has important drawbacks. Among them are problems such as limited government budgets due to foregone taxes and the impossibility to adjust government policies to the 'invisible' needs of the informal sector. Furthermore, enterprises operating informally may face constraints that directly impact on employment and income prospects of large parts of the population (Perry et al. 2007). If informal enterprises are limited in their growth and if existing constraints force them to produce below their optimum output level, the income of workers might be capped lastingly. Additionally, workers in the informal sector often remain uninsured against health shocks and other risks as well as uncovered by retirement benefit schemes, since the informal enterprises often do not provide formal mechanisms to cope with shocks for their workers. Thus workers tend to remain poor and vulnerable to adverse shocks despite employment.

To mitigate the problems of both migration and the informal sector, and harness their development potential, a clear understanding of the mechanisms at work is crucial. The present thesis aims to contribute to such an understanding by examining several issues that have not been resolved. The first two essays focus on the relationship between international migration and household investments addressing the problem of brain drain and the use of remittances. Essays three and four explore the constraints of enterprises in the informal sector. In the remaining part of this introduction we will first present the general context and background of each aspect and thereafter summarize the findings presented in detail in the four essays.

\section{Migration, Investment and Human Capital Formation}

In the classical contributions to the literature the determinants of agents' migration decisions were considered only at the individual level (e.g. Sjaastad 1962, Lee 1966, Todaro 1969, Harris and Todaro 1970, Fields 1975). The impact of migration on the sending communities and migrant households was almost absent from the literature. This gap was filled by the "New Economics of Labor Migration" (NELM) (e.g. Stark and Bloom 1985, Stark and Taylor 1989). The new class of models differed in two respects from existing research. First, it rejected the individualistic framework of the neo-classical models and spelled out migration as a household decision. Second, NELM concentrated on the effects of migration on sending communities and household members left behind. Under NELM migration is seen as a strategy to overcome liquidity constraints and as an instrument to diversify the household income portfolio in the presence of imperfect credit and insurance markets. Hence, the optimal decision is taken at the household-level and takes into account the trade-off between maximizing household income and minimizing income risk in imperfect markets. 
While empirical investigations have documented the positive effect of migration on poverty reduction and consumption in developing countries (e.g. Adams and Page 2005, Acosta et al. 2008), it is still disputed how these remittances are used. At the macro-level there is no evidence that remittances have had any impact on economic growth. Barajas et al. (2009) provide evidence that during the period 1970 to 2004 in their sample of 84 countries there was no effect of remittances on growth. They conclude that although increasing household income leads to poverty alleviation and increasing consumption levels, remittances are not used for productive investments. However at the micro-level the picture remains quite mixed. There is some evidence of a negative correlation between agricultural investments and remittances, for example from China (De Brauw and Rozelle 2008) and the Philippines (Quisumbing and McNiven 2010), while the opposite, i.e. a positive effect of migration on productive investments, has been documented for example for Pakistan (Adams 1998) and Mexico (Chiodi et al. 2012).

Essay 1 adds to this literature by providing novel evidence for the case of Mexico. In this paper we seek to assess empirically how remittances affect the investment behavior of households. Our approach differs from previous contributions by accounting explicitly for the diverse income generating activities of rural households by distinguishing between agriculture and livestock and by considering the presence of life-cycle effects in all estimations. We employ a panel dataset for the years 2002 and 2007 that is representative for rural Mexico and includes 1511 households in both waves. After addressing the problem of endogeneity by using an instrumental variable approach three results emerge from our analysis. First, life-cycle effects exert a strong and robust effect on investment activities in all households. More specifically, household investments decrease as the household head ages. There is some suggestive evidence that migrant households disinvest more strongly than households without migrants. Second, our results indicate that production fundamentals such as cash flows from other activities remain highly important for farm investments despite the presence of remittances. Throughout all estimated model specifications and investment categories cash flows are the best predictor of productive investments. Third, the differentiation of agriculture and livestock exposes important differences in the investment activities in these two categories. We find that migrants have accumulated more agricultural productive capital than nonmigrants while there is no significant difference with respect to livestock. This could indicate that households continue their agricultural activities to ensure daily consumption throughout the lifecycle. This result is closely in line with the finding by Damon (2010) that migrant households tend to give up high value crops and focus increasingly on subsistence crops.

Monetary remittances are only one aspect of migration. Human mobility also affects the transmission of information, values and norms. Recently these so called social remittances have been 
investigated primarily with a focus on political institutions and outcomes. Both, studies relying on macro data (e.g. Docquier et al. 2011, Beine and Sekkat 2011, Spilimbergo 2009), as well as analysis using micro data (e.g. Batista and Vicente 2011, Omar Mahmoud et al. 2012, Chauvet and Mercier 2013) find that migration has indeed a strong effect on democratic institutions and political values in the countries of origin. Integrating social change into the list of possible migration outcomes is important to allow a holistic analysis of the migration-development nexus. Yet, it should not be limited to the political realm but also include a wider array of social norms such as educational values.

In Essay 2 we analyze the effect of migration on educational aspirations of caregivers and the resulting accumulation of human capital in migrant sending households. After outlining the causal mechanism underlying the relationship between migration, aspirations and human capital investments in the conceptual framework the essay's focus is on the empirical estimation of the effect of migration on the educational aspirations of caregivers in Moldova. The data we use comes from a nationally representative household survey that was conducted in 2011/12. While the whole dataset contains detailed information about 3539 households we restrict our analysis to the 2082 households in the sample with children. We correct for self-selection of migrants using instrumental variables based on GDP growth at the migration destinations and the presence of Soviet military personnel in the community before 1990. Our results suggest that migration can have a strongly positive effect on the educational trajectory of children in migrant households at the lower end of the human capital distribution through migration-induced upward adjustment of the educational aspirations of caregivers. Based on this finding we suggest a new channel of brain gain in the context of international migration. More precisely, while theoretical brain gain models only rely on monetary incentives we argue that an increase in human capital investment could also stem from the changes in aspirations triggered by international migration. We therefore present additional evidence that the pessimistic view of a brain drain caused by the outflow of human capital might not necessarily be true.

\section{Informal Sector Linkages and Constraints}

Early contributions to the literature on the informal sector often departed from a dualistic labor market, where entry barriers would force enterprises to remain informal. In this context salaried work in the informal sector and informal self-employment was traditionally seen as a survival strategy (e.g. Leibenstein 1968, Fields 1975, Mazumdar 1976, Dickens and Land 1985). This approach assumes that individuals are forced to work in the informal sector because of institutional barriers and discrimination. The models characterizing the informal sector as an option of last resort became 
challenged by recent empirical contributions characterizing the informal sector as vibrant and dynamic (Ranis and Stewart 1999, Maloney 2004). In this context informality is seen as a rational choice where entrepreneurs, after weighing the costs and benefits, opt voluntarily for the informal sector. The primary reason for this rational choice is often seen in the existence of regulatory burden and formal sector inefficiencies. However the informal sector also offers non-pecuniary benefits such as flexible work time or the opportunity to use entrepreneurial abilities. For young people it also provides easier entry into the labor market that allows them to obtain experience and training (Arias and Khamis 2008).

Another aspect that has recently received more attention is the heterogeneous character of the informal sector itself. Various authors have suggested that the informal sector is comprised of smallscale subsistence firms and larger firms. Ranis and Stewart (1999) differentiated between a dynamic sub-sector that is tied to the formal sector by subcontracts and a subsistence sub-sector. The existing empirical evidence supports the theory that the informal sector is in fact not homogenous and consists of both a lower-tier segment that is constrained and an upper-tier segment that is composed of vibrant and dynamic firms that opt voluntarily for the informal sector (e.g. Günther and Launov 2012, Bruhn 2013). The heterogeneity of the informal sector implies that a reform of business registration regulations to minimize the costs associated with formalization would affect the behavior of enterprises differently. Various studies have shown that micro-enterprises do not benefit from formalization (e.g. Fajnzylber et al. 2011, McKenzie and Sakho 2010). De Mel et al. (2012) argue that the reason for this result is the low net benefit of formalization. Analyzing a policy experiment from Sri Lanka they show that the mean increase in profits due to formalization is driven only by firms in the upper tier of the productivity distribution. These firms indeed engage in increased advertising and the use of advanced accounting instruments once formalized. Yet, if formality is only beneficial for mid-sized and large firms the focus should not be on simply formalizing firms but to allow them to grow. There is ample evidence that investments in these micro-firms can yield very high returns (e.g. McKenzie and Woodruff 2008, Grimm et al. 2012). Hence, the fact that these firms do not graduate from their (informal) micro status has to be understood as evidence for the existence of binding constraints. In Essays 3 and 4 we will concentrate on two types of constraints informal enterprises face.

Essay 3 investigates the forward and backward linkages of enterprises in the informal sector with the formal sector. We seek to find out how informal enterprises are linked to the formal sector and how these linkages affect their performance in general. We use a cross-sectional dataset called "Enquêtes 1-2-3" that was assembled between 2001 and 2003. It contains detailed information about 5785 informal enterprises in Cotonou, Ouagadougou, Abidjan, Bamako, Dakar and Lomé. We 
find that although informal enterprises have both forward and backward linkages with the formal sector, backward linkages are more prevalent. We also observe that informal-formal linkages occur less frequently if firms have a high degree of informality or low capital stocks. These descriptive results call standard dual economy models into question and suggest a complex interaction between the formal and the informal sector. With respect to the effect of linkages on firm performance we find positive effect of formal backward linkages on all performance indicators employed. Using both ordinary least squares and instrumental variable estimation strategies we find that informality affects enterprise performance only indirectly through the existence of linkages to the formal sector. These estimation results let us conclude that one way to support the informal enterprises under investigation would be legal reforms that facilitate the interactions and transactions between firms in both the informal and the formal sector.

To understand the constraints of enterprises not only supply side factors are important but also the demand structure they face. The last essay of this thesis therefore looks at the demand side of informal firms by investigating the expenditure structure of urban households in six West African countries. The data for this analysis is based on a household expenditure module that was part of the "Enquêtes 1-2-3". It recorded expenditures and point of sale for 315 different products and services. The different characteristics of these products and services allow us to infer their informal or formal nature. We first analyze the distribution channel of both formal and informal products. There seem to be strong linkages between the formal and informal sector as many formal products are sold through retailers in the informal sector. However specifically informal goods are rarely bought at formal points of sale. We then turn to the demand elasticities of these different products. Based on estimated Engel curves our results tend to show that rising incomes are associated with an increased propensity to consume formal sector goods. By contrast elasticities for informal goods remain below unity throughout. Interestingly enough we observe little systematic variation in our estimates across the six countries. These results indicate that although there is a strongly overlapping customer base between the formal and the informal sector, the informal sector might be limited in its growth prospects by the changing demand structure of developing and emerging countries. 


\section{Essay 1}

\section{Does Migration Raise Agricultural Investment?}

An Empirical Analysis for Rural Mexico

\section{Abstract}

The effect of remittances on capital accumulation remains a contested topic. This essay uses a panel data set from rural Mexico to investigate the impact of remittances on agriculture and livestock investments. After controlling for the endogeneity of migration through an instrumental variable estimation our empirical results show that international migration has a significantly positive effect on the accumulated agricultural assets but not on livestock capital. This suggests that households use the capital obtained from international migration only to overcome liquidity constraints for subsistence production whereas migration itself seems to be the superior investment option compared to other productive activities such as livestock husbandry.

Keywords: migration, investment, Mexico, agriculture

JEL classification: D1, J6, 01 


\subsection{Introduction}

Migration has received increasing attention in the development discussion over the last couple of years. This is due to the sheer magnitude of national and international migration and the perceived development opportunities this holds when considering the flows of money generated by migrants in the form of remittances. Nevertheless it remains disputed which strata of the society in sending countries benefit most from migration and what consequences the dynamic process of migration has for society in general. One topic that lacks consensus in particular is the use of remittances.

The New Economics of Labor Migration (NELM) theory considers migration as a household strategy to overcome market failures such as credit constraints and missing insurance markets (e.g. Stark and Bloom 1985, Taylor 1999). Accordingly, it is argued that migration generates liquidity in the form of remittances which enables the households to invest in profitable activities. Hence, if credit constraints are binding for the households that have migrants, theory predicts that remittances will increase productive investments. Additionally, if the income generated by migration is uncorrelated or negatively correlated with other available income sources, it also reduces the overall income risk of the household. This insurance function can also have indirect effects on the investment behavior of farm households. Since modern production technology can increase the ex-ante risk farmers face, all activities that reduce the overall income risk can lead to the adoption of more risky but also more profitable production technologies (e.g. Lamb 2003, Mendola 2008).

In the empirical literature that is explicitly concerned with the nexus of migration and investment the effects of remittances on productive investments remain contested. Some authors present evidence that remittance receiving households have a higher propensity to invest (e.g. Adams 1998, Yang 2008, Chiodi et al. 2012) and that they are able to raise agricultural productivity (e.g. Lucas 1987, Taylor et al. 2003, Taylor and Lopez-Feldman 2010). However, various other authors find that remittances often have only weakly positive or even negative effects on the productive investment propensity and volume of households engaged in the agricultural sector (e.g. De Brauw and Rozelle 2008, Quisumbing and McNiven 2010) and that migration can also result in falling productivity for agricultural households (e.g. Rozelle et al. 1999, Damon 2010).

The conflicting findings regarding the impact of migration on the accumulation of productive agricultural assets are often reconciled by invoking theoretical explanations. One prominent explanation that is given in the context of NELM is the effect of missing labor markets (e.g. Rozelle et al. 1999, Damon 2010). If it is impossible to compensate the loss of household labor by hiring workers or hired labor is not a perfect substitute for family labor, a decrease in production, a move away from labor intensive crops or the use of labor-saving technologies can be expected as a 
consequence of remittances. If the negative labor market effect is bigger than the beneficial effect of relaxing credit constraints then there will be a negative impact of migration on agricultural investment and production.

Apart from this theoretical reconciliation of NELM with the ambiguous empirical results there are three additional issues that may give rise to more complex empirics than NELM suggests but are often neglected in empirical studies. First, studies that investigate the effect of migration on agricultural investments often do so without taking into account the structure of the standard factor demand model that describes investment behavior for a value maximizing farm. One central prediction of the financial theory of investment is that under imperfect capital markets investment decisions will be determined strongly by internal sources of finance (Hubbard 1998). Empirical approaches to agricultural investment behavior often employ a measure of cash flows to estimate the effect of inside finance on investments (e.g. Elhorst 1993, Hubbard and Kashyap 1992, Bierlen and Featherstone 1998). However, most studies that are concerned with the role of migration in the agricultural investment process only consider a reduced causal model without taking into account cash flows.

Second, most studies do not account for the timing and heterogeneity of investments, either by neglecting the difference between capital stocks and flows or by pooling different capital categories. Although capital stocks depend by definition on capital flows and both are assumed to be proportional to each other, the measurement of stocks and flows is characterized by different issues. While observed stocks are determined by past investments, depreciation and retirement, observed capital flows in a particular period might be a weak representation of overall investment behavior due to the lumpy and infrequent nature of many capital investments. With respect to the pooling of distinct capital categories, such as agriculture and livestock, it is clear that neglecting the fundamental difference in characteristics of different agricultural income generating activities is likely to result in estimation results that do not reflect the true investment process. In the empirical literature, only the differential effect of migration on farm and non-farm investments has received considerable attention. Various studies have shown that remittances and the savings of returning migrants enable households to engage in off-farm self-employment in Albania (Piracha and Vadean 2010), China (Démurger and Xu 2011), Egypt (McCormick and Wahba 2003), Pakistan (Ilahi 1999), and Turkey (Dustman and Kirchkamp 2002). Also for Mexico, evidence has been presented that remittances facilitate the formation of off-farm self-employment opportunities (e.g. Mesnard 2004, Woodruff and Zenteno 2007).

Third, most studies are based on cross-sectional data and cannot take into account household and migration life-cycle effects. Yet if the permanent income hypothesis holds for rural households 
we should observe that households seek to smooth consumption over the course of their life time. In the context of NELM the life-cycle has not been considered explicitly. The implicit assumption is that due to the transmission of wealth over generations, capital accumulation would not be affected by consumption smoothing. Yet without this bequest motive households would start to disinvest during old age. On the other hand households that do not bequest but can smooth consumption due to the increased liquidity provided by remittances might follow life-cycle consumption patterns more than those that are liquidity constrained (Zeldes 1989). Ahituv and Kimhi (2002) explored this topic in the context of agricultural investments and off-farm work. They found that the capital accumulation of farmers in Israel tends to follow an inverted U-curve over the life-cycle. With regard to international migration life-cycle effects have only received attention in the context of the savings and return behavior of migrants (e.g. Dustmann 1997, Dustmann and Kirchkamp 2002, Mesnard 2004) but not for productive investments.

This essay contributes to the literature by concentrating on these three neglected aspects of the migration-investment nexus. By emphasizing the role of demographic variables and production fundamentals that underlie observed household behavior and differentiating between different productive categories as well as stock and flow variables it offers a new perspective on the effect of migration on productive investments. Also, by employing a unique panel dataset we can address some of the problems faced by previous cross-sectional studies. To briefly summarize our findings, migration that occurs at a late stage of the household life-cycle might not alter productive investments due to the short horizon for the realization of investment returns, production fundamentals such as cash flows generated through sales turn out to be the most important determinant of investments, and capital from migration is used to invest in subsistence categories such as crop production but not for other risky activities such as livestock husbandry.

The remainder of the essay is organized as follows. In section 1.2 we lay out the theoretical framework that will guide the empirical analysis. In section 1.3 we describe the data set and define our core variables. Section 1.4 outlines the econometric approach and discusses the estimation methods employed, while section 1.5 presents our main results. The essay concludes with a short summary and discussion of the results.

\subsection{Theoretical Considerations}

In this section, we discuss a simple two period farm household model with migration which forms the theoretical framework of our empirical analysis. We use a household model comparable to the one 
proposed by Wouterse and Taylor (2008). The household is assumed to have a well-behaved twoperiod utility function:

$$
U=U\left(C_{1}, C_{2}\right)=U\left(C_{1}\right)+\beta \cdot U\left(C_{2}\right)
$$

This additively separable utility function is continuously differentiable, monotonically increasing and strictly concave in both periods. Utility comes only from consumption $\left(C_{1}, C_{2}\right)$ in both periods and is discounted by $\beta$ in the second period. While the standard agricultural household model separates agricultural and market purchased goods we simplify this structure by assuming without loss of generality that agricultural production generates the means for consumption. Our setup naturally assumes that household resources are pooled and that the allocation of resources and the organization of production are efficient. The production constraint the household faces is characterized by:

$$
Q=f(K, L)
$$

where $K$ is capital and $L$ labor and $Q$ exhibits the characteristics $f_{k}^{\prime}(\bullet)>0, f_{k}^{\prime \prime}(\bullet)<0, f_{L}^{\prime}(\bullet)>0$ and $f_{L}^{\prime \prime}(\bullet)<0$. In this static model we omit the risk involved in agricultural production and assume perfect foresight on the part of the household. We assume that the household produces without hired labor which implies that $\mathrm{L}$ represents the total stock of household time. The household can allocate time in the first period either to agricultural production $(Q)$ or to migration $(M)$, which generates remittances $(R)$.

$$
R=g(M, X, W, E)
$$

The decision to migrate and therefore the receipt of remittances depend on the characteristics of the individual $(X)$, the wages at the destination $(W)$, and the expenditures necessary to pay for migration $(E)$. This decision process and the role of wage differentials have been amply discussed in the literature (e.g. McKenzie and Rapoport 2010). Remittances increase in wages (i.e. the wage differential) and the probability to find employment abroad, and decrease in the cost of migration. However, since our interest lies in the use of remittances there is no need to model this process explicitly.

In our model there is no capital market. Hence cash flows are the only means to finance investments. We choose to limit our analysis to the internal funds to reflect the prevalent capital market imperfection in rural Mexico. ${ }^{2}$ Cash flows are generated by either the remittances sent by migrants or agricultural production revenues and can be used for consumption $(C)$ and investments

\footnotetext{
${ }^{2}$ See Fazzari, Hubbard and Petersen (1988) for an extensive discussion of the role of internal funds for investments in a constrained environment.
} 
$(I)$ or can be saved $(S)$. If they are invested they augment the capital stock in the second period. The time path of the capital stock is described by $K_{t+1}=(1-\zeta) K_{t}+I$, where $\zeta$ is the depreciation of capital. We can summarize the behavioral constraints as follows:

$$
C_{1}=p_{1} \cdot f\left(K_{1}, L-M\right)+R-I-S
$$

$$
C_{2}=p_{2} \cdot f\left((1-\zeta) K_{1}+I, L\right)+(1+\delta) S
$$

where $p_{t}$ is the market price of the produced commodity, and $\delta$ is the return to savings $(S)$. We assume that farmers cannot liquidate their capital. Thus, while we do not explicitly include installation and adjustment cost, this irreversibility assumption of investment can be interpreted as an adjustment cost. The household thus faces the following maximization problem:

$$
\begin{array}{cc}
\max _{\{M, I, S\}} U\left(p_{1} \cdot f\left(K_{1}, L-M\right)+g(M, X, W, E)-I-S\right)+ \\
\beta U\left(p_{2} \cdot f\left((1-\zeta) \cdot K_{1}+I, L\right)+(1+\delta) S\right)
\end{array}
$$

Maximizing equation (6) with respect to migration, investment and savings yields the following first order conditions:

$$
\begin{array}{ll}
\text { FOC }(\mathrm{S}): & (1+\delta)=\frac{U^{\prime}\left(C_{1}\right)}{\beta U^{\prime}\left(C_{2}\right)} \\
\text { FOC (M): } & p_{1} \cdot f_{M}^{\prime}\left(K_{1}, L-M\right)=g_{M}^{\prime}(M, X, W, E) \\
\text { FOC (I): } & \frac{U^{\prime}\left(C_{1}\right)}{\beta U^{\prime}\left(C_{2}\right)}=p_{2} \cdot f_{I}^{\prime}\left((1-\zeta) \cdot K_{1}+I, L\right)
\end{array}
$$

The first order condition for savings describes the standard intertemporal substitution of present and future consumption. Equation (8) represents the first order condition with respect to migration. It states that the migration must yield a marginal return that is (at least) as big as the marginal product of labor in the household production. Equation (9) shows that investments are determined by the marginal productivity of additional capital, the capital depreciation, and the intertemporal discount factor. It is also clear that market forces, represented by fluctuations in the output price, are an important determinant.

In this simple setting there are three potential mechanisms that could explain a lack of investment. First, if the discounting is very strong, we should expect, based on equation (9), that investments are very small. The high preference for current consumption must not necessarily be 
due to impatience but could also reflect decreasing utility from investment in the context of the permanent income hypothesis. According to this logic it is also possible that household heads get too old to work on the farm. In this case labor input becomes zero and the household has no agricultural labor and no production in the second period. Both of these lines of argument imply that the marginal utility from investment would become very small or even zero.

Second, it could be that households adjust their income portfolio based on the investment horizon and the marginal return of investment for different categories. For example, contrary to the standard NELM arguments, households invest until their marginal returns to investment in a specific category such as agriculture or livestock are equalized with the marginal cost and then start looking for a more profitable investment alternative: migration. In this scenario equation (5) would be reduced to savings and no investment would be undertaken. One explanation why rural households do not start investing in migration in the first place can be found in the comparatively high cost of migration. This is also the reason why often the middle class starts to migrate first (McKenzie and Rapoport 2007). While we do not model risk explicitly we have to acknowledge that the portfolio adjustment could also be brought about by the risk attached to additional investments in combination with the age of the household head. Gollier and Zeckhauser (2002) demonstrated theoretically the relationship between the risk of the asset category and the investment horizon of an agent. They showed that older people prefer less risky assets compared to younger individuals with the same characteristics under the assumption of risk aversion.

A third explanation would be the rejection of the fungibility hypothesis of remittances. This implies that money received from migrants is not spent at the margin like income from other household activities but is used only for specific expenditure categories. Remittances could be earmarked by the migrant for specific uses such as human capital investments. Davies et al. (2009) argue that the significantly different marginal propensities to consume of various income categories and remittances they estimate for households in Malawi can be interpreted as evidence for the presence of mental accounting. Investments would then be financed only through cash flows from the production in the first period. Given that in case of migration the output in period one is likely to decrease due to the loss of labor, the overall cash available for investment would also decrease. In this case the investment predicted by equation (9) is by definition smaller than in a situation where remittances can be freely allocated.

Guided by this discussion we proceed in the empirical analysis as follows. First, we try to find out how funds obtained through migration change investment. We do so by looking at the direct effect of migration on investments as well as the indirect effect migration has on the financing structure of investments. Second, we distinguish two types of activities and capital, namely agriculture and 
livestock, to evaluate if they are qualitatively the same and can be aggregated as practiced in many empirical investigations. Third, we evaluate the presence of life-cycle effects in all estimations. If the expectations of the household are independent of time, the age of the farmer should not play a significant role.

\subsection{Data and Descriptive Evidence}

Our panel data set contains the results of two nationally representative rural household surveys called Encuesta Nacional a Hogares Rurales de Mexico (ENHRUM) which were implemented by the Colegio de Mexico (PRECESAM) and the University of California at Davis in 2002 and 2007 in 14 states of Mexico (see Figure 1.1). The multi-stage sampling frame was based on a general population census of the year 2000 for municipalities of between 500 and 2499 inhabitants. Due to attrition we lost 222 households in the second round, which leaves us with a sample of 1511 observations that are present in both waves.

The ENHRUM covered a broad range of topics including individual migration histories, labor market participation and various socio-economic variables such as education, health and fertility as well as agricultural production and non-agricultural business activities. As shown in Table 1.1, households had on average 4.5 (4.3) members and a household head with an average age of 48.9 (53.4) years in 2002 (2007). ${ }^{3}$ Migrant households were significantly older in both years and had significantly less education than non-migrant households. In both years, income from farm activities constituted on average less than 10 percent of total income for all households. Income from livestock and non-farm businesses was also rather small, accounting for 4-8 percent of total income. This is due to the fact that less than half of the households had agricultural activities or livestock income and less than a third had non-agricultural businesses. The major sources of income were farm (11-19 percent) and non-farm wages (21-31 percent). For households with international migrants farm and non-farm wages constituted only between 11 and 13 percent of total income while remittances made up 38 percent and 36 percent of their annual total income in 2002 and 2007, respectively. Income from transfers was equivalent to 14 percent (2002) and 18 percent (2007) of annual total income for non-migrant households and 11 percent (2002) and 13 percent (2007) of annual total income for households with international migrants. The average household was endowed with agricultural machinery worth 4,722 (8,785) Mexican pesos (MXN) and livestock with an average value

\footnotetext{
${ }^{3}$ Since only 14 households had a household head in 2007 that was different from the household head in 2002 there is no reason to be concerned about changes in the intra-household composition.
} 
of MXN 8,579 (11,186) in 2002 (2007). Comparing the descriptive statistics of income composition with respect to wages and remittances suggests that migrants substitute local wage employment with international migration. Furthermore, income shares earned from agriculture and livestock activities do not differ significantly between migrant and non-migrant households. Yet, Table 1.1 shows that migrant households had significantly higher per capita income and accumulated significantly more agricultural assets as well as livestock.

Table 1.1 - Household Characteristics

\begin{tabular}{|c|c|c|c|c|c|c|c|c|}
\hline & (1) & (2) & (3) & (4) & (5) & (6) & (7) & (8) \\
\hline & \multicolumn{4}{|c|}{2002} & \multicolumn{4}{|c|}{2007} \\
\hline & all & nonmig & mig & $\operatorname{Pr}($ diff! $=0)$ & all & nonmig & mig & $\operatorname{Pr}($ diff $!=0)$ \\
\hline HH Size & 4.48 & 4.53 & 4.28 & 0.07 & 4.25 & 4.35 & 3.98 & 0.01 \\
\hline Children $(<16)$ & 1.55 & 1.61 & 1.30 & 0.00 & 0.94 & 1.02 & 0.72 & 0.00 \\
\hline Sex of HH Head (1 = male) & 0.86 & 0.86 & 0.86 & 0.78 & 0.84 & 0.84 & 0.83 & 0.51 \\
\hline Age of $\mathrm{HH}$ Head & 48.93 & 47.81 & 53.54 & 0.00 & 53.44 & 51.49 & 58.54 & 0.00 \\
\hline Years of Education of HH Head & 4.50 & 4.67 & 3.79 & 0.00 & 4.64 & 4.93 & 3.87 & 0.00 \\
\hline Income per Capita (in LCU) & 11978.00 & 10359.77 & 18648.47 & 0.01 & 15525.96 & 12991.32 & 22157.79 & 0.01 \\
\hline \multicolumn{9}{|l|}{ of which (in \%) } \\
\hline Agriculture & 0.09 & 0.09 & 0.09 & 0.76 & 0.08 & 0.08 & 0.08 & 0.95 \\
\hline Livestock & 0.04 & 0.04 & 0.05 & 0.68 & 0.05 & 0.05 & 0.04 & 0.52 \\
\hline Non-Agricultural Business & 0.07 & 0.08 & 0.07 & 0.36 & 0.07 & 0.08 & 0.06 & 0.16 \\
\hline Agricultural Wages & 0.17 & 0.19 & 0.12 & 0.00 & 0.16 & 0.19 & 0.11 & 0.00 \\
\hline Non-Agricultural Wages & 0.27 & 0.31 & 0.11 & 0.00 & 0.23 & 0.27 & 0.13 & 0.00 \\
\hline Transfers & 0.14 & 0.14 & 0.11 & 0.01 & 0.17 & 0.18 & 0.13 & 0.00 \\
\hline International Remittances & 0.07 & 0.00 & 0.38 & 0.00 & 0.10 & 0.00 & 0.36 & 0.00 \\
\hline Ag. Machinery (in LCU) & 4722.18 & 3937.44 & 7956.93 & 0.00 & 8785.09 & 6633.54 & 14414.53 & 0.00 \\
\hline Livestock (in LCU) & 8579.83 & 6778.10 & 16006.72 & 0.01 & 11186.22 & 9468.88 & 15679.57 & 0.00 \\
\hline Priv. Land (in ha) & 1.10 & 1.01 & 1.50 & 0.43 & 1.44 & 1.43 & 1.46 & 0.97 \\
\hline International Migration (US) & 0.20 & 0.00 & 1.00 & - & 0.28 & 0.00 & 1.00 & - \\
\hline Obs & 1762 & 1418 & 344 & - & 1537 & 1112 & 425 & - \\
\hline
\end{tabular}

Note: All income figures are in constant 2003 Mexican pesos and include negative incomes. In 2003, 1 Mexican peso was worth USD 0.62. Transfer income includes PROCAMPO, PROGRESA, transfers by non-governmental organizations and friends. For 2007 transfers also includes PROARBOL and PROGAN. Author's calculation based on ENRUM.

The migration prevalence in our sample has increased by 10 percent between the two waves. ${ }^{4}$ In 2002, 344 of the households (about 20 percent) had members who migrated internationally. Five years later we encountered 425 households (28 percent) with international migrants in our survey. As can be seen from Table 1.1, households with migrants had on average significantly less children than those without migrants. We also find that household heads of families that have migrants were older than the household heads of families without migrants. This tendency as displayed in Figure1.2 reflects the general trend of children to migrate. The age distribution of heads from migrant

\footnotetext{
${ }^{4}$ Migrants are defined as individuals who reside or work abroad for at least 3 month out of the last 12 months.
} 
households is shifted to the left, indicating that households with very young household heads have a lower likelihood to have migrants compared to older households.

Figure 1.1 - Interview Distribution

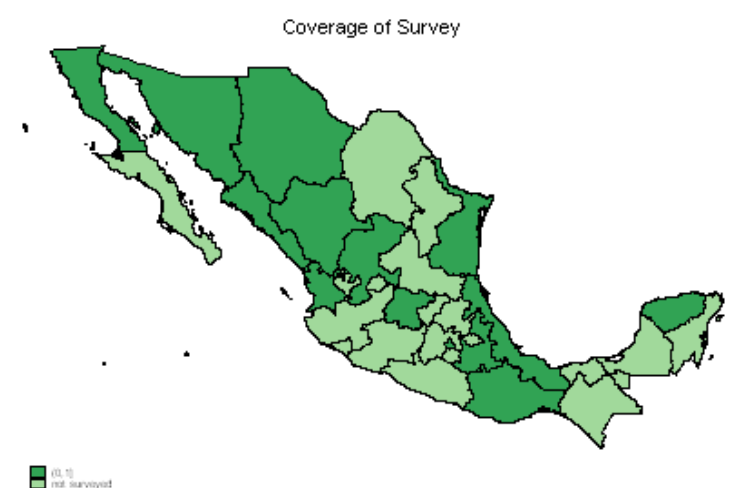

Sonce: Antors cakstabos Laxedor ENRUM

As can be seen in Table 1.2, only 31 percent (17 percent) of all households with international migrants in 2002 (2007) had a migrant household head. Migrants are mostly male household members with an average age of 32.6 (33.2) years. The high average migration duration reflects the fact that two thirds of the households in 2007 had at least one member who spent the last 12 months entirely abroad. Unfortunately we have no measure that captures their return intentions. The most important aspect in Table 1.2 is that it is mostly sons and daughters who migrate. When we split these statistics by the average age of the household head of migrant households (i.e. 56 years) it becomes even more explicit that in older households mostly the household heads' children migrated.

The survey asked households whether remittances were sent for a specific purpose, i.e. earmarked for a certain use. Interestingly only around 4 percent of the remittance receiving households stated that remittances were sent for the purchase of production inputs, livestock or land. All other households stated that remittances were sent to cover debt repayment, daily expenditures as well as health and schooling expenditures. This attitude regarding the use of remittances could also reflect the mental accounting of households and would suggest that remittances do not affect investments. However, household income is fungible and a clear judgment with respect to the mental accounting hypothesis cannot be reach based on these self-stated intentions. It is also important to note that only around 12 percent of the households had a debit, credit or savings account in 2007. To cover large lump sum investments the households would then have to hold all savings in cash which might be too risky. The stated preference for daily expenditures could therefore also reflect the inaccessibility of an adequate savings vehicle. 
Table 1.2 - Migrant Characteristics

\begin{tabular}{|c|c|c|c|c|c|}
\hline & (1) & (2) & (3) & (4) & (5) \\
\hline & all & 2002 & 2007 & $\begin{array}{c}<56 \\
\text { [pooled] }\end{array}$ & $\begin{array}{c}\geq 56 \\
\text { [pooled] }\end{array}$ \\
\hline Male & 0.82 & 0.85 & 0.80 & 0.87 & 0.78 \\
\hline Age & 32.96 & 32.64 & 33.21 & 30.19 & 35.54 \\
\hline Primary Education & 0.49 & 0.55 & 0.45 & 0.48 & 0.51 \\
\hline Secondary Education & 0.30 & 0.26 & 0.33 & 0.32 & 0.28 \\
\hline Married & 0.60 & 0.63 & 0.57 & 0.55 & 0.64 \\
\hline Average Annual Migration Duration & 10.05 & 9.41 & 10.55 & 9.42 & 10.62 \\
\hline Years of Migration Experience & 7.80 & 7.85 & 7.70 & 6.24 & 9.19 \\
\hline Migrants per Household & 1.81 & 1.43 & 2.02 & 1.42 & 2.07 \\
\hline HH Head (male) & 0.24 & 0.31 & 0.17 & 0.43 & 0.06 \\
\hline HH Head (female) & 0.02 & 0.02 & 0.01 & 0.03 & 0.00 \\
\hline Daughter (at least 1 ) & 0.25 & 0.18 & 0.29 & 0.15 & 0.33 \\
\hline Son (at least 1 ) & 0.68 & 0.59 & 0.71 & 0.50 & 0.81 \\
\hline Other relative & 0.05 & 0.03 & 0.07 & 0.04 & 0.06 \\
\hline Obs & 737 & 326 & 411 & 370 & 367 \\
\hline
\end{tabular}

Note: All figures are expressed in Mexican pesos and are unconditional means. Author's calculation based on ENRUM.

Following the literature we separate investment alternatives into two logically coherent categories: agriculture and livestock. The former includes investments in agricultural assets such as expenditures to improve the plot and the installation of irrigation systems, acquisition of new machinery as well as expenditures to maintain productive assets. Investments in livestock include expenditure categories such as the acquisitions of new livestock and expenditures for new machinery. About one-third of the households invested productively ${ }^{5}$. The households with international migrants seem to have slightly higher propensities to invest in agricultural assets and livestock. Regarding the investment shares, neither category stands out. While livestock makes up the biggest part of investments in terms of frequency, agriculture seems to account for the bigger share in total investment volumes in both years. Unfortunately the survey data does not allow us to analyze the stocks and investment flows of other income generating activities.

Given that the age of household heads differs markedly between non-migrant and migrant households, as observed in Table 1.1, the subsequent question is whether this pattern holds for the households' investment activities. In Figures 1.3 and 1.4 we capture the relationship between investment status and the age of the household head differentiated into households that had no migrants and those that had international migration. The graphs reveal two things. First, households with international migrants seem to hold more agriculture and livestock assets in both years. Second, especially for livestock assets we observe a strong curvature that indicates a life-cycle investment structure. More precisely, the value of livestock increases up to the age of around 40 years of the

\footnotetext{
${ }^{5}$ Not reported in the Tables.
} 
household head and remains quite stable until the age of 60 . Thereafter households seem to hold less livestock.

Figure 1.2 - Age Distribution of Household Heads and Spouses by Migration Status
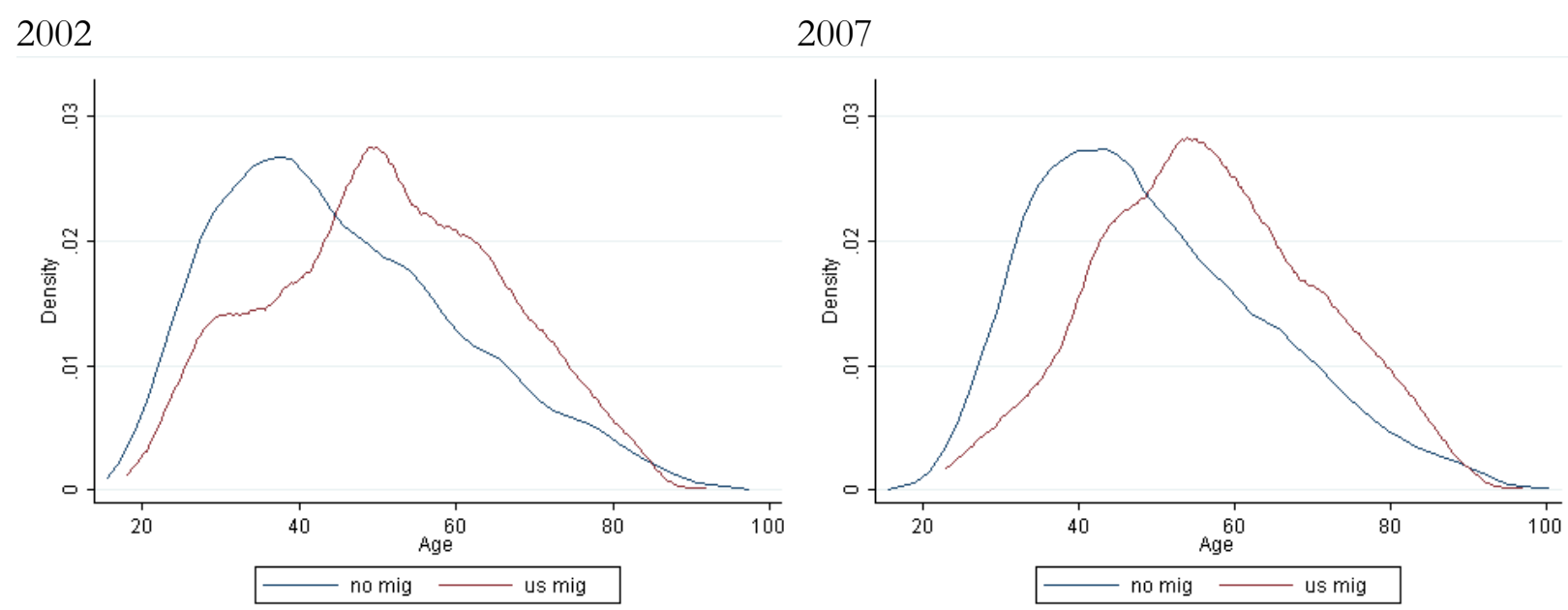

Figure 1.3 - Profile Plots of Agricultural Assets
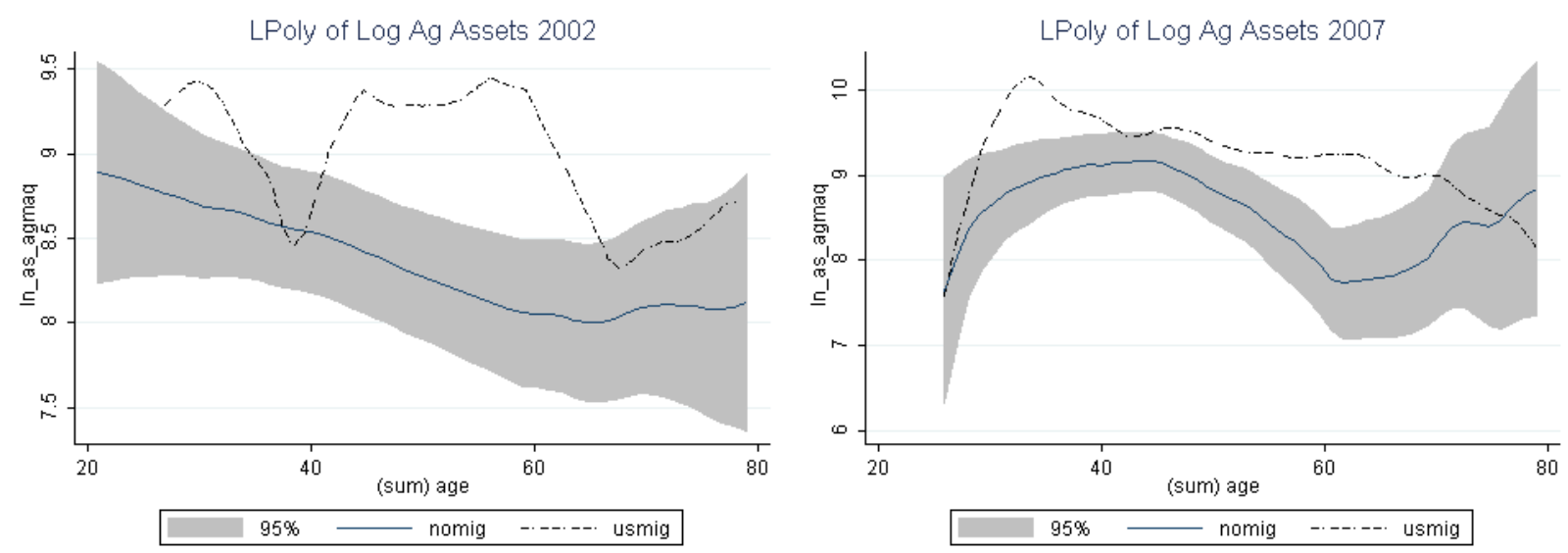

Figure 1.4 - Profile Plots of Livestock
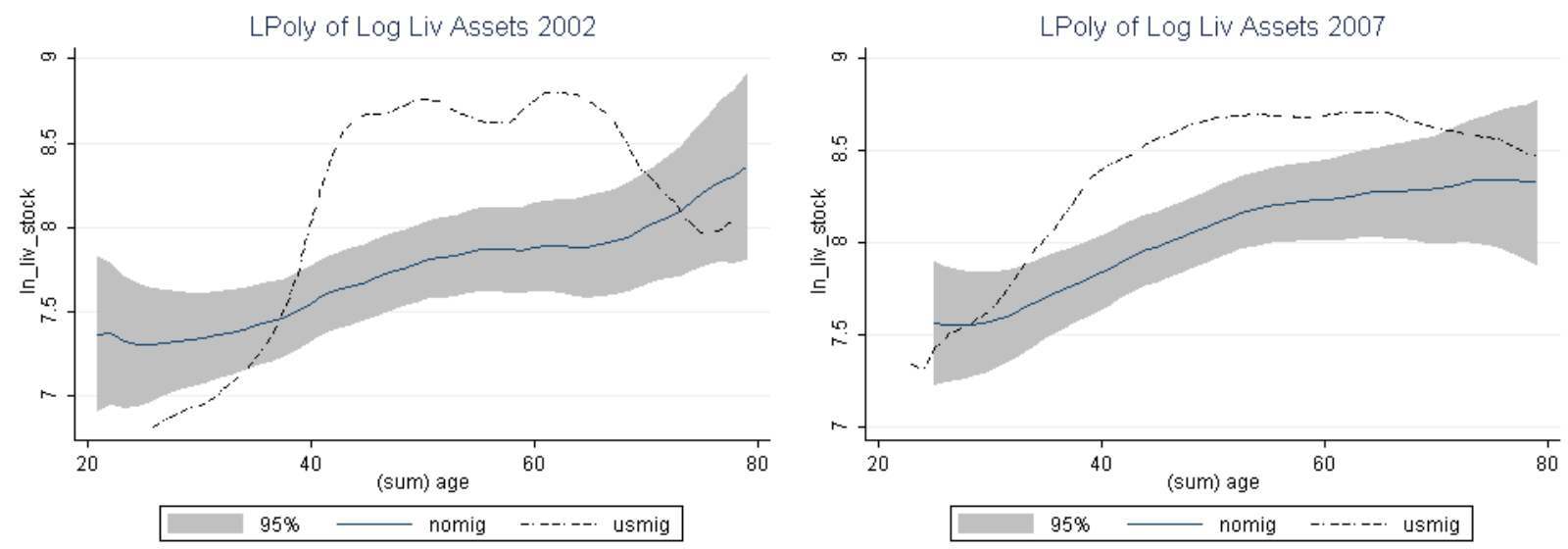


\subsection{Econometric Strategy}

Econometrically the relation between investments and migration has been previously approached using a simple setup. Typically a certain type of investment is regressed on remittances controlling for household characteristics to account for their heterogeneity. However, this ignores the variables highlighted by the financial theory of investment, i.e. the importance of internal sources of finance in imperfect capital market situations (Hubbard 1998). By rearranging equation (4) it becomes clear that investments are determined by

$$
I=p_{1} \cdot f\left(K_{1}, L-M\right)+g(M)-S-C
$$

The investment equation we test differs from previous agricultural investment estimations (e.g. Elhorst 1993, Hubbard and Kashyap 1992) in two respects. First, due to data limitations we cannot include any measure of output or factor input prices. Yet this should not affect our estimates because although prices are most likely heterogeneous across regions it is unlikely that households in the same states face significantly different factor input and output prices. The variation between communities should be absorbed to a large extent by state fixed effects. We use only agricultural and livestock sales as a proxy for cash flows since we do not observe directly the savings or changes in inventories of households. We also deviate from the common approach where investments are estimated as a share of total capital. The reason for this deviation lies in the structure of our data. As outlined before the survey did ask explicit questions about investments, but the categories used in these investment questions do not perfectly match the categories of productive household assets. Second, we do not have any measure of market opportunities in the form of fundamental $q$ as it is commonly used in investment analysis (e.g. Bierlen and Featherstone 1998). However, this should not be a major problem as we approach the data with a reduced form and do not derive a structural interpretation from the estimation model. In addition, the structural derivation of the $q$-model assumes perfect competition and constant returns to scale which would be unrealistic in our context. Taking these limitations into account our general estimation equation takes the following form:

$$
\log \left(I_{i t}\right)=\alpha_{i}+\beta_{1} X_{i t}+\beta_{3} K_{i t}+\beta_{3} C_{i t}+\theta M_{i t}+\varepsilon_{i t} \quad \mathrm{i}=1, \ldots, \mathrm{N} ; \mathrm{t}=1,2
$$

where $I$ is investment or an investment good, $X$ is a vector of household characteristics, $K$ is capital and $C$ represents cash flows. The variable of main interest is migration $(M)$. Household characteristics consist of the number of adults in the household as well as the age and education of the household head. We also included a squared age term for the household head to capture potential non-linear effects. Throughout all estimations the quadratic term should not have any statistical significance if there are no life-cycle effects. The capital vector contains the capital stocks of the household, i.e. the 
aggregated value of agricultural assets and the value of the livestock the household owned. These stocks are not only important as a measure of productive capacity but also because they reflect the wealth of the household. This duality makes this measure somewhat ambiguous as it indicates both, the production setup and degree of specialization as well as the accumulated wealth of the household. The vector $C$ describes the household's cash flows and access to capital. Again the interpretation of the elasticity of investment with respect to cash flows is somewhat difficult as these variables contain different types of information. On the one hand they reflect the internal financing capacity of the household represented by cash flows vis-á-vis external capital in the form of credits. On the other hand cash flows could also indicate future investment opportunities and market conditions instead of the role of internal funds (Gilchrist and Himmelberg 1995). But since the objective of this analysis is not to determine whether households are credit constrained due to imperfect capital markets, the size of the effect is not of primary importance. Rather, the difference in the importance of cash flows for migrants and non-migrants is sufficient to test if migration provides capital for investment and thereby changes the financing structure of investments. It is worth noting that while this investigation focuses on capital expenditures it is also possible that cash flows are used to finance other production-relevant categories such as cash holdings, increases in inventories or non-farm activities.

In addition to the theoretical reasons why farmers do not invest as outlined in section 1.2 there are also some empirical reasons why we might not observe investments. Most likely, capital investments are quite infrequent which is why the observation period of a single year cannot fully reflect the investment activity of a farmer. It is also possible that unobservable factors are driving the investment decision. For example, transaction cost can be too high due to the remote location of some municipalities, or the overall market situation depresses the expectations of the farmer. Unfortunately we have no way to clearly identify the cause of zero observations in our investment flows. The exclusion of households with zero investments for a given year would imply zero demand which is not necessarily true. If the selection into the observable subgroup is non-random OLS estimates are inconsistent. We address this problem in two ways. First, we use not only investment flows but also capital stocks which are by definition the result of all prior investment flows. Second, we use a Tobit model which produces consistent parameter estimates in the presence of a truncated dependent variable (Amemiya 1973).

We begin the analysis by pooling the data set so as to evaluate the changes of investment between the years, i.e. the effect of time. This also allows us to check for attrition. By including a dummy that indicates if the household was observed in 2007, we can evaluate systematic differences of attriters. As pointed out by Arslan and Taylor (2011) attrition can be caused by (non-random) 
whole-household migration. If this was indeed the case the estimations of our migration coefficients would be upward biased since these migrant households did not invest in agricultural assets but were unobservable in the second survey round.

To exploit the advantage of having two periods we then employ a Lagged Dependent Variable (LDV) estimation. This approach helps us to control for events that happened prior to the period of observation and possibly influenced investment behavior permanently, but also to capture slow changing or invariant characteristics of the household such as entrepreneurial abilities and risk attitudes. Hence, the LDV must be understood as a proxy for all unobserved time-invariant variables that affect investment. One problem of this approach is the possible correlation of the lagged dependent variable with the error term. The bias introduced by this correlation shifts the coefficients of our explanatory variables toward zero (e.g. Griliches 1961). However, since we are neither relying on the point estimate of the lagged investment variables nor emphasizing the exact coefficient size of the other variables, there is no reason to refrain from using lagged variables. We should understand the LDV parameter estimates as the lower bound of the possible effects.

The main advantage of the panel structure of our dataset is that it allows us to control for constant and slow changing household specific effects. Both, our pooled OLS and our LDV estimates would be biased and inconsistent in the presence of unobserved individual heterogeneity. To address this problem we also employ fixed effects estimation. However, since we are restricted to two periods this estimation is equivalent to first differences and only captures the effect of variation within our unit of observation. In our sample 203 households decided to migrate after 2002 and 76 households ceased to have migrants in 2005. The FE estimation represents a comparison of new migrants and households that have concluded their migration activities. ${ }^{6}$

The central problem for the identification of the effect of migration in all of these setups is the non-random selection of households into migration. More precisely households that have migrants might be systematically different from those who do not. This intuition is supported by a simple Durbin-Wu-Hausman $\mathrm{Chi}^{2}$ test which rejects the exogeneity of our migration indictor in almost all regressions. For Mexico various migration instruments have been used successfully, among them migration networks (Chiodi et al. 2012), historic state-level migration rates (Woodruff and Zenteno 2007, Taylor and Lopez-Feldman 2010), and migrant-weighted economic conditions at the destination (Orrenius et al. 2010, Arslan and Taylor 2011). We employ the number of years since the first migration occurred in each community. This variable reflects the age of the network and

\footnotetext{
${ }^{6}$ We do not report our random effects estimation since after controlling for year and state fixed effects the results are quantitatively comparable and qualitatively the same as our pooled estimation results, which is due to the fact that we only observe two periods.
} 
therefore the level of migration costs. Following the argumentation by McKenzie and Rapoport (2007) we expect migration probability to increase with the age of the network. ${ }^{7}$ In addition to using the age of existing migration networks, which partly captures the effect of historic migration, we construct an instrumental variable based on the U.S. state-level GDP growth weighted by the number of migrants each community had in 2002 and 2007 in different states.

$$
I V_{i j t}=\frac{1}{D} \cdot \sum_{k=1}^{D}\left(M I G_{j k t} \cdot G D P g r o w t h_{j k t}\right) \quad \mathrm{j}=1, \ldots, 60
$$

According to equation (12), the instrumental variable $\left(I V_{i j t}\right)$ for household $i$ in village $j$ is a weighted average of the GDP growth in all states $D$ the community had a migration network with at time $t$. The assumption behind this instrument is that increased economic activity is strongly correlated with higher wages and a higher probability of finding employment for a migrant. There is no reason to believe that economic growth in U.S. states affects the investment activity in specific Mexican communities. This exclusion restriction would only be violated if for example farmers marketed their production in the United States as well which is unlikely since the households in our sample are small scale producers who only cater to local markets.

Since we are not able to address the endogeneity of migration in the Tobit model due to the binary nature of our migration variable we follow the recommendation by Angrist (2001) to employ a conventional two-stage least squares (2SLS) estimation. In addition to obtaining consistent parameter estimates, this also allows us to perform a broad range of tests regarding the strength and validity of our instrumental variables. The Hansen $J$ test cannot reject the hypothesis that our instruments are uncorrelated with the error term. We can therefore accept the orthogonality conditions required for our instruments to be valid. To evaluate the strength of our instrument we use the Kleinbergen-Paap test of under-identification and the Cragg-Donald F-statistic of our first stage regression. We report both tests in the last two rows of each table and find that our instruments are jointly significant throughout. Furthermore the Cragg-Donald F-statistic mostly exceeds the critical 10 percent value for weak instruments proposed by Stock and Yogo (2002) that stands at 19.93 for our specifications. Overall, these tests confirm the adequacy of our two instruments.

Our estimation and instrumentation strategy has two important implications that should be considered before we turn to the results. First, a system estimation approach could help us to gain efficiency. However, we found only a very small correlation of agriculture and livestock residuals. This observation and our primary interest in migration shift the balance in favor of a single-equation

\footnotetext{
${ }^{7}$ The variable also captures indirectly the effect of the diplomatic agreements signed by the United States and Mexico in the 1940s known as the Bracero Program that initiated the recruitment of temporary migrant workers. The communities with the oldest networks are also the ones that were visited by Bracero recruiters.
} 
approach in this context. Albeit being less efficient our single-equation estimates remain consistent. Second, the 2SLS estimation model can only yield local average treatment effect (LATE) estimates since some households are defiers in the sense that they do not react to changes in the market conditions at the destinations. One way to overcome this limitation and also investigate the possible heterogeneity of other explanatory variables in both migrant and non-migrant households is to employ an endogenous switching regression model (SRM) which is a generalization of a Heckman selection correction (Heckman 1979). In doing so we are using a control function in form of the inverse Mill's ratio that is added to equation (11). The exogenous variables used to derive the inverse Mill's ratio are the same as in the 2SLS specification (see equation 12). This approach also allows us to observe the effect of age separately for migrant and non-migrant households without using instrumented interaction terms which could possibly suffer from decreased efficiency due to the lower correlation between the interacted endogenous migration variable and the interacted instrument.

\subsection{Estimation Results}

To evaluate the migration decision process that underlies our instrumental variable strategy we display Probit estimates of having an international migrant in the household in Table 1.3. After augmenting the basic setup with our migration instruments the estimated coefficients show that the exogenous instruments have significant effects on the propensity to migrate. We find that the age of the migration network increases the propensity to migrate. Similarly, the growth of GDP at the destination states weighted by the size of the diasporas increases the likelihood of having at least one migrant in the household. For both years we find that the probability of migration first increases with age and decreases after a turning point at around 61 and 72, in 2002 and 2007, respectively, keeping all other variables constant. When examining economic characteristics of the households, we find strong evidence that international migration is associated with current income flows. Higher current income from livestock sales and non-farm activities significantly reduces the probability that the household has at least one international migrant. Agricultural sales have no statistically significant relation with the propensity to migrate. By contrast, we find that agricultural assets have a slightly positive correlation with the probability of having an international migrant in the household. This could reflect asymmetric migration costs that only wealthier households are able to cover. A second interpretation that does not conflict with the first is that mostly the wealthier households start investing in more profitable activities such as migration. 
Table 1.3 - Migration Determinants (Probit)

\begin{tabular}{|c|c|c|c|c|c|}
\hline & $(1)$ & (2) & (3) & (4) & (5) \\
\hline & \multicolumn{2}{|c|}{2002} & \multicolumn{2}{|c|}{2007} & Pooled \\
\hline \multicolumn{6}{|l|}{ Household } \\
\hline adults (fem) & -0.0034 & -0.0108 & 0.0078 & 0.0112 & -0.0042 \\
\hline adults (male) & -0.0380 & -0.0527 & $-0.0753^{* *}$ & $-0.0746^{*}$ & $-0.0654^{* *}$ \\
\hline age (in years) & $0.0744 * * *$ & $0.0876^{* * *}$ & $0.0748^{* * *}$ & $0.0810^{* * *}$ & $0.0751^{* * *}$ \\
\hline age $^{2}$ & $-0.0006^{* * *}$ & $-0.0007^{* * *}$ & $-0.0005^{* * *}$ & $-0.0006 * * *$ & $-0.0006^{* * *}$ \\
\hline edu (in years) & -0.0012 & -0.0035 & -0.0120 & -0.0150 & -0.0109 \\
\hline \multicolumn{6}{|l|}{ Productive Assets } \\
\hline plotsize (ha/10) & $0.1598^{* * *}$ & $0.1978^{* * *}$ & 0.0001 & 0.0097 & $0.0822^{* * *}$ \\
\hline ag capital $(\log )$ & 0.0008 & 0.0005 & $0.0155^{* * *}$ & $0.0129 * *$ & $0.0092 * *$ \\
\hline liv capital (log) & 0.0025 & 0.0034 & 0.0099 & 0.0099 & $0.0088^{* *}$ \\
\hline \multicolumn{6}{|l|}{ Cash Flow and Liquidity } \\
\hline agsales (log) & 0.0005 & -0.0016 & 0.0080 & 0.0080 & 0.0042 \\
\hline livesales $(\log )$ & $-0.0152 *$ & $-0.0202^{* *}$ & $-0.0127^{*}$ & $-0.0127 *$ & $-0.0169 * * *$ \\
\hline other income (log) & $-0.0327 * * *$ & $-0.0319 * * *$ & $-0.0494 * * *$ & $-0.0490 * * *$ & $-0.0311 * * *$ \\
\hline Credit (1=yes) & -0.1050 & -0.1016 & $-0.4477 * *$ & $-0.4681 * * *$ & $-0.2973^{* *}$ \\
\hline \multicolumn{6}{|l|}{ Instruments } \\
\hline network age (in years) & & $0.0260^{* * *}$ & & $0.0112^{* * *}$ & $0.0176^{* * *}$ \\
\hline gdpgrowth & & $0.0018^{* * *}$ & & $0.0018^{* *}$ & $0.0019 * * *$ \\
\hline Constant & $-4.1359 * * *$ & $-4.5939 * * *$ & $-4.0988^{* * *}$ & $-4.3320 * * *$ & $-4.3816^{* * *}$ \\
\hline State Fixed Effects & Yes & Yes & Yes & Yes & Yes \\
\hline Year Fixed Effects & No & No & No & No & Yes \\
\hline Obs & 1733 & 1733 & 1506 & 1506 & 3239 \\
\hline $\mathrm{Chi}^{2}$ & 218.03 & 267.34 & 191.70 & 200.91 & 454.88 \\
\hline McFadden $\mathrm{R}^{2}$ & 0.166 & 0.210 & 0.157 & 0.168 & - \\
\hline Count $\mathrm{R}^{2}$ & 0.826 & 0.835 & 0.767 & 0.771 & - \\
\hline BIC & -11271 & -11332 & -9294 & -9299 & - \\
\hline
\end{tabular}

Note: Dependent variable is one if household has a member living or working more than three month per year in the US and zero otherwise; * significant at $10 \%$, ** significant at $5 \%$, *** significant at $1 \%$; T-statistics (two-tailed) based on robust standard errors. Author's calculation based on ENRUM.

In Table 1.4 we report the estimation results for the pooled estimations of both, the investment flows and stocks. The agricultural investment intensity seems to be independent of age while livestock investment flows decrease significantly with age. This could indicate that most households rely on agriculture for their daily consumption throughout the life-cycle. The asset accumulation follows a clear life-cycle pattern for both agricultural and livestock assets, peaking at the age of 48 and 63 in the 2SLS specification, respectively. Apart from the age of the household head all production characteristics, i.e. productive assets and cash flows, are practically and statistically important determinants of investment behavior. The cash flow elasticity of investment of both agriculture and livestock is throughout strongly category specific. That is, investments in livestock are more sensitive to profits from livestock sales than from retained agricultural profits and vice versa. 
Plot size as well as the value of agricultural assets and livestock have robustly positive effects. This result does not reject the decreasing returns to capital as predicted by theory but rather reflects the fact that our investment variable contains replacement expenditures. Furthermore if we use the share of investment as independent variable the asset coefficients have a negative sign. The year fixed effects show that both agricultural investments and assets are higher in the second wave in 2007. From the attrition indicator we see that households that were not surveyed in 2007 seem to be characterized by slightly lower investments and assets throughout. In both the Tobit and the 2SLS specification, international migration seems to have a slightly positive effect on livestock investment flows and a robustly positive effect on agricultural assets.

Table 1.4 - Determinants of Investment Volume and Assets (Pooled Regressions)

\begin{tabular}{|c|c|c|c|c|c|c|c|c|}
\hline & (1) & (2) & (3) & (4) & (5) & (6) & (7) & (8) \\
\hline & \multicolumn{4}{|c|}{ Investment Volume } & \multicolumn{4}{|c|}{ Assets (End of Period) } \\
\hline & \multicolumn{2}{|c|}{$\mathrm{AG}$} & \multicolumn{2}{|c|}{ LIV } & \multicolumn{2}{|c|}{$\mathrm{AG}$} & \multicolumn{2}{|c|}{ LIV } \\
\hline & Tobit & 2SLS & Tobit & 2SLS & Tobit & 2SLS & Tobit & 2SLS \\
\hline \multicolumn{9}{|l|}{ Household Characteristics } \\
\hline adults (fem) & -0.0390 & -0.0438 & 0.0047 & 0.0648 & -0.0158 & 0.0034 & $0.1745^{*}$ & $0.2488 * *$ \\
\hline adults (male) & -0.1024 & -0.0709 & $0.1128^{*}$ & $0.1773^{*}$ & $0.4251 * * *$ & $0.5929 * * *$ & $0.2631 * *$ & $0.2927^{*}$ \\
\hline age (in years) & $0.0113^{*}$ & 0.0031 & $-0.0189 * * *$ & $-0.0261 * * *$ & $0.1752^{* * *}$ & $0.0961 *$ & $0.1351 * * *$ & $0.1832^{* *}$ \\
\hline age $^{2}$ & & & & & $-0.0016^{* * *}$ & $-0.0010^{* *}$ & $-0.0011^{* *}$ & $-0.0014 * *$ \\
\hline educ (in years) & 0.0443 & $0.0373^{*}$ & -0.0024 & 0.0287 & $0.1058^{* * *}$ & $0.1440^{* * *}$ & $-0.0731^{* *}$ & $-0.0741 * *$ \\
\hline \multicolumn{9}{|l|}{ Productive Assets } \\
\hline plot $(\mathrm{ha} / 10)$ & $0.3758^{* * *}$ & $0.3996 * * *$ & $0.1826^{* * *}$ & $0.3053^{* * *}$ & $0.4935^{* * *}$ & $0.6616^{* *}$ & $0.7249 * * *$ & $1.0424 * * *$ \\
\hline ag capital (log) & $0.1858^{* * *}$ & $0.1680^{* * *}$ & $0.0260 * *$ & $0.0361 * *$ & & & & \\
\hline livestock (log) & $0.0342^{*}$ & 0.0085 & $0.2942 * * *$ & $0.3400 * * *$ & & & & \\
\hline \multicolumn{9}{|l|}{ Cash Flow and Liquidity } \\
\hline agsales (log) & $0.1250^{* * *}$ & $0.1167 * * *$ & $0.0250 * *$ & $0.0404 * *$ & $0.1317 * * *$ & $0.1560 * * *$ & $0.0592 * * *$ & $0.0864 * * *$ \\
\hline livsales $(\log )$ & $0.0467 * *$ & $0.0609 * *$ & $0.0759 * * *$ & $0.1938^{* * *}$ & $0.0847 * * *$ & $0.1290 * * *$ & $0.3820 * * *$ & $0.5667 * * *$ \\
\hline other income (log) & 0.0361 & 0.0289 & $0.0542 * * *$ & $0.0535^{* *}$ & 0.0063 & 0.0514 & $0.0911 * * *$ & 0.0662 \\
\hline credit ( $1=$ yes $)$ & -0.2832 & -0.0834 & $0.5837 * *$ & $1.0611 * * *$ & $1.2344 * * *$ & $1.9057 * * *$ & -0.3196 & -0.5308 \\
\hline Migration & -0.1468 & 0.4616 & $0.5667 * * *$ & $3.1313^{*}$ & $0.6569 * *$ & $5.8220^{* * *}$ & 0.4675 & -1.5479 \\
\hline Year $(1=2007)$ & $0.6323^{* *}$ & $0.4483^{* *}$ & $-0.7127^{* * *}$ & $-0.9865^{* * *}$ & $1.1515^{* * *}$ & $0.8341^{* *}$ & -0.0644 & 0.1207 \\
\hline Attrition (1 = not in 2007) & 0.1683 & 0.1308 & $-0.4875^{*}$ & $-0.5562^{*}$ & $-1.1815^{* * *}$ & $-0.8872 * *$ & $-0.7845^{*}$ & $-0.8261 *$ \\
\hline State Fixed Effects & Yes & Yes & Yes & Yes & Yes & Yes & Yes & Yes \\
\hline Year Fixed Effects & Yes & Yes & Yes & Yes & Yes & Yes & Yes & Yes \\
\hline Obs & 3239 & 3239 & 3239 & 3239 & 3239 & 3239 & 3239 & 3239 \\
\hline p-value Hansen J & & 0.708 & & 0.187 & & 0.499 & & 0.073 \\
\hline K-P Wald F-Stat & & 15.701 & & 15.701 & & 15.704 & & 15.704 \\
\hline Cragg-Donald F-Stat & & 38.914 & & 38.914 & & 42.682 & & 42.682 \\
\hline
\end{tabular}

Note: Dependent variables in logs; * significant at 10\%, ** significant at 5\%, *** significant at 1\%; Tobit estimates are marginal effects (conditional on being uncensored); all censored observations are left-censored at zero; T-statistics (two-tailed) based on robust standard errors clustered at the village level. Author's calculation based on ENRUM. 
Table 1.5 reports the results for the Lagged Dependent Variable estimation. The lagged variable is also an indicator of the persistence of investment activities. That is, it measures how strongly current investment depends on past investments. The strong difference between flows and stocks can be interpreted as an indication of an infrequent and lumpy adjustment process of capital. Specifically for livestock, we can observe that past investments have a low predictive power for current investments, whereas our asset measure is quite persistent. Almost all of the results observed in the pooled specification regarding the demographic structure of investments, the importance of cash flows and the effect of migration remain unchanged.

Table 1.5 - Determinants of Investment Volume and Assets (Lagged Dependent Variable)

\begin{tabular}{|c|c|c|c|c|c|c|c|c|}
\hline & (1) & $(2)$ & (3) & (4) & (5) & (6) & (7) & (8) \\
\hline & \multicolumn{4}{|c|}{ Investment Volume } & \multicolumn{4}{|c|}{ Assets (End of Period) } \\
\hline & \multicolumn{2}{|c|}{ AG } & \multicolumn{2}{|c|}{ LIV } & \multicolumn{2}{|c|}{$\mathrm{AG}$} & \multicolumn{2}{|c|}{ LIV } \\
\hline & Tobit & 2SLS & Tobit & 2SLS & Tobit & 2SLS & Tobit & 2SLS \\
\hline Lagged Dependent & $0.1108^{* * *}$ & $0.1107^{* *}$ & $0.0382 * *$ & $0.0767 * * *$ & $0.1746^{* * *}$ & $0.2012^{* * *}$ & $0.2473^{* * *}$ & $0.3053^{* * *}$ \\
\hline \multicolumn{9}{|l|}{ Household Characteristics } \\
\hline adults (fem) & -0.0149 & -0.0711 & 0.0877 & 0.1560 & 0.1271 & 0.0911 & 0.1325 & 0.1875 \\
\hline adults (male) & $-0.3280 * *$ & -0.1073 & 0.0546 & 0.0883 & $0.3519 * *$ & $0.7091 * * *$ & $0.2862^{* *}$ & $0.3414^{* *}$ \\
\hline age (in years) & 0.0063 & -0.0248 & $-0.0238^{* * *}$ & $-0.0343^{* *}$ & $0.1772^{* * *}$ & -0.0668 & $0.1529 * *$ & $0.1750^{*}$ \\
\hline age $^{2}$ & & & & & $-0.0016^{* * *}$ & -0.0000 & $-0.0014 * *$ & $-0.0016^{* *}$ \\
\hline educ (in years) & 0.0313 & 0.0544 & 0.0161 & 0.0540 & $0.1473^{* * *}$ & $0.2264^{* * *}$ & -0.0478 & -0.0355 \\
\hline \multicolumn{9}{|l|}{ Productive Assets } \\
\hline plot (ha/10) & $0.2906^{* *}$ & 0.3135 & $0.1254^{* *}$ & $0.3021 * *$ & 0.1536 & 0.2025 & $0.3077^{* * *} *$ & $0.4307 * * *$ \\
\hline ag capital (log) & $0.1760^{* * *}$ & $0.1316^{* * *}$ & $0.0206^{*}$ & 0.0199 & & & & \\
\hline livestock (log) & $0.0710^{* * *}$ & 0.0225 & $0.3013^{* * *}$ & $0.3374 * * *$ & & & & \\
\hline \multicolumn{9}{|l|}{ Cash Flow and Liquidity } \\
\hline agsales $(\log )$ & $0.1372 * * *$ & $0.1270^{* * *}$ & 0.0141 & 0.0283 & $0.1025^{* * *}$ & $0.0992^{* *}$ & $0.0426^{* *}$ & $0.0579 * *$ \\
\hline livsales (log) & 0.0397 & $0.0961^{* * *}$ & $0.0764 * * *$ & $0.2177^{* * *}$ & $0.0719 * * *$ & $0.1188^{* * *}$ & $0.3200^{* * *}$ & $0.4721^{* * *}$ \\
\hline other income (log) & 0.0528 & $0.1287^{* *}$ & -0.0247 & -0.0103 & -0.0053 & $0.1786^{* *}$ & 0.0591 & 0.0462 \\
\hline credit $(1=$ yes $)$ & -0.8499 & 0.0755 & $0.7115^{* *}$ & $1.3413^{* * *}$ & -0.2427 & 1.3447 & $-0.9230^{*}$ & -0.9223 \\
\hline Migration & -0.2498 & 6.1696 & $0.3058^{*}$ & 2.8312 & $0.8816^{* * *}$ & $13.9189^{* * *}$ & 0.3152 & 0.3871 \\
\hline State Fixed Effects & Yes & Yes & Yes & Yes & Yes & Yes & Yes & Yes \\
\hline Obs & 1487 & 1487 & 1487 & 1487 & 1487 & 1487 & 1487 & 1487 \\
\hline p-value Hansen J & & 0.9329 & & 0.0639 & & 0.4477 & & 0.0922 \\
\hline K-P Wald F-Stat & & 9.192 & & 8.645 & & 10.084 & & 10.370 \\
\hline Cragg-Donald F-Stat & & 9.992 & & 9.403 & & 11.957 & & 11.375 \\
\hline
\end{tabular}

Note: Dependent variables in logs; * significant at 10\%, ** significant at 5\%, *** significant at 1\%; Tobit estimates are marginal effects (conditional on being uncensored); all censored observations are left-censored at zero; T-statistics (two-tailed) based on robust standard errors clustered at the village level. Author's calculation based on ENRUM. 
The results of Tables 1.4 and 1.5 suggest that the internally generated cash flows from market integration of the rural households in the form of sales are more important for the accumulation of livestock than the funds generated by the migration of household members, while agricultural asset accumulation clearly benefits from migration. However, to find out if the age of the household head and the cash flows the household receives have different effects in migrant and nonmigrant households the estimates provided by our 2SLS specifications do not suffice. If migration in fact injects capital for investment only for specific types of agricultural production we should observe marked differences in cash flow sensitivity between migrant and non-migrant households. To test this hypothesis we turn in Table 1.6 to the split sample parameter estimates obtained through the switching regression model. We find that the correlation coefficient of the error terms in the selection and regression equation (rho) is throughout negative for migrant households. This confirms that the households with migrants are positively selected in terms of the two instruments and are more likely to have higher investments and more accumulated assets than a household drawn at random from the population mirroring the results obtained from the 2SLS specification as reported in Table 1.4.

Table 1.6 yields two important insights. First, the estimated elasticity of agricultural investment to changes in category specific cash flows represented by sales for households without migrants is 12.4 percent, while migrant households exhibit an elasticity of about 15.1 percent. The difference is very small and statistically insignificant. The same is true for livestock investments and assets. In the NELM literature it is generally argued that remittances are used to overcome financing constraints. The comparison of the cash flow coefficients across the two subsamples of migrant and non-migrant households in Table 1.6 shows that the cash flow sensitivity does not vary systematically across households. Only for agricultural assets we see that the cash flow sensitivity becomes statistically insignificant for migrant households. While this evidence does not allow us to judge the extent of the existing credit constraints, it allows us to reject the hypothesis that funds generated by migration change the capital demand of farm households indiscriminately, but only do so for agricultural activities. Second, to find out if migrant households' investment behavior follows a pattern that is consistent with the permanent income hypothesis more strongly than non-migrant households as indicated by the profile plots in Figure 3 we included an old age dummy, reflecting the mean age of household heads in 2007, instead of the continuous age variable in the switching regression model. We see that although the coefficient of the age dummy is negative for all specifications of migrant households, it is only significant for agricultural assets. A comparison of migrant and non-migrant households indicates that migrant households seem to disinvest more strongly during old age than non-migrant households. However, since this finding is not very robust we have to regard it with caution. 
Table 1.7 shows the results from the fixed effects estimation of agricultural and livestock investments and capital stocks. Since the demographic characteristics of the household, i.e. age, composition and education, as well as plot size can be considered fixed over the short period of observation we did not include them. We find that agricultural and livestock sales are again positive and significant at the 1 percent level for the respective asset category throughout. International migration has again a positive and highly significant effect on agricultural assets in both the standard and the instrumented fixed effect specification. We also observe a strongly positive effect of migration on agricultural investments and a negative effect on livestock investments in the 2SLS specification. Since these parameter estimates are based on the comparison between households that had a migrant in 2002 but none in 2007 and households that started to migrate in 2007 we can conclude that revenues from migration are indeed only used to build up the subsistence category of agricultural capital. The negative coefficient of livestock investments can be interpreted as suggestive evidence that migration serves as a substitute for livestock production.

Table 1.6 - Determinants of Investment Volume and Assets (LDV - Split Sample)

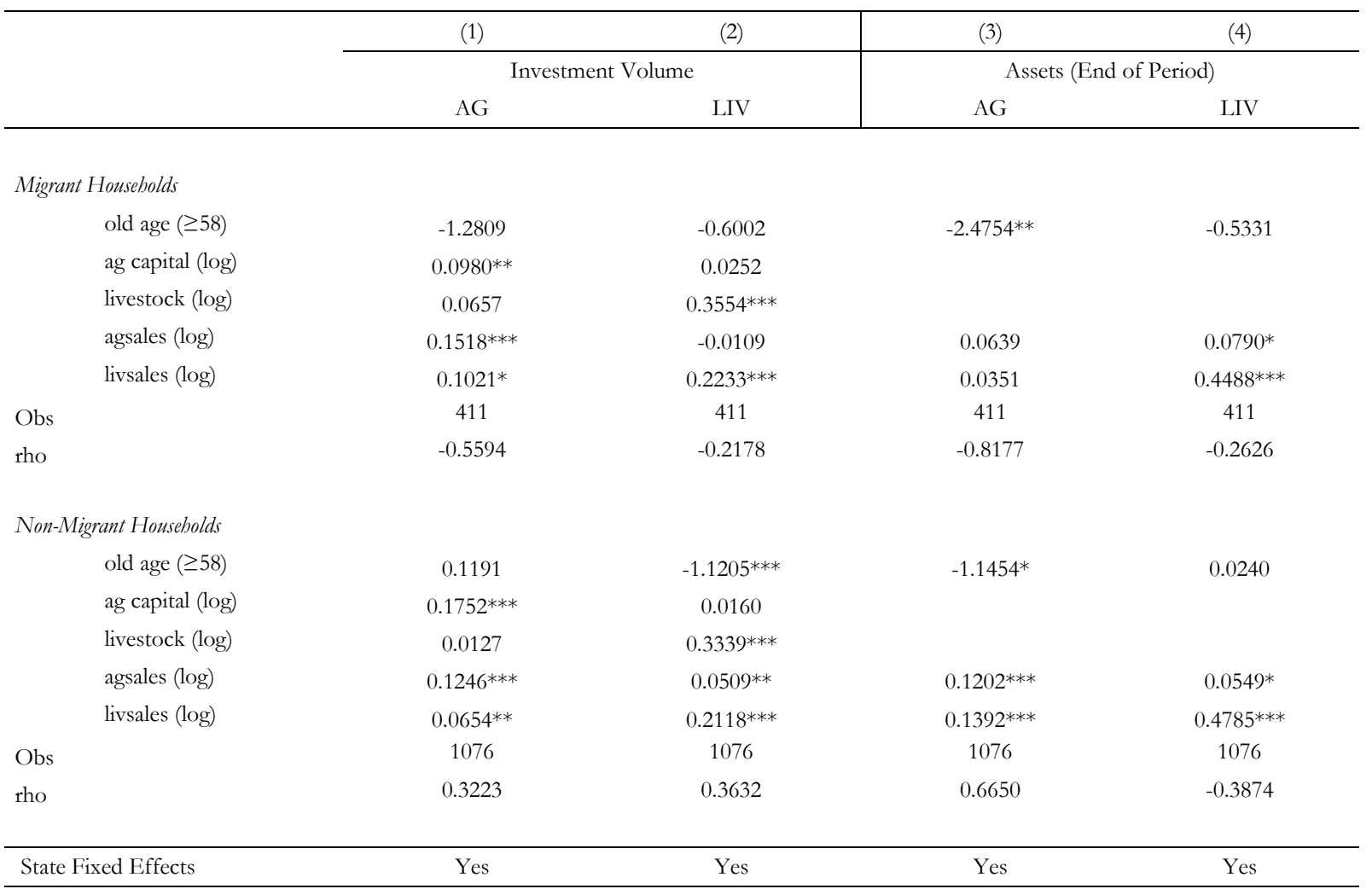

Note: Dependent variables in logs; Included control variables are number of adult women and men, education of the household head, plot size (ha/10), other income, credit; * significant at 10\%, ** significant at 5\%, *** significant at 1\%; Author's calculation based on ENRUM. 
Table 1.7 - Determinants of Investment Volume and Assets (Fixed Effects)

\begin{tabular}{|c|c|c|c|c|c|c|c|c|}
\hline & $(1)$ & $(2)$ & (3) & (4) & (5) & (6) & $(7)$ & (8) \\
\hline & \multicolumn{4}{|c|}{ Investment Volume } & \multicolumn{4}{|c|}{ Assets (End of Period) } \\
\hline & \multicolumn{2}{|c|}{$\mathrm{AG}$} & \multicolumn{2}{|c|}{ LIV } & \multicolumn{2}{|c|}{$\mathrm{AG}$} & \multicolumn{2}{|c|}{ LIV } \\
\hline & FE & 2SLS-FE & FE & 2SLS-FE & FE & 2SLS-FE & FE & 2SLS-FE \\
\hline \multicolumn{9}{|l|}{ Productive Assets } \\
\hline ag capital (log) & $0.1820^{* * *}$ & $0.1666^{* * *}$ & 0.0255 & $0.0465^{*}$ & & & & \\
\hline livestock (log) & -0.0068 & -0.0125 & $0.3314^{* * *}$ & $0.3393 * * *$ & & & & \\
\hline \multicolumn{9}{|l|}{ Cash Flow and Liquidity } \\
\hline agsales $(\log )$ & $0.1053^{* * *}$ & $0.0920^{* * *}$ & 0.0323 & $0.0505^{*}$ & $0.0777^{* *}$ & 0.0391 & $0.0652^{* *}$ & $0.0614^{* *}$ \\
\hline livsales $(\log )$ & 0.0316 & $0.0516^{*}$ & $0.1545^{* * *}$ & $0.1272 * * *$ & $0.0826^{* * *}$ & $0.1259 * * *$ & $0.3544 * * *$ & $0.3585^{* * *}$ \\
\hline other income (log) & 0.0333 & 0.0408 & 0.0242 & 0.0139 & $0.0863^{*}$ & $0.1007^{*}$ & $0.1057 * * *$ & $0.1071 * * *$ \\
\hline credit $(1=y e s)$ & $-0.9590 *$ & $-1.1677 * *$ & 0.2091 & 0.4951 & 1.0863 & 0.4961 & 0.2360 & 0.1792 \\
\hline Migration & 0.1355 & $6.0482^{* * *}$ & 0.2953 & $-7.8053 * *$ & $0.9657^{*}$ & $16.3096^{* * *}$ & 0.3083 & 1.7833 \\
\hline Obs & 3244 & 2978 & 3244 & 2978 & 3244 & 2978 & 3244 & 2978 \\
\hline rho & 0.40 & 0.45 & 0.40 & 0.47 & 0.47 & 0.49 & 0.58 & 0.57 \\
\hline p-value Hansen J & & 0.1426 & & 0.7785 & & 0.3620 & & 0.1426 \\
\hline K-P Wald F-Stat & & 13.924 & & 13.924 & & 14.369 & & 14.369 \\
\hline Cragg-Donald F-Stat & & 27.034 & & 27.034 & & 28.797 & & 28.797 \\
\hline
\end{tabular}

Note: Dependent variables in logs; * significant at $10 \%, * *$ significant at $5 \%$, *** significant at 1\%; T-statistics (two-tailed) based on robust standard errors clustered at the village level. Author's calculation based on ENRUM.

To summarize, we find that migration has strong positive effects on agricultural assets but not so much on livestock. Agricultural assets are built up with the capital received from migration. These effects are statistically significant, robust to changes in the specification of our estimation equation and are also practically significant since they have stronger effects than most of the other variables included. The estimates based on investment flow variables do not show a clear pattern, possibly due to their more volatile and infrequent nature. Our estimations also show that livestock seems to be driven more consistently by life-cycle effects than agriculture where we cannot observe a robust effect of age on investments and capital stocks. One possible interpretation of these findings is that livestock and migration are substitutes while agriculture seems to be a subsistence category that will never be excluded from the income portfolio since it guarantees a minimum level of consumption. This would explain why we do not observe strong life-cycle effects for agriculture but a strongly positive effect of migration on agricultural asset accumulation. In the context of our theoretical framework, these results support the argument that households adjust their income portfolio and use migration as a profitable investment alternative. A different reading of our results, which does not invalidate the subsistence hypothesis, is that livestock also serves as a risk buffer as argued by 
Dercon (1998) for the case of rural Tanzania. This essential insurance function of livestock could become obsolete and no investments would take place if migration had a risk diversifying effect.

\subsection{Conclusion}

This essay addressed the prediction of NELM theory that remittances increase productive investments if credit constraints are binding for the migrant sending households. We explored three aspects that have so far not received enough attention in the literature regarding the nexus between migration and investments and that could possibly reconcile the contradicting results in the empirical literature on remittances and investments: the distinction between different productive investment categories, cash flows as fundamental investment determinants and possible life-cycle effects as important investment constraints. We employed various econometric techniques to investigate the effect of international migration on investment volumes and accumulated capital stocks.

After ruling out that our results are driven by selection or endogeneity, we take away three important findings from our investigation. First, life-cycle effects may inhibit an increase in investments. Our estimates show strong live-cycle effects but no systematic difference between migrant and non-migrant households. We found some evidence that migrant households disinvest more strongly at the later stage of their life-cycle than non-migrant households. This observation calls for an explicit consideration of the stage of the migration cycle in future research regarding the effect of international migration on productive investments and asset accumulation. If migration occurs at a late stage of the life-cycle there is no reason to expect strong investments since the horizon for the returns to investments become shorter. Second, production fundamentals appear to be very important. Throughout category specific cash flows are the most predictive indicator of investments. Since all of the cash flows we observe are generated through market sales we have to conclude that market integration remains the strongest driver of investment. Third, pooling different investment categories distorts the causal relationship underlying the estimation. While our results indicate that migrants have accumulated more agricultural productive capital this is not the case for livestock, indicating that most households rely on agriculture for their daily consumption throughout the life-cycle. We should not expect strong investments in agriculture in general but only in the activities that secure the subsistence of the household. 


\title{
Essay 2
}

\section{Migration and Educational Aspirations Another Channel of Brain Gain?}

\begin{abstract}
International migration not only enables individuals to earn higher wages but also exposes them to new environments. The norms and values experienced at the destination country could change the behavior of the migrant but also of family members left behind. In this essay we argue that a brain gain could take place due to a change in educational aspirations of caregivers in migrant households. Using unique survey data from Moldova, we find that international migration raises parental aspirations in households located at the lower end of the human capital distribution. The identification of these effects relies on GDP growth shocks in the destination countries and migration networks. We conclude that aspirations are a highly relevant determinant of intergenerational human capital transfer and that even temporary international migration can shift human capital formation to a higher steady state by inducing higher educational aspirations of caregivers.
\end{abstract}

Keywords: education, aspirations, migration, brain gain

JEL classification: D03, 012, 121, J61 


\subsection{Introduction}

The nexus between international migration and human capital remains a disputed topic. At the individual level the positive effect remittances can have by relaxing liquidity constraints and thus by enabling educational investments are often cited and widely acknowledged. However, at the aggregate level especially the outflow of skilled migrants - what has been termed brain drain - has been characterized as detrimental to sustainable growth of developing countries. Only recently this perspective has been challenged by various authors (e.g. Stark et al. 1997, Beine et al. 2001) who show theoretically that the option to migrate could actually increase human capital investments by individuals. Their argument is rooted in a neo-classical framework emphasizing that the incentive to invest is driven by the possible monetary gains from going abroad. Since not all individuals who invest in education to migrate actually leave the country, a net increase of the human capital stock in the sending countries takes place. This hypothesis has been supported empirically by recent macro studies (e.g. Beine et al. 2007). Only few studies have attempted to test the human capital externalities of migration empirically at the household level. Batista et al. (2012) constitute a notable exception. The authors present evidence for the case of Cape Verde that cannot reject the brain gain hypothesis.

In this essay we suggest a brain gain effect through a different causal channel and test it empirically. We argue that individuals and households do not maximize their utility independent of their environment and social context but that their decisions to e.g. invest in education are bound to the goals and aspirations set by their environments. This approach was suggested recently by Ray (2006) who pointed out that aspirations are an important determinant of behavior and could represent a key element of economic development. In line with this perspective we test the hypothesis that individuals adapt their aspirations if exposed to new environments. We exploit the variation of norms and values international migrants are exposed to in order to find out if migration has positive or negative human capital externalities by changing the educational aspirations of households.

In our empirical analysis of household data from Moldova we find a strong relationship between enrollment, schooling expenditures and the educational aspiration caregivers have for their children, which supports the importance of aspirations for the analysis of household behavior. More importantly, using a 2SLS approach to address the endogeneity of migration, we find a positive shortrun impact of international migration on educational aspirations. These results provide a new perspective on the ongoing discussion about human capital externalities of migration and a possible brain gain. We thereby contribute to the growing literature about the effects of migration on 
households in the sending countries with an emphasis on human capital accumulation. By focusing on aspirations, our analysis is also related to the nascent discussion about the transfer of norms and values in the context of international migration.

The essay proceeds as follows. In the next section we review the literature on aspirations and human capital investment and describe the role of migration in this context in depth. In section 2.3 we formulate a simple conceptual framework. We introduce the data used for the empirical analysis in section 2.4 and describe the econometric strategy in section 2.5. We present the descriptives and estimation results in section 2.6 and 2.7, respectively, and conclude in section 2.8 .

\subsection{Previous Literature}

Because the concept of aspirations is a social construct it lends itself to a variety of definitions. Broadly defined aspirations can be understood as a desire to achieve a certain objective. Aspirations differ from expectations in that they often represent ideals or higher values. Expectations on the other hand account for constraints and perceived limitations. Accordingly we will use the term aspirations to describe goals that one would like to achieve in an ideal world without constraints and with full information and expectations as probabilistic goals that one expects to achieve taking into consideration all limitations one faces.

In economics the idea of aspirations has been present for quite some time. Questioning classical economic theory and utility maximization, Herbert Simon (1959: 263) noted "[...] the conditions for satisfying a drive are not necessarily fixed, but may be specified by an aspiration level that itself adjusts upward or downward on the basis of experience". When Kahneman and Tversky (1984) speak of the importance of reference points for utility maximization they reconcile ordinal utility theory with the observation that judgment and evaluations are based on prior experiences. Broadly speaking reference points are one major determinant of the goals people aspire to achieve.

The connection between human capital accumulation and aspirations has recently gained more attention and has been used to model inequality and poverty persistence. Dalton et al. (2010) show formally that aspirations can serve as a behavioral explanation of poverty persistence. Their model establishes a theoretical link between constraints that are internal to the economic agent and persistent poverty. They define aspirations as a reference point and consider effort to be complementary to this reference point. The authors argue that an initially low reference point raises the likelihood of a persistent and binding internal constraint leading to a poverty trap. Dalton et al. (2010) use these results as a normative justification for empowerment programs that increase individuals' aspirations. Mookherjee et al. (2010) analyze the effect of social context and parental 
aspirations as determinants of investments in children's education. At the core of their model stands the assumption that parental pride in their children's achievements is on the one hand determined by the economic situation of their neighbors and does on the other hand determine their investment behavior. They conclude that spatial segregation and the implicit limitation of the aspiration window can lead to persistent inequalities.

There is also a growing body of empirical evidence on the role of aspirations in the context of economic development that speaks to the relevance of the topic. Analyzing the nexus between aspirations and poverty Bernard et al. (2011) apply the theoretical framework proposed by Ray (2006) to households in Ethiopia. The authors argue that self-efficacy is an important determinant of goal content and pursuit and use a locus of control measure to proxy aspirations. The locus of control is a concept referring to the degree to which individuals believe they can influence important events in their lives. They find that the locus of control and the aspirations gap are strongly related and that the locus of control plays a central role in the credit demand of households.

Apart from establishing that some kind of low aspiration equilibrium might be present, the central question is why these low aspirations prevail and how they can be changed. Various authors have proposed that aspirations could be influenced by the exposure to new role models. Chiapa et al. (2010) exploit data from the Mexican anti-poverty program Progresa and find that children that were randomly exposed to highly educated staff such as doctors and nurses had significantly higher educational aspirations. Another study that focused on the importance of role models is Beaman et al. (2012). The authors provide strong evidence from a randomized natural experiment in India where female community leadership inspired girls' educational attainment. Macours and Vakis (2009) also use the random variation of female leadership in communities in Nicaragua to identify the effect of role models on human capital and educational aspirations. The authors show that changing aspirations brought about by new role models can have significant impacts on the investment behavior of households. An example for a direct intervention is presented by Krishnan and Krutikova (2010). The authors evaluate a NGO-program that attempts to raise the self-esteem and aspirations of children in slums of Bombay. They find that the program increases the aspiration window measured by the number of people children could name who are wealthier and serve as role models.

These studies suggest that aspirations are responsive to changes in the environment and can be modified. Yet, they cannot overcome two problems. First, the authors often do not distinguish between aspirations and information. In a situation of incomplete information it is impossible to disentangle the information and aspiration effect. A pure aspiration effect must be understood as goal setting under perfect information. Second, it must be noted that ambitious goals or high 
expectations do not translate with certainty into high educational achievements. Alexander et al. (1994) have shown that children from less advantaged background are less likely to convert their educational aspirations into the desired educational achievement. However, there is no doubt that with low aspirations high educational achievements are more unlikely.

While the importance of aspirations for human capital formation is well established, there is no consensus as to whether the externalities of international migration are positive or negative for children's education. While migration can improve the financial situation of the household through remittances, thereby alleviating the resource constraint of the household, it can also negatively affect the intra-household time allocation. Kandel and Kao (2001) find positive effects of parental migration on children's school performance in Mexico. They attribute their finding to the improved financial situation of migrant families but also argue that parental migration changes the motivation of children to attain a good education. Mansuri (2006) presents evidence for Pakistan that points in the same direction. While migration eases the resource constraint and has positive effects on human capital accumulation in general, the prospect of migration does not alter schooling decisions. In contrast to these two contributions, Antman (2011) finds that paternal migration from Mexico to the U.S results in a reduction of time allocated to studies and an increased work load of children. Her estimates suggest that these negative short-term effects are driven primarily by boys in the age range of 12 to 15 . Similar results are presented by McKenzie and Rapoport (2006) who also observe that migration seems to depress educational attainment of children. Additionally they show that the reduction in schooling is accounted for by the increased propensity of migration for boys and an increased household workload for girls.

There are various other factors that will moderate the effects of migration on educational investments apart from the additional financial resources obtained via remittances. First, the permanent absence of one parent and the resulting lack of guidance and encouragement could have adverse effects on the educational attainment of children. This is especially important since the parental nurture effect is one of the main drivers of intergenerational human capital transfer (Holmlund et al. 2011) and might not be compensated by the increased income (Shea 2000).

Second, migrants are exposed to new environments and ideas which can lead to an adjustment of their pre-migration priors. This migration induced transmission of knowledge, norms and values has been demonstrated to affect the up-take of low-fertility norms (Beine et al. 2009) but also the political realm (Spillimbergo 2009). For the case of Moldova empirical evidence by Omar Mahmoud et al. (2012) suggests a strong link between the political atmosphere in the migration receiving country and the subsequent voting behavior of migrant households in the sending country. More 
precisely, westward migration seems to reduce the electoral support for the far left of the political spectrum in Moldova.

Third, migration itself could become a viable option for the children who see their parents work abroad and thus affect educational attainment. Jensen (2012) has demonstrated that individuals adjust their behavior quite quickly to new job market opportunities. Using data from a randomized labor market intervention in India he shows that young women increase their schooling investments and postpone marriage when given the opportunity of non-farm employment. That migration has a similarly strong but qualitatively different effect on life-cycle planning of households has been proposed by Kandel and Massey (2002). They argue that migration becomes part of the household's life plan in the migrant sending countries. They find that the prospect of migration to the U.S. shapes children's behavior in Mexico by increasing the likelihood of migrating to the U.S. and by lowering their odds of continuing with school. Thus, low aspirations of children could be the result of their perception that education is not necessary to migrate, i.e. an underestimation of the return on investments in education that is induced by the exposure to an apparently "easy" exit. In line with this argument McKenzie et al. (2012) present evidence from Tonga that there is a systematic bias in the expected wage differential. The authors attribute this bias to underreporting of earnings by current migrants to moderate demands for remittances, and to disproportionate emphasis potential migrants put on negative migration experiences reported by other people. An alternative explanation could be the employment of their highly educated migrant parents in low skill jobs. Returns to foreign education are often low (e.g. Hartog and Zorlu 2009, Sanromá et al. 2009) and could therefore discourage parents and children who plan to migrate to adjust their aspirations upwards.

There are only two papers we are aware of that have focused on the relationship of educational aspirations and migration. In a sample of Mexican students Dreby and Stutz (2012) detect a positive impact of maternal migration on educational aspirations while the migration of fathers leaves the aspirations children have unchanged. Opposed to this finding, Kandel and Kao (2001) report lower educational aspirations at all academic levels of Mexican children growing up in households with international migrants. Unfortunately both papers do not account for the self-selection of migrants and can therefore not establish the causal link between migration and educational aspirations convincingly. Our own analysis makes a contribution to the literature by carefully identifying causality (see Section 2.5). 


\subsection{Conceptual Framework}

Most models that are concerned with the effect of migration on human capital investments and a possible brain gain are built on the premise that wage differentials are the main determinant of migration (e.g. Stark et al. 1997, Mountford 1997, Vidal 1998, Beine et al. 2001). A problem with this setup is that it does not account for the intrinsic value of education. The present framework intends to clarify the relationship between aspirations and human capital investments. To allow an accessible interpretation of and direct predictions from our framework we keep matters as parsimonious as possible. We employ a simple static model with no general equilibrium effects based on Stark et al. (1997) to show that the exclusion of the intrinsic value of human capital can lead to underestimating the effects of migration on human capital investments. Our approach proceeds in three steps looking at investments (1) under autarky, (2) with migration and (3) with dynastic migration. Our framework suggests that increased human capital investments might prevail after the migration option has ceased to be available in a dynastic human capital investment scenario.

Assume individuals live for two periods, childhood and working age. Individuals derive utility from consumption $c_{t}$ in both periods and from the intrinsic value of human capital $\theta$ in the first period in each dynasty $d$. In the first period individuals can invest in human capital $\theta$ or work to finance consumption $c_{1}$. In the second period individuals can only work to finance consumption $c_{2}$. Their objective function is given by:

$$
U_{d} \equiv U\left(c_{1}, \psi(\theta), c_{2}\right)
$$

Consumption is financed only by wages. Individuals can earn wage $W^{H}(\theta)$ in their home country. Labor demand and the wage function are exogenously determined and identical for all individuals. To keep matters simple we assume a linear wage function such that $W^{H}(\theta)=w_{0}^{H}+$ $w_{1}^{H} \theta$ where $w_{1}^{H}$ is the education premium which is time invariant. Individuals face an exponentially increasing human capital cost function $C(\theta)=\gamma \theta^{2}$ were $\gamma>1$. Human capital is aquired instantly in the home country in period one and remains unchanged in period two. For ease of exposition we impose no restrictions on the total amount of human capital that can be accumulated. Also there is no capital market. The individual faces the following resource constraints in the first and second period, respectively:

$$
\begin{aligned}
& c_{1}=W^{H}(\theta)-C(\theta)=w_{0}^{H}+w_{1}^{H} \theta-\gamma \theta^{2} \\
& c_{2}=W^{H}(\theta)=w_{0}^{H}+w_{1}^{H} \theta
\end{aligned}
$$


In addition to these standard elements we introduce a reference point dependent disutility following the discussion by Kogszegi and Rabin (2006), which is represented by $\psi(\theta)$. The individual will choose the education of a certain reference group $\theta^{R}$ that acts as a benchmark to evaluate her own household's education level. ${ }^{8}$ This reference point or aspiration level of education will most likely be influenced by the environment the individual is exposed to, e.g. family, neighborhood, coworkers. This relates to the results by Mookherjee et al. (2010) who have argued that spatial segregation will lead to persistent reference points, i.e. aspirations traps. The individual will aspire to this reference point and experience increasing disutility the farther away she is from this benchmark. Let $\psi(\theta)=\left(\theta^{R}-\theta\right)^{2}$. It is reasonable to assume that individuals mostly aspire to higher goals and therefore - if available - choose a higher reference group than their current educational level such that $\theta^{R} \geq \theta$.

Before introducing migration, let us consider the optimal human capital investment in autarky. By substitution we find that the individual will maximize the following objective function:

$U_{d} \equiv U\left(c_{1}, \psi(\theta), c_{2}\right)=w_{0}^{H}+w_{1}^{H} \theta-\gamma \theta^{2}-\left(\theta^{R}-\theta\right)^{2}+w_{0}^{H}+w_{1}^{H} \theta$

Solving for $\theta$ we observe that the optimal autarky level of human capital $\theta^{*}$ is:

$$
\theta^{*}=\frac{w_{1}^{H}+\theta^{R}}{\gamma+1}
$$

In autarky human capital accumulation will be driven by the education premium $w_{1}^{H}$, by the reference level $\theta^{R}$, and by the cost of education $\gamma$. Now we allow for the possibility to migrate temporarily in the second period to work abroad. Assume that the probability to migrate $p$ is exogenous and applies equally to all individuals. In the foreign country individuals can earn a wage $W^{F}(\theta)$ where $W^{F}(\theta)=w_{0}^{F}+w_{1}^{F} \theta$. Let the education premium in the foreign country be bigger than the education premium in the home country, i.e. $w_{1}^{F}>w_{1}^{H}$. Migration will be costly such that migrants will earn $\kappa W^{F}(\theta)$ in the foreign country were $0<\kappa \leq 1$ is a cost factor. The resource constraint in the second period will therefore take the following form:

$$
c_{2}=p \kappa W^{F}(\theta)+(1-p) W^{H}(\theta)=p \kappa\left[w_{0}^{F}+w_{1}^{F} \theta\right]+(1-p)\left[w_{0}^{H}+w_{1}^{H} \theta\right]
$$

By substituting the second period consumption of equation (6) into equation (4) the objective function reads:

$$
U\left(c_{1}, \psi(\theta), c_{2}\right)=w_{0}^{H}+w_{1}^{H} \theta-\gamma \theta^{2}-\left(\theta^{R}-\theta\right)^{2}+p \kappa\left[w_{0}^{F}+w_{1}^{F} \theta\right]+(1-p)\left[w_{0}^{H}+w_{1}^{H} \theta\right](7)
$$

\footnotetext{
${ }^{8}$ One possible way of describing the evolution of $\theta^{R}$ could be $\theta^{R}=\sum_{k=1}^{N} \frac{\theta_{k}}{N}$ were $N$ represents the total number of families in the neighborhood.
} 
The optimal level of human capital $\theta^{*}$ given the probability to migrate $p$ thus becomes:

$$
\theta^{*}=\frac{2\left(w_{1}^{H}+\theta^{R}\right)+p\left(\kappa w_{1}^{F}-w_{1}^{H}\right)}{2(\gamma+1)}
$$

Notice that the only difference between equations (5) and (8) is that the latter contains the probability weighted wage difference term $\left(\kappa w_{1}^{F}-w_{1}^{H}\right)$. It is readily observable that a higher probability to migrate and/or a higher wage differential will increase the investments in education in the first period. Given that migrants are only temporarily permitted to work abroad each generation faces the same decision.

In a dynastic migration setting the implications of the reference point $\theta^{R}$ become even more pronounced. Let the migration of the last generation only have an effect on two variables: the migration $\operatorname{cost} \kappa$ and the reference point $\theta^{R}$. To emphasize the intergenerational transmission of these two variables we will use the subscript $d$.

First, migration might decrease the migration cost. This effect reflects the strong evidence regarding the importance of migrations networks (e.g. Munshi 2003). By introducing the indicator variable $m_{d}=\{0,1\}$ - where $m_{d-1}=1$ if the last dynasty migrated and zero if not - we can write $\kappa_{d}=\kappa_{d-1}+\alpha\left(1-\kappa_{d-1}\right) m_{d-1}$. Alpha $(\alpha)$ is a deterministic indicator reflecting how much the migration experience reduces migration costs and is defined as $0<\alpha<1$. Thus, if the probability of migration is non-zero $(p>0)$ and the last generation also migrated $\left(m_{d-1}=1\right)$ we would observe increased human capital investment compared to a scenario where there is no connection between dynasties.

Second, the migration in the last generation could also raise the reference point the dynasty uses. This change could come about through either externalities in the labor market in the destination country due to the matching of the migrant with a certain sector or other market interactions, or through externalities in social surroundings, i.e. interactions with coworkers, friends or neighbors. Let $\lambda$ represent the difference between the home and the foreign reference group such that $\lambda=\theta^{R_{F}}-\theta^{R_{H}} \geq 0$. We can think of the link of the reference point between dynasties as:

$$
\theta_{d}^{R}=\theta_{d-1}^{R}+\lambda m_{d-1}
$$

If the last generation has migrated $\left(m_{d-1}=1\right)$ and the migrants adopted a higher reference point $(\lambda>0)$ then the aspired level of education $\theta_{d}^{R}$ will increase compared to migration without dynasties. It is important to note that in absence of the possibility to migrate or a positive wage differential for the second dynasty, migration could induce higher human capital investments. 
The two questions we will address primarily in the empirical analysis are (a) whether the reference point matters for human capital investment, i.e. whether $\theta^{*}$ really depends on $\theta^{R}$ and (b) whether migration through $\lambda$ really affects $\theta_{d}^{R}$. We will also briefly look at the migration aspirations caregivers have for their children. High migration aspirations of caregivers could be a indication of lower migration costs $\left(\kappa_{d}\right)$, i.e. parents will try to facilitate and support the migration of their children by providing information and guidance.

\subsection{Data}

To investigate the role and evolution of aspirations empirically we employ a unique household survey dataset that was collected in Moldova between October 2011 and February 2012. Moldova is an excellent environment to study the effects of migration on aspirations and education. After Moldova emerged from the Soviet Union it faced the transition problems also observed in other post-soviet countries. High unemployment and a stagnant economy in the late 1990s led to increasing emigration of Moldovans. Thus international migration is a relatively new socio-economic phenomenon in Moldova. However, only few states worldwide have a higher net migration rate than Moldova, among them Samoa and Tonga. ${ }^{9}$ This is also reflected in the high volume of official remittances which is about 24 percent of the Moldovan GDP.

We conducted a survey to understand the effects of migration on "Children and Elderly Left Behind" (CELB). The survey was built as a national representative survey of households with children, elderly people and migrants using the National Labor Force Survey (LFS) as sampling frame. In line with the LFS the survey is a stratified random sample of 3539 households in 129 communities. ${ }^{10}$ The questionnaire consisted of four modules. The first module elicited basic household characteristics including the household composition, labor market activity and income. It also contained an extensive section on the international migration of household members. This migrant section allowed us to capture in detail the migration history of each household member since 1999. Based on this first module, caregivers of all children, children in the age range of 10 to 18 and all elderly people in the household were identified. In a second module all caregivers were interviewed about topics such as health, education and behavior of their children. We interviewed caregivers of 3594 children in 2082 different households. In a separate third module 1282 children between the age of 10 and 18 were interviewed concerning similar topics. Due to the structure of our sampling strategy we only

\footnotetext{
${ }^{9}$ Comparisons are made based on data in 2010 from World Development Indicators compiled by the World Bank.

${ }^{10}$ Since the LFS does not include Transnistria our sample is limited to households that are located in the West of the River Dniester.
} 
cover cases in which migrants have left Moldova at some stage during the last 12 months while their child stayed behind. ${ }^{11}$ Additionally, we conducted a community questionnaire collecting information on general aspects such as education, health, infrastructure and labor markets in each community.

Central for our analysis are the questions we asked the caregiver. Two specific questions focused on the aspirations and expectations caregivers had for their children. First we asked caregivers the following question:

(1) "Imagine finances were not a problem and everything else went right, what is the highest level of formal education you WISH [CHILD] could complete?"

As noted before the literature often does not go into detail when defining what constitutes aspirations: a change in the information set available or a change in the utility maximization reference point under perfect information. Since Moldova has very good media coverage as well as free education, we believe that our results capture a pure aspiration effect under perfect information.

For the level of formal education we used a scale that resembles the International Standard Classification of Education (ISCED) designed by the UNESCO. In the following analysis we converted this ordinal classification of educational attainment into years of schooling. In addition to these absolute aspirations we also elicited the level of expectations. This is important for two reasons. First it is a forward looking measure that characterizes and refines the parental mind set. Secondly it allows us to contrast the novel notion of aspirations with the traditional expectations and investigate possible differences and similarities. We asked caregivers the following question to measure their expectations:

(2) "Consider your current financial situation and the child's prospects. Using this card on which 0 means impossible and 10 is certain, how likely is it that [CHILD] will complete this level of education?"

This question aims at capturing the probabilistic expectations of parents. We choose this approach in line with the recommendations by Delavande et al. (2011) and Attanasio (2009). More specifically we presented the respondent the stylized image of a ladder with 10 steps, explained the concept of probability and made clear that the last step represents certain achievement of a set goal.

To corroborate the parental aspirations we also asked children about their aspirations in separate interviews. The correlation between the two is 0.98 , which suggests that the intergenerational transmission of aspirations is very strong. In the following we will concentrate on

\footnotetext{
${ }^{11}$ Migration is defined as being abroad for at least 3 months during the last 12 months.
} 
parental aspirations for two reasons. First, it is contested whether educational plans can actually be interpreted as long-term goals. For example Alexander and Cook (1979) showed that the mere expression of intent by children can be quite volatile over time. Second, parents do control the financial resources of the household. Their decisions will therefore have a larger impact on the allocation of resources as compared to the aspirations of children.

To validate our aspiration measures we also included questions to measure the locus of control as done by Coleman and de Leire (2003) and Bernard et al. (2011). In our data this personality measure is as expected positively correlated with aspirations and expectations but has no significantly predictive value for aspirations or expectations after controlling for household and child characteristics. Cebi (2007) for example finds no effect of locus of control on human capital investments in the form of high school graduation. She underscores the assertion that the locus of control merely proxies the unobserved ability of children. To use the locus of control approach for our research would require us to neglect these conceptual difficulties and would force us to assume that locus of control and aspirations can be equated, which excludes the possibility to evaluate the difference between idealistic goals (aspirations) and realistic expectations. For these reasons we will refrain from using the locus of control measure in the subsequent analysis.

For our analysis we define aspirations as the unconstrained goal parents set for their children (i.e. question 1) and expectations as the product of the aspired years of education (question 1) and the expected probability of achieving this goal (question 2).

To evaluate how migration as an alternative to local employment is transmitted between generations we also included one question about migration aspirations in the questionnaire of the caregivers. We asked them:

(3) Do you think it would be good for [CHILD] to live or work in a different country when [CHILD] finishes his/her formal education?

About one in five of the caregivers answered this question affirmatively; they were also asked about the reason for giving this answer, which country they would their children like to go to and whether formal education was important to work in the particular destination country. The two main reasons they stated were the absence of job opportunities in Moldova and a better way of life abroad. Family reunions were only mentioned by roughly 2 percent of the caregivers as a reason. In line with the two major migration corridors of Moldova about 41 percent of the caregivers named Russia as the most preferable destination followed by 20 percent who wanted their children to go to Italy. Irrespective of the destination there was a broad consensus regarding the importance of formal 
education: 96 percent of the caregivers said that it would be an important requisite to work in the destination country.

\subsection{Empirical Identification Strategy}

Our goal is to find out if, as assumed in the conceptual framework, a causal relationship between migration and aspirations exists. The parsimonious structural equation we will use to test the hypothesis of Eq. (9) is:

$$
\theta_{\mathrm{ij}}=\alpha+\lambda \mathrm{M}_{i j}+\mathrm{X}_{i j}^{\prime} \beta+\varepsilon_{\mathrm{ij}}
$$

In this baseline specification $\theta_{i j}$ is the observed aspiration, $\mathrm{X}_{i j}$ a vector of individual characteristics of the child $i$ in household $j$ and $\mathrm{M}_{i j}$ is the observed migration status of the household the child is living in. While we will concentrate primarily on educational aspirations, as suggested by our framework, we will also include expectations and migration aspirations in our analysis. The former will allow us to examine whether the concepts of aspirations and expectations differ. The latter enables us to test the presence of chain migration dynamics.

Since none of our dependent variables is independent of migration $\left(\mathrm{M}_{i j}\right)$ we cannot expect that $E\left(\varepsilon_{\mathrm{ij}} \mid \mathrm{M}_{i j}\right)=0$. Suppose we observe a household were two parents raise two children. We observe that one parent migrates to Italy and that the remaining caregiver has high educational aspirations for her children. The couple could have had high aspirations for their children before one of them migrated and choose to work abroad to overcome the credit constraints to fulfill these aspirations. They could also be very ambitious in general which let them choose the migration strategy but is reflected by high aspirations independently of this migration decision. Thus, because migrants are not randomly drawn from the population, OLS estimates could be severely upward biased if positive self-selection is present. However, if negative self-selection is the dominant migration pattern the OLS estimates could also underestimate the effect migration has on aspirations. To address this problem we employ an exogenous variable $(\mathrm{Z})$ as an instrument for the migration status in a twostage least squares (2SLS) setup. The structural equation of our first stage is then:

$$
\mathrm{M}_{i j}=\alpha+\phi \mathrm{Z}_{\mathrm{ij}}+\mathrm{X}_{i j}^{\prime} \beta+\zeta_{\mathrm{ij}}
$$

Following McKenzie and Rapoport (2007) and Antman (2011) we use as an instrumental variable the GDP per capita growth rate in each of the destination countries between 2004 and 2010 
weighted by the size of the migrant network proxied by the number of migrants from the community who had migrated to the destination country by 2004 . The instrument is based on the assumption the that higher GDP per capita growth the more likely are migrants to find employment and the higher are the wages, i.e. we emphasize the pull effects of economic growth at the destination. While there is no doubt that the change in GDP growth is completely exogenous to the conditions and characteristics of the household in Moldova it seems necessary to adjust the strength of this pull effect by the size of the migrant network at the time of the change. We regard the migration network as the information channel through which the exogenous shock operates. Migration networks proxied by current migrant stocks have also been used in a number of studies to capture the migration cost decreasing effect networks have as they improve the chances of employment and finding housing at the destination. Using the World Development Indicator data base we found that GDP per capita (in constant 2005 international \$) grew on average 2.9 percent per annum in the 90 countries the index is built from. The most prevalent migration destinations in 2004 were Russia, Italy, Romania, Ukraine and Portugal which consequently weight most heavily in the index. These five countries had an average growth rate of GDP per capita of 2.6 percent between 2004 and 20010. Our identifying assumption is that changes in economic growth represented by GDP per capita in the destination countries, weighted by the strength by which communities in Moldova were connected to these countries through migration networks in 2004, are predictive of current migration rates and only have an impact on current enrollment and educational aspirations through migration.

In the context of Moldova there is - in addition to the issue of self-selection - the question of sorting. There are two major migration corridors that lead to the West, mainly Italy, due to lingual proximity of Romanian and Italian, and to the East, mainly Russia due to historic ties. Yet, it is not possible to use the GDP variation to estimate the effect of migration to one specific country since this instrument only represents an overall pull effect. Thus, we cannot disentangle the effect of going to Russia compared to migrating to Italy using only the GDP per capita growth rate. Nevertheless this difference is of crucial importance since Russia alone absorbs around 60 percent of Moldovan migrants in our sample. We therefore employ an additional second instrument: the presence of Soviet military personnel in each community before 1990. The assumption behind this binary variable is that the allocation of Soviet military in Moldova was independent of household characteristics and regional differences but that it was rather driven by strategic factors. Because Moldova as part of the Soviet Union constituted one of the border countries with the West it was considered strategically important. Additionally, because of the small size of Moldova Soviet military personnel was present in many communities. In about one quarter of the communities in our sample community leaders told us that Russian military personal was living or working in the community before 1990 . The assumptions this instrument is based on are similar to those described in the case of migration 
networks. Since soldiers became part of the local social network we expect their presence to decrease the migration cost to Russia for people living in these communities. Thus the presence of Russian military personnel before 1990 should only boost migration to Russia but have no effect on migration to the West.

One threat to the validity of our instruments is the recent emergence of the migration networks. Since migration in Moldova only took off in the late 1990s we use relatively recent migration stocks as a proxy for the evolving networks. This bears the risk that our instruments do not only capture the network effect but also the current economic conditions of the region. We therefore include regional fixed effects and various household control variables. To ensure that we only capture the migration effects for one migration spell independent of the migration history we also tested the robustness of our findings by including a dummy variable that indicates if the household had migrants before 2011 . This dummy did not alter our results qualitatively. A second problem is the non-linearity of the effects migration has on the households in the sending country. More specifically, parents would have to spend a longer time at the destination to update their priors about education, i.e. to decrease or increase their aspirations. Also from a financial perspective, migrants who leave the country for the first time will have to bear more costs than regular migrants which will decrease the amount of money remitted to their families. The observed effects of recent migration can therefore be understood as the lower bound of the overall effect migration has.

\subsection{Descriptives}

Table 2.1 reports the basic summary statistics. On average the household size is 4.9 and 2.1 children live in each household (see column 2). Out of all households with children 28 percent had a member who lived or worked abroad for at least 3 months in 2011. About one third of the migrants go to countries in Western Europe and two thirds migrate to the East, i.e. almost exclusively Russia (see column 4). On average about 60 percent of the migrants that leave for Western destinations are female. By contrast, migrants to the East are predominantly male (74 percent). We also observe a convergence of migrant skill levels for eastward and westward migrants (see Figure 2.1), which suggests that the positive selection of migrants who go to the West seems to have decreased since 1999. Migrants are on average 34 years old and have 11.12 years of education at the mean. About 63 percent of all migrants are married. It is mostly the husbands who leave their wife and children behind. However an increasing feminization of migration seems to take place as also women migrate in increasing numbers, mostly to the West. 
Table 2.1 - Descriptive Statistics

\begin{tabular}{|c|c|c|c|c|c|c|}
\hline & & (1) & (2) & (3) & (4) & (5) \\
\hline & & $\mathrm{N}$ & all & $\begin{array}{c}\text { mean } \\
\text { non-migrant } \\
(\mathrm{N}=2584)\end{array}$ & $\begin{array}{c}\text { migrant } \\
(\mathrm{N}=1014)\end{array}$ & $\begin{array}{l}\text { p-value } \\
\text { [diff (3)- } \\
\text { (4)] }\end{array}$ \\
\hline \multicolumn{7}{|l|}{ Panel $A$} \\
\hline \multirow[t]{10}{*}{ Households } & Household size & 3598 & 4.89 & 4.81 & 5.1 & 0.00 \\
\hline & Number of Children & 3598 & 2.12 & 2.16 & 2.01 & 0.00 \\
\hline & Migrant household & 3598 & .28 & - & 1 & - \\
\hline & West Migrant & 3598 & .10 & - & .35 & - \\
\hline & East Migrant & 3598 & .19 & - & .68 & - \\
\hline & HH Income in US\$ & 3201 & 3588.27 & 3180.77 & 4622.09 & 0.00 \\
\hline & Remittances as share of Income & 3201 & .13 & - & .46 & - \\
\hline & Educ. expenditure as share of Income & 3201 & .20 & .22 & .15 & 0.00 \\
\hline & Below Poverty Line (2 Int. \$) & 3201 & .03 & .03 & .02 & .02 \\
\hline & Urban (yes=1) & 3598 & .23 & .26 & .16 & 0.00 \\
\hline \multicolumn{7}{|l|}{ Panel B } \\
\hline \multirow[t]{6}{*}{ Caregiver } & Age of Caregiver & 3337 & 38.15 & 37.61 & 39.52 & 0.00 \\
\hline & Gender of Caregiver $($ male $=1)$ & 3337 & .10 & .08 & .16 & 0.00 \\
\hline & Education in years & 3333 & 11.01 & 11.03 & 10.95 & .43 \\
\hline & Educ. Aspirations in years & 2860 & 15.41 & 15.36 & 15.53 & .09 \\
\hline & Educ. Expectations in years & 2777 & 11.53 & 11.36 & 11.98 & 0.00 \\
\hline & Migration Aspirations (yes $=1$ ) & 3598 & .20 & .19 & .21 & .16 \\
\hline \multicolumn{7}{|l|}{ Panel C } \\
\hline \multirow[t]{5}{*}{ Children } & Age & 3598 & 9.84 & 9.75 & 10.05 & .15 \\
\hline & Gender $($ male $=1)$ & 3598 & .51 & .52 & .51 & .62 \\
\hline & Enrolled (10 - 18 years) & 1918 & .90 & .91 & .88 & .07 \\
\hline & Enrolled (10 - 15 years) & 1166 & .98 & .99 & .98 & .32 \\
\hline & Enrolled (16 - 18 years) & 752 & .76 & .77 & .76 & .77 \\
\hline
\end{tabular}

Note: Authors calculation based on households with children in CELB 2012. Answers "Don't know" and "Refused to answer" excluded.

Figure 2.1 - Self-Selection and the Education of Migrants

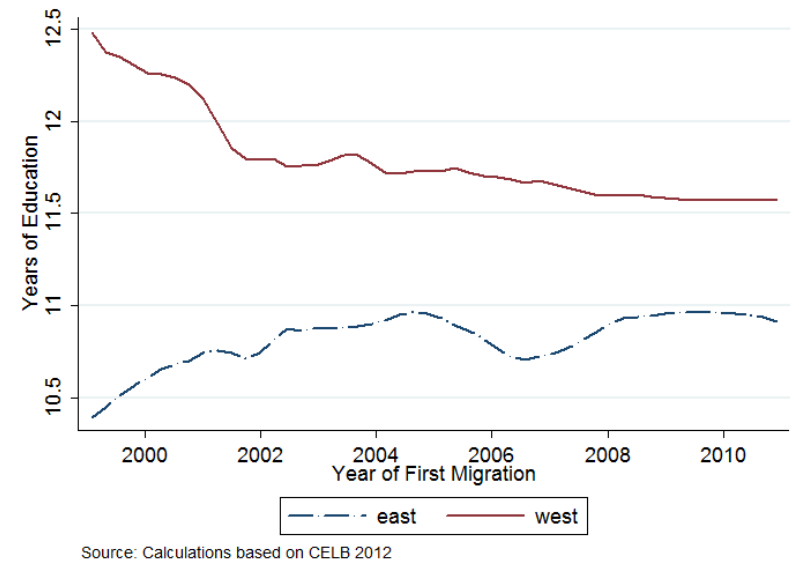


Nearly half the migrants were unemployed before they left for the first time and most of them worked in agriculture and construction. Roughly 84 percent of the migrants come back at least once a year or go back and forth on a regular basis. While abroad, 85 percent communicate with household members at least once a week or more often. Thus, the connection between migrants and those left behind is by all means quite close. On average 63 percent of the migrants have a work permit for the destination country. In the destination countries the migrants work mostly in the construction sector or have individual household employers, i.e. sectors that are likely to have a low education premium. The remittances generated by these migrants make up about 46 percent of the total household income of migrant households in Moldova. This also explains the significant difference between total income of migrant and non-migrant households. ${ }^{12}$

Caregivers are predominantly the biological parents of the children (87 percent). However, about 10 percent of the children live in so called gap-household structures where both biological parents have migrated and grandparents have taken on the role of caregivers. On average caregivers are 38 years old and have 11 years of schooling (see Panel B in Table 2.1). The significant difference in age of about two years between migrant and non-migrant caregivers is attributable to the gaphouseholds. There is no significant difference in the average years of schooling between caregivers in migrant and non-migrant households. We also looked at the education of migrants and caregivers and could not find any significant difference.

Caregivers would like their children to complete on average 15.4 years of schooling (see Panel B in Table 2.1). When taking into consideration the constraints they face they expect their children to complete around 11.5 years of schooling which equals upper secondary. These means conceal that aspirations are actually concentrated around tertiary education (see Figure 2.2). Caregivers desire in 53.15 percent of the cases a first stage tertiary degree for their children. Note that very few households in the total sample stated second tertiary education as their aspiration. Caregivers expect that their children will reach the set educational goal on average with a probability of 74.2 percent. When asked what the main reason for not reaching the set goal was, 9 out of 10 caregivers cited financial constraints. Caregivers in migrant households expect their children to complete a significantly higher number of years of formal education. This is confirmed by the visual comparison of the distribution of expectations of migrant and non-migrant households in Figure 3. Caregivers in migrant households tend to have a more optimistic attitude towards the realization of the educational aspirations of their children. However, the enrollment rates of children in all cohorts are

\footnotetext{
${ }^{12}$ Total income comprises the personal income of all household members from compensation for labor, pensions, social insurance benefits, remittances and other transfers as well as the income of the household as a whole from the sale of agricultural production and livestock and social security benefits.
} 
almost indistinguishable based on simple means testing (see Panel C in Table 2.1). The median expenditure per child is around 6 percent of the total household income. ${ }^{13}$

Figure 2.2 - Distribution of Aspirations

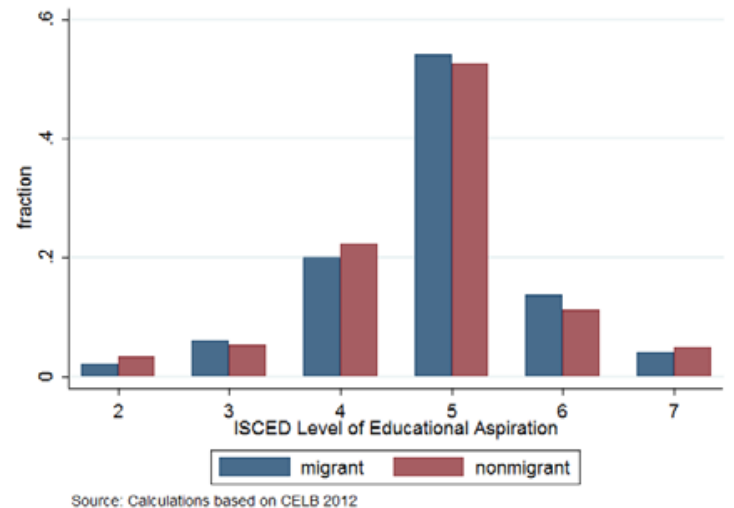

Figure 2.3 - Distribution of Expectations

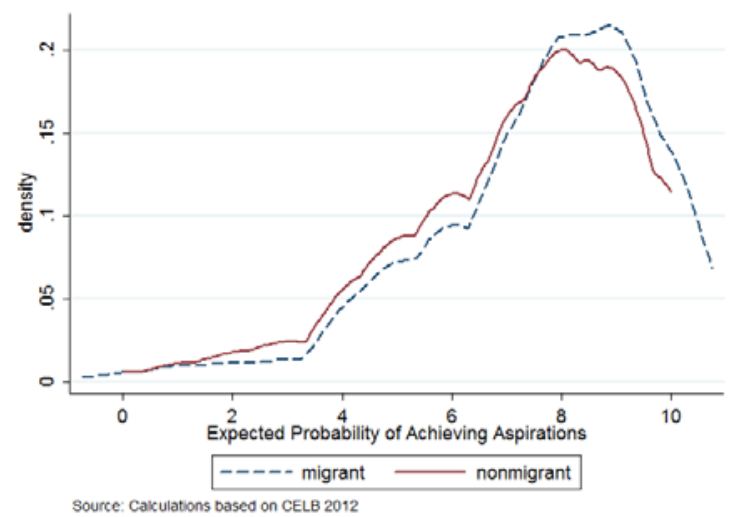

When asked about migration aspirations 20 percent of the caregivers stated that it would be good for their children to work or live abroad (see Panel B in Table 2.1). Since we also asked the 1018 year olds we were able to compare their answers with the point of view of their caregivers. The transmission of migration aspirations between children and parents is quite strong. After controlling for various individual and household characteristics we found that children were 53.5 percent more likely to state that they would like to migrate if their caregiver also told us so.

\subsection{Estimation Results}

Clearly, putting aspirations at the center of an economic analysis is only justified if it affects behavior. Before turning to the relationship of migration and aspirations, we therefore test this hypothesis by analyzing the correlations of aspirations and enrollment as well as the monetary expenditure of households for schooling. Because education is compulsory for 9 years from age 7 to 16 in Moldova we concentrate on the narrow age range of 16-18 which captures enrollment in the upper secondary level which is not compulsory since this education permits access to higher education. Unfortunately we cannot investigate the effects of aspirations on higher education directly since we only have cross-sectional data for children up to the age of 18 due to the structure of the survey.

Table 2.2 contains the results of the estimations concerning the effect of aspirations on enrollment (columns 1-4). A one year increase in aspirations is associated with a 2.4 percent higher

\footnotetext{
${ }^{13}$ Schooling expenditure per child comprises expenditures on schooling materials such as textbooks and uniforms as well as additional gifts to school teachers, transportation expenditures and the cost of supplemental tutoring.
} 
probability of being enrolled in the age range of 16-18. Our expectations measure has a quantitatively less important impact on enrollment but is also significant at the one percent level while the aspiration to migrate has no effect on the enrollment of children aged 16-18. Two observations warrant attention. First, the education of the caregiver has a significantly positive effect on enrollment. Second, aspirations are not fully independent of caregiver education. Since the effect of aspirations on enrollment works slightly at the expense of other variables such as caregiver education, marital status and socio-economic status of parents we have to conclude that they are to some extent a mediator of parental education. On the other hand if they were a mere representation of parental education we should not observe any significant effect of parental education on educational investments after introducing the aspiration measure. To evaluate the robustness of our continuous aspiration and expectation variables we also included a dummy variable which equals unity if parents have educational aspirations lower than secondary education. Again this aspiration failure has throughout a significantly negative impact on enrollment rates (not reported in Table 2). Based on these results we therefore conclude that aspirations are partly independent of parental characteristics in the context of enrollment.

Table 2.2 - Effect of Aspirations on Enrollment (age 16-18) and Schooling Expenditure

\begin{tabular}{|c|c|c|c|c|c|c|c|c|}
\hline & \multicolumn{4}{|c|}{ enrollment 16-18- logit } & \multicolumn{4}{|c|}{ schooling expenditure - OLS } \\
\hline & $(1)$ & (2) & (3) & (4) & (5) & (6) & (7) & (8) \\
\hline $\begin{array}{l}\text { Ed. Aspirations in } \\
\text { years }\end{array}$ & & $\begin{array}{c}0.60^{* * *} \\
(0.10)\end{array}$ & & & & $\begin{array}{c}272.38^{* * *} \\
(42.95)\end{array}$ & & \\
\hline $\begin{array}{l}\text { Ed. Expectations in } \\
\text { years }\end{array}$ & & & $\begin{array}{c}0.57^{* * *} \\
(0.09)\end{array}$ & & & & $\begin{array}{c}154.93 * * * \\
(34.65)\end{array}$ & \\
\hline $\begin{array}{l}\text { Mig. Aspirations } \\
\text { (yes=1) }\end{array}$ & & & & $\begin{array}{l}-0.21 \\
(0.37)\end{array}$ & & & & $\begin{array}{l}333.68^{*} \\
(178.81)\end{array}$ \\
\hline Age of Child in years & $\begin{array}{c}-0.85^{* * *} \\
(0.18)\end{array}$ & $\begin{array}{c}-0.85^{* * *} \\
(0.20)\end{array}$ & $\begin{array}{c}-0.81^{* * *} \\
(0.27)\end{array}$ & $\begin{array}{c}-0.85^{* * *} \\
(0.18)\end{array}$ & $\begin{array}{c}311.43^{* * *} \\
(35.81)\end{array}$ & $\begin{array}{c}291.45^{* * *} \\
(38.02)\end{array}$ & $\begin{array}{c}280.76^{* * *} \\
(39.33)\end{array}$ & $\begin{array}{c}312.14^{* * *} \\
(35.87)\end{array}$ \\
\hline $\begin{array}{l}\text { Gender of Child } \\
(\text { male=1) }\end{array}$ & $\begin{array}{c}-0.74^{* *} \\
(0.35)\end{array}$ & $\begin{array}{l}-0.30 \\
(0.44)\end{array}$ & $\begin{array}{c}-1.10^{* *} \\
(0.48)\end{array}$ & $\begin{array}{c}-0.74 * * \\
(0.35)\end{array}$ & $\begin{array}{l}-129.04 \\
(117.53)\end{array}$ & $\begin{array}{c}55.89 \\
(141.68)\end{array}$ & $\begin{array}{c}-3.42 \\
(134.40)\end{array}$ & $\begin{array}{l}-135.19 \\
(116.77)\end{array}$ \\
\hline $\begin{array}{l}\text { Education of } \\
\text { Caregiver in years }\end{array}$ & $\begin{array}{c}0.35^{* * *} \\
(0.09)\end{array}$ & $\begin{array}{l}0.23^{* *} \\
(0.11)\end{array}$ & $\begin{array}{l}0.17 \\
(0.11)\end{array}$ & $\begin{array}{c}0.34^{* * *} \\
(0.09)\end{array}$ & $\begin{array}{c}118.54 * * * \\
(42.77)\end{array}$ & $\begin{array}{l}64.40 \\
(47.15)\end{array}$ & $\begin{array}{l}66.43 \\
(49.55)\end{array}$ & $\begin{array}{c}118.66^{* * *} \\
(42.91)\end{array}$ \\
\hline Other children (yes $=1)$ & $\begin{array}{l}-0.11 \\
(0.36)\end{array}$ & $\begin{array}{l}-0.34 \\
(0.47)\end{array}$ & $\begin{array}{l}-0.59 \\
(0.55)\end{array}$ & $\begin{array}{l}-0.11 \\
(0.37)\end{array}$ & $\begin{array}{l}-266.21 \\
(169.87)\end{array}$ & $\begin{array}{l}-72.70 \\
(182.38)\end{array}$ & $\begin{array}{l}-117.90 \\
(183.54)\end{array}$ & $\begin{array}{l}-256.85 \\
(167.89)\end{array}$ \\
\hline $\begin{array}{l}\text { Absolute Poverty } \\
(\text { yes=1) }\end{array}$ & $\begin{array}{c}-1.83^{* * *} \\
(0.60)\end{array}$ & $\begin{array}{c}-1.48^{* *} \\
(0.59)\end{array}$ & $\begin{array}{l}-1.31 \\
(0.91)\end{array}$ & $\begin{array}{c}-1.84^{* * *} \\
(0.61)\end{array}$ & $\begin{array}{c}-1,164.30^{* * *} \\
(401.21)\end{array}$ & $\begin{array}{l}-650.89 \\
(428.73)\end{array}$ & $\begin{array}{l}-762.09 * \\
(447.82)\end{array}$ & $\begin{array}{c}-1,160.79 * * * \\
(399.79)\end{array}$ \\
\hline $\begin{array}{l}\text { Obs } \\
\text { Adj. } \mathrm{R}^{2}\end{array}$ & 472 & 406 & 467 & 472 & $\begin{array}{l}1828 \\
0.22\end{array}$ & $\begin{array}{l}1685 \\
0.25\end{array}$ & $\begin{array}{l}1655 \\
0.24\end{array}$ & $\begin{array}{l}1828 \\
0.22\end{array}$ \\
\hline McFadden's $\mathrm{R}^{2}$ & 0.26 & 0.36 & 0.51 & 0.26 & & & & \\
\hline District FE & Yes & Yes & Yes & Yes & Yes & Yes & Yes & Yes \\
\hline
\end{tabular}

Notes: Authors calculation based on households with children in CELB 2012. Robust standard errors in parentheses; *** $\mathrm{p}<0.01, * * \mathrm{p}<0.05$, * $\mathrm{p}<0.1$; Controlling also for child health, school distance, subjective school quality, relationship with caregiver, marital status of parents, orphan and semi-orphan, ethnicity, household composition; Standard errors clustered at the household level. Grade level fixed effects included. 
Our OLS estimates of the effect of aspirations on expenditure on schooling are displayed in columns 5-8 of Table 2.2. Again both aspirations and expectations matter greatly for the investment in the education of children. A one year increase in aspirations yields an average increase in schooling expenditure of about 7 percent per child per year. We also observe that migration aspirations have a significantly positive effect on schooling expenditures. If parents favor the future migration of their children the education expenditure increases by 10.6 percent over a baseline of mean effects of 3162 Moldovan Leu per child per year.

Overall, this evidence highlights the importance of aspirations and expectations for the extensive and intensive margin of human capital accumulation. We can therefore not reject the hypothesis of the conceptual framework that $\theta^{R}$ increases human capital investments.

Table 2.3 - The Effect of Migration (OLS)

\begin{tabular}{|c|c|c|c|c|c|c|c|c|c|}
\hline & $(1)$ & (2) & (3) & (4) & (5) & (6) & $(7)$ & (8) & $(9)$ \\
\hline & \multicolumn{3}{|c|}{ Educational Aspirations } & \multicolumn{3}{|c|}{ Expectations } & \multicolumn{3}{|c|}{ Migration Aspirations } \\
\hline Migration Total since 1999 & & $\begin{array}{c}0.38^{* *} \\
(0.17)\end{array}$ & & & $\begin{array}{c}0.47^{* *} \\
(0.21)\end{array}$ & & & $\begin{array}{l}0.27 * \\
(0.14)\end{array}$ & \\
\hline Migration Total in 2011 & & & $\begin{array}{c}0.44^{* *} \\
(0.17)\end{array}$ & & & $\begin{array}{c}0.42^{* *} \\
(0.18)\end{array}$ & & & $\begin{array}{l}0.05 \\
(0.17)\end{array}$ \\
\hline Age of Child in years & $\begin{array}{l}0.03 \\
(0.03)\end{array}$ & $\begin{array}{l}0.03 \\
(0.03)\end{array}$ & $\begin{array}{l}0.03 \\
(0.03)\end{array}$ & $\begin{array}{c}0.11 * * * \\
(0.04)\end{array}$ & $\begin{array}{c}0.10^{* * *} \\
(0.04)\end{array}$ & $\begin{array}{c}0.11^{* * *} \\
(0.04)\end{array}$ & $\begin{array}{c}0.06^{* * *} \\
(0.02)\end{array}$ & $\begin{array}{c}0.05^{* * *} \\
(0.02)\end{array}$ & $\begin{array}{c}0.06^{* * *} \\
(0.02)\end{array}$ \\
\hline Gender of Child (male=1) & $\begin{array}{c}-0.78^{* * *} \\
(0.10)\end{array}$ & $\begin{array}{c}-0.77^{* * *} \\
(0.10)\end{array}$ & $\begin{array}{c}-0.77^{* * *} \\
(0.10)\end{array}$ & $\begin{array}{c}-1.05^{* * *} \\
(0.14)\end{array}$ & $\begin{array}{c}-1.04^{* * *} \\
(0.14)\end{array}$ & $\begin{array}{c}-1.04 * * * \\
(0.14)\end{array}$ & $\begin{array}{c}0.15 \\
(0.12)\end{array}$ & $\begin{array}{c}0.15 \\
(0.12)\end{array}$ & $\begin{array}{c}0.15 \\
(0.12)\end{array}$ \\
\hline Education of Caregiver & $\begin{array}{c}0.22^{* * *} \\
(0.02)\end{array}$ & $\begin{array}{c}0.22^{* * *} \\
(0.02)\end{array}$ & $\begin{array}{c}0.22 * * * \\
(0.02)\end{array}$ & $\begin{array}{c}0.41^{* * *} \\
(0.05)\end{array}$ & $\begin{array}{c}0.40^{* * *} \\
(0.04)\end{array}$ & $\begin{array}{c}0.41^{* * *} \\
(0.04)\end{array}$ & $\begin{array}{l}0.00 \\
(0.03)\end{array}$ & $\begin{array}{l}-0.00 \\
(0.03)\end{array}$ & $\begin{array}{l}-0.00 \\
(0.03)\end{array}$ \\
\hline Other children (yes=1) & $\begin{array}{c}-0.34^{* *} \\
(0.14)\end{array}$ & $\begin{array}{c}-0.31^{* *} \\
(0.14)\end{array}$ & $\begin{array}{c}-0.30^{* *} \\
(0.14)\end{array}$ & $\begin{array}{l}-0.10 \\
(0.16)\end{array}$ & $\begin{array}{l}-0.07 \\
(0.15)\end{array}$ & $\begin{array}{l}-0.07 \\
(0.15)\end{array}$ & $\begin{array}{l}-0.21 * \\
(0.11)\end{array}$ & $\begin{array}{c}-0.19^{*} \\
(0.11)\end{array}$ & $\begin{array}{l}-0.20^{*} \\
(0.11)\end{array}$ \\
\hline Absolute Poverty (yes=1) & $\begin{array}{c}-1.04^{* *} \\
(0.52) \\
\end{array}$ & $\begin{array}{l}-0.99 * \\
(0.52) \\
\end{array}$ & $\begin{array}{c}-1.04^{* *} \\
(0.51) \\
\end{array}$ & $\begin{array}{l}-0.96^{*} \\
(0.51) \\
\end{array}$ & $\begin{array}{l}-0.90^{*} \\
(0.52) \\
\end{array}$ & $\begin{array}{c}-0.97 * \\
(0.51) \\
\end{array}$ & $\begin{array}{l}-0.14 \\
(0.49) \\
\end{array}$ & $\begin{array}{l}-0.08 \\
(0.50) \\
\end{array}$ & $\begin{array}{l}-0.14 \\
(0.49) \\
\end{array}$ \\
\hline Obs & 1685 & 1685 & 1685 & 1655 & 1655 & 1655 & 1964 & 1964 & 1964 \\
\hline McFadden's R ${ }^{2}$ & 0.25 & 0.25 & 0.25 & 0.27 & 0.27 & 0.27 & 0.08 & 0.08 & 0.08 \\
\hline District Fixed Effects & Yes & Yes & Yes & Yes & Yes & Yes & Yes & Yes & Yes \\
\hline
\end{tabular}

Notes: Authors calculation based on households with children in CELB 2012. Robust standard errors in parentheses; ${ }^{* * *} \mathrm{p}<0.01,{ }^{* *} \mathrm{p}<0.05$, * $\mathrm{p}<0.1$; Controlling also for child health, school distance, subjective school quality, relationship with caregiver, marital status of parents, orphan and semi-orphan, ethnicity, household composition; Standard errors clustered at the household level. Grade level fixed effects included for educational Aspirations and Expectations.

In Table 2.3 we report the OLS estimation results concerning the association between migration, aspirations and expectations. Throughout all specifications migration is associated with significantly higher levels of aspirations and expectations (see columns 1-6). We employ two different measures of migration experience. The first variable captures if any migration has taken place in a household since 1999, which is when large scale migration from Moldova to other countries started. We introduce this variable to find out whether accumulated migration experience is a confounding 
factor. The reason is that first time migration is likely to be more costly then repeated migration and first time migration could also be insufficient to alter the migrant's stance on education. Thus someone with 10 years of migration experience will make different contributions to the household than someone who left the country recently for the first time. Since we do not observe significant differences between the accumulated migration experience since 1999 and the current migration in 2011 we do not have to be overly concerned about the non-linearity of migration effects. In columns 6-9 we also relate the household's migration status to the migration aspirations the caregivers have for their children. Here we observe that only in households with a long migration history caregivers seem to favor the migration of their children. This could be due to the before mentioned nonlinearity of migration effects.

Table 2.4 - First Stage - The Migration Decision (Logit)

\begin{tabular}{|c|c|c|c|c|c|c|}
\hline & $(1)$ & (2) & (3) & (4) & $(5)$ & (6) \\
\hline & \multicolumn{6}{|c|}{ Current migrant 2011} \\
\hline & All & West & East & All & West & East \\
\hline \multirow[t]{2}{*}{ GDPpc Growth 2004} & $0.25^{* * *}$ & $0.48^{* * *}$ & -0.04 & $0.35^{* * *}$ & $0.50^{* * *}$ & 0.07 \\
\hline & $(0.09)$ & $(0.11)$ & $(0.12)$ & $(0.09)$ & $(0.12)$ & $(0.12)$ \\
\hline \multirow[t]{2}{*}{ Migrant Stock in Italy 2004} & -0.00 & 0.00 & $-0.02 * * *$ & $-0.01 *$ & 0.00 & $-0.02^{* * *}$ \\
\hline & $(0.00)$ & $(0.00)$ & $(0.00)$ & $(0.00)$ & $(0.00)$ & $(0.01)$ \\
\hline \multirow[t]{2}{*}{ Migrant Stock in Russia 2004} & -0.01 & $-0.04 * * *$ & $0.02 *$ & $-0.02 * *$ & $-0.04 * * *$ & 0.01 \\
\hline & $(0.01)$ & $(0.01)$ & $(0.01)$ & $(0.01)$ & $(0.01)$ & $(0.01)$ \\
\hline \multirow[t]{2}{*}{ Military Base } & & & & $0.35^{* * *}$ & 0.21 & $0.42^{* *}$ \\
\hline & & & & $(0.13)$ & $(0.19)$ & $(0.17)$ \\
\hline \multirow[t]{2}{*}{ Age Household Head } & $-0.02^{* * *}$ & -0.00 & $-0.02 * * *$ & $-0.02^{* * *}$ & -0.00 & $-0.03^{* * *}$ \\
\hline & $(0.00)$ & $(0.00)$ & $(0.00)$ & $(0.00)$ & $(0.01)$ & $(0.01)$ \\
\hline \multirow[t]{2}{*}{ Education Household Head } & $0.05 * * *$ & $0.12^{* * *}$ & -0.01 & $0.05^{* * *}$ & $0.12^{* * *}$ & -0.01 \\
\hline & $(0.02)$ & $(0.02)$ & $(0.02)$ & $(0.02)$ & $(0.02)$ & $(0.02)$ \\
\hline \multirow[t]{2}{*}{ Household Size } & $0.38^{* * *}$ & $0.29^{* * *}$ & $0.34^{* * *}$ & $0.40^{* * *}$ & $0.30^{* * *}$ & $0.34 * * *$ \\
\hline & $(0.03)$ & $(0.04)$ & $(0.03)$ & $(0.03)$ & $(0.04)$ & $(0.03)$ \\
\hline Obs & 2989 & 2989 & 2989 & 2437 & 2437 & 2437 \\
\hline McFadden $\mathrm{R}^{2}$ & 0.14 & 0.10 & 0.15 & 0.15 & 0.12 & 0.15 \\
\hline Wald $\mathrm{Chi}^{2}$ & 618.6 & 240.8 & 517.3 & 450.5 & 233.8 & 350.6 \\
\hline
\end{tabular}

Notes: Authors calculation based on all households in CELB 2012. Robust standard errors in parentheses; ${ }^{* * *} \mathrm{p}<0.01, * * \mathrm{p}<0.05, * \mathrm{p}<0.1$; Controlling also for migration stocks in Romania and Ukraine and gender of household head. Standard errors clustered at the household level. Regional fixed effects included.

Because estimating the causal effect of migration on an observable outcome is often problematic due to endogeneity we resort to an instrumental variable strategy as outlined before. Using the conventional Wu-Hausman $\mathrm{F}$ and the Durbin-Wu-Hausman $\mathrm{Chi}^{2}$ test (not reported) we have to accept the null that migration is an endogenous regressor. Table 2.4 shows the effects of our instruments in the first stage. As expected the average GDP growth in the destination countries between 2004 and 2010 increases the propensity to migrate in communities which have networks 
with these countries. A one unit increase of the growth in all destinations weighted by the stock of migrants in each destination increases the probability to migrate by 3.5-5 percent (see columns 1 and 4). This effect is statistically significant and robust over all specifications except for migration to the East. We also observe a clear specialization of networks; communities that had migrants in Italy in 2004 are less likely to witness migration to the East in 2011 while households in communities with strong migratory ties to the East in 2004 are less likely to migrate to the West in 2011. It is important to note that the former presence of Russian military personnel in the community increases the likelihood of migrating in 2011 to Russia by around 4.2 percent but has no effect on migration to the West. This allows us to instrument not only the migration decision of households but also the selfsorting of migrants into Eastern and Western countries. Under our identification assumption, the strong effect of the exogenous GDP growth at the destination and the quasi-random presence of Russian military personnel in the community on migration allow us to test the causal effect of migration on aspirations.

The corresponding IV estimates of migration effects are reported in Table 2.5. In column 1 the coefficient of migration is positive and statistically significant which points to a strong effect of migration on the educational aspirations of caregivers. Since the level of aspirations is capped at the post tertiary education the migration experience cannot shift the aspirations any further than 22 years of education. Hence the effect of migration should be stronger for households with a low human capital endowment. In column (2) we interact our instrument with a dummy variable (LEduc) if the caregiver has less than 11 years of education. The threshold of 11 years represents the mean level of education of caregivers. We observe that the migration of household members in households with poorly educated caregivers has a significantly positive effect on the educational aspirations of caregivers while the overall effect of migration becomes indistinguishable from zero. One possible interpretation of this finding is that highly educated households already have aspirations for their children that are at the high end of our aspiration scale. Thus the migration experience cannot shift the aspirations any further up. On the other hand they also do not seem to decrease their aspirations. If highly educated migrants were not able to generate a wage premium from their education during their stay abroad they might be induced to consider education for their children as futile and reduce their aspirations. This is not the case. When we split the effect of migration by destination we see that the sign for eastward migration is positive and significant at the 5 percent level, while the sign for westward migration is positive but statistically insignificant (see column 3 ). This also reflects the negative selection of eastward migrants. In conclusion, households with a small endowment of human capital have a tendency to adjust the educational aspirations caregivers have for their children upwards due to the migration experience of the household members. Evoking the 
notation of the framework this analysis is based on, we cannot reject the hypothesis that migration changes the aspiration of the household, i.e. $\lambda>0$, which translates into an increase in $\theta_{d}^{R}$.

Columns 4- 6 of Table 2.5 contain the effect of migration on expectations. Our results indicate that caregivers become more confident about the educational attainment of their children. This may reflect the relaxation of the resource constraint of migrant households as a result of receiving remittances. Direct schooling cost and foregone earnings of the child due to continuing education appear less problematic which allows caregivers to be more optimistic and to expect higher educational attainment. It is interesting that only caregivers in households with migrants in the West have more positive expectations whereas living in a household with migrants in the East has no effect on the expectations of caregivers at any conventional significance level. We believe that this result reflects the different returns to migration. Westward migrants sent on average 16 percent more remittances than migrants in the East. This interpretation is in line with the hypothesis that the expectations are strongly driven by the resource constraint of the household. The strong difference between the effect of migration on educational aspirations and expectations also underline the different implications of these closely related measures.

Table 2.5 - The Effect of Migration (2SLS)

\begin{tabular}{|c|c|c|c|c|c|c|c|c|c|}
\hline & (1) & (2) & (3) & (4) & (5) & (6) & (7) & (8) & (9) \\
\hline & \multicolumn{3}{|c|}{ Educational Aspirations } & \multicolumn{3}{|c|}{ Expectations } & \multicolumn{3}{|c|}{ Migration Aspirations } \\
\hline \multirow[t]{2}{*}{ Mig_2011 } & $3.24 * *$ & 0.74 & & $3.77 * *$ & 2.68 & & $0.40^{*}$ & $0.76^{* * *}$ & \\
\hline & $(1.64)$ & $(2.05)$ & & $(1.73)$ & $(2.02)$ & & $(0.21)$ & $(0.25)$ & \\
\hline \multirow[t]{2}{*}{ Mig_2011*LEduc } & & $4.70^{*}$ & & & 0.85 & & & -0.68 & \\
\hline & & $(2.42)$ & & & $(3.06)$ & & & $(0.49)$ & \\
\hline \multirow[t]{2}{*}{ Mig_2011 West } & & & 1.98 & & & $6.62 * *$ & & & 0.32 \\
\hline & & & $(2.01)$ & & & $(2.98)$ & & & $(0.25)$ \\
\hline \multirow[t]{2}{*}{ Mig_2011 East } & & & $4.75^{* *}$ & & & 0.78 & & & 0.57 \\
\hline & & & $(2.24)$ & & & $(2.31)$ & & & $(0.36)$ \\
\hline Obs & 2503 & 2503 & 2503 & 2435 & 2435 & 2435 & 2926 & 2926 & 2926 \\
\hline F-Statistic & 20.18 & 18.05 & 15.91 & 21.77 & 23.69 & 18.01 & 7.472 & 5.691 & 6.388 \\
\hline CDW F-Statistic & 15.63 & 8.550 & 11.74 & 16.32 & 9.188 & 13.57 & 10.20 & 4.389 & 7.681 \\
\hline Hanson I-Statistic & 0.177 & 0.479 & _- & 0.097 & 0.194 & - & 0.430 & 0.197 & - \\
\hline
\end{tabular}

Notes: Authors calculation based on households with children in CELB 2012. Robust standard errors in parentheses; *** $\mathrm{p}<0.01, * * \mathrm{p}<0.05, *$ $\mathrm{p}<0.1$; Controlling also for age and gender of child, caregiver and household characteristics, migration stocks in Italy, Russia, Ukraine and Romania. Standard errors clustered at the household level; Instruments are GDP per capita growth (2004-2010) and migration stocks (2004) in destination countries. Regional fixed effects included.

Contrary to the OLS results regarding the effects of migration on migration aspirations (see Table 2.3) we find a significant increase in migration aspirations of caregivers living in households with migrants. The linear probability estimates in columns 7 to 9 of Table 5 suggest an increase in the likelihood of favoring the migration of their children. In the context of our conceptual framework we cannot reject the hypothesis that migration networks $\left(\kappa_{d}\right)$ show self-reinforcing dynamics by 
transmitting preferences for migration to the next generation of the household. This observation supports what has been called chain migration.

At the bottom of Table 2.5 we also report the results of two tests to evaluate the validity and strength of our instruments. First, the results for the Hanson J reported in the last row of Table 2.5 cannot reject the null that the excluded instruments are valid with one exception. Second, we use the Cragg-Donald F-statistic of the first-stage estimations to check the relevance of our instruments. We report these F-statistics and conclude based on a comparison with the reference values for weak instruments presented by Stock and Yogo (2002) that our instruments will allow us to infer the effect of migration on aspirations and expectations. However, we have to be cautious with the interpretation of our results regarding the effect of migration on migration aspirations due to possibly weak instruments.

While both our OLS and 2SLS estimates point to the economically significant effects of migration we have to note the considerable differences in estimated coefficients. As noted before one explanation for the higher coefficients of the instrumented estimation effects compared to OLS could be negative self-selection of migrants. Yet, since from our descriptive statistics no clear picture regarding self-selection emerges we think a more plausible explanation for the higher 2SLS coefficients is the heterogeneity of the treatment effects. Our 2SLS estimates only represent a local average treatment effect since we cannot be sure that those responsive to our instrumentation, i.e. the GDP per capita growth at the destination, are representative of the overall population (see Angrist et al. 1996). Using a threshold of 0.5 our first stage correctly predicts 75 percent of the cases. The households which do not respond to the exogenous variation in GDP at the destinations but still migrate are concentrated in the north of the country and are mostly located at the border with the Ukraine or Romania. Migrants in these households are more likely to go to the East than those who comply with the variation of our instrument. However, these correlations do not reveal possible differences in unobservable characteristics such as the motivation to migrate and we are not able to identify the true subpopulation of compliers. We hypothesize that the non-compliers leave out of economic necessity, irrespective of the change of the situation at the destination, and do not consider the migration option as an opportunity. This pressure could lead them to reject the norms at the destination and thereby leave aspirations unaffected. Those who respond to the improving situation at the destination reflected by the change in GDP might be able to choose migration as a superior income source and are more receptive to influences at the destination.

We have to acknowledge several potential caveats when interpreting our findings. As noted before it is difficult to disentangle the information and aspiration effect of migration. We believe our results reflect a pure aspiration effect, i.e. that migration changes the goal setting of households 
under full information for two reasons: First, 91.6 percent of the households in our sample have a television and about one third of the households have a computer, i.e. people have the means to access information. Second, and more importantly, if migration was only an information channel previous village migration would have made pure information available before 2011. Since our estimations control for the migration stock in 2004 the access to information e.g. about available education premia abroad would have already been supplied by these migrant networks.

Another drawback of our analysis is that we cannot observe the effect of remittances directly. This means that we cannot eliminate the possibility that the additional financial resources are responsible for the change in aspirations. Although we explicitly included a condition of "unlimited resources" in the question for aspirations, we cannot be sure that this phrasing was enough to visualize this situation. While this income effect is a serious issue our results suggest that it rather affects expectations than aspirations. If the observed effect was driven only by the decreased liquidity constraints due to remittances the effect of aspirations and expectations should show no differences. Yet, by comparing column 3 and 6 in Table 2.5 it becomes clear that migration to the East and to the West have significantly different effects on aspirations and expectations. While eastward migration changes aspirations, it has no effect on expectations. On the other hand westward migration has a strong impact only on expectations. We would argue that this difference reflects the different amounts of remittances received, with migrants in the west sending significantly more money, which allows households with migrants in the West to be more confident about the educational achievements of their children.

Finally, the interpretation of our results with respect to a possible "Brain Gain" requires two qualifications. First, the cross-sectional nature of our data set does not allow us to observe the realization of the educational aspirations that constitute the core of our argument. Second, it must be acknowledged that the brain gain will only take place if not all children in migrant households leave the country, after realizing more education. In this respect we rely on the same assumption as contributions that argue in favor of the monetary incentive effects.

\subsection{Concluding Remarks}

In this essay we have argued that international migration affects human capital accumulation apart from relaxing the resource constraints of households through a change in the educational aspirations caregivers have for their children in the migrant sending households. By using a unique household survey dataset we were able to test this hypothesis. The different lines of evidence we have 
presented converge on the conclusion that parental migration can change the educational trajectory of children in migrant households with low human capital endowment through an upward adjustment of educational aspirations. This suggests that migrants update their priors about the importance of education while abroad and transmit them to the caregivers of children in the sending country. Since we tested our hypothesis of the relationship between aspirations and migration in a country with high enrollment rates and a generally high level of formal education our results must be interpreted as the lower bound of the effect migration can have on aspirations.

Overall, these findings suggest a new channel of brain gain as a result of international migration. While the current models are based on the premise that human capital investments will be increased by the opportunity to migrate we suggest that an increase in human capital could also be triggered by the positive externality migration has on educational aspirations. Our results imply that even a temporary migration spell could induce increased human capital investments. Thus, a brain gain could even take place if parents had the chance to migrate while children do not have this opportunity.

Our results are also highly policy relevant in a broader context. Important determinants of human capital accumulation such as parental education are quite inflexible whereas aspirations react quite flexibly to new impulses. If intergenerational human capital transfer is regulated strongly by the aspiration levels of parents, public policy could increase overall human capital accumulation by implementing measures that shift the educational aspirations parents have for their children upwards. Such a policy would not only counter inequality but could also be more cost-effective than other policy measures since supply-side interventions in the education sector will have a low return on investment without the necessary demand for education; more schools will not lead to an increased human capital stock without high educational aspiration of parents and children. 


\title{
Essay 3
}

\section{Informal-formal Linkages and Informal Enterprise Performance in Urban West Africa}

with Rainer Thiele

\begin{abstract}
Employing a unique dataset that covers almost 6000 informal enterprises from six West African urban centers, this essay examines the backward and forward linkages of these enterprises to the formal sector. We first provide a descriptive analysis of the existing formal-informal linkages. It turns out that formal backward linkages are much more prevalent than formal forward linkages, and that linkages vary with the degree of informality, occurring less frequently if firms have no ties to the formal sector at all or low capital stocks. In the second step, we employ a Probit approach to identify major factors associated with the observed backward linkages. The Probit analysis corroborates the importance of the degree of informality for the existence of linkages and shows various enterprise characteristics to be significant determinants as well. Finally, we analyze whether backward linkages matter for enterprise performance using both OLS and IV estimations. We find a positive and robust impact of backward linkages, whereas the degree of informality of the enterprises in our sample seems to affect firm performance only indirectly through their linkages to the formal sector.
\end{abstract}

Keywords: Informal sector, formal-informal linkages, enterprise performance, West Africa JEL codes: D22, D40, 017 


\subsection{Introduction}

By far the largest part of urban employment in Sub-Saharan Africa (SSA) is generated by informal enterprises. These enterprises often lack the financial means or the managerial and technological skills required to expand their activities. One way of overcoming these constraints is to establish links with the formal sector. As emphasized by Hirschmann $(1958,1977)$, the interdependence of economic actors plays an important role in the dynamics of economic development. More recently, Ciccone (2002) and Rodriguez-Clare (1996) have shown theoretically that economic growth and industrialization relies on deep vertical linkages. The exchange between different economic actors can take the form of fiscal, consumptive and productive linkages. While the informal sector is per definition characterized by the absence of fiscal linkages, it remains unclear how well informal enterprises are connected with the formal sector in terms of consumptive and productive linkages.

Based on the dual economy literature (e.g. Lewis 1954, Todaro 1969), the urban informal sector was traditionally considered as the residual part of a segmented urban labor market, providing employment for the labor surplus that cannot be absorbed by the formal urban economy (e.g. Fields 1975). A growing urban informal labor force competing in the same market would then exert downward pressure on informal sector earnings (Mazumdar 1976). Linkages via product markets were also assumed to be largely absent (Harriss 1990). The formal and informal sector were modeled as supplying similar goods but serving different markets at different prices and qualities, with markets segmented by purchasers' income. According to this view, demand for informal products would predominantly come from poor informal customers (e.g. Fortin et al. 2000; La Porta and Shleifer 2011; Reilly et al. 2006), providing another reason for a weakly performing informal sector.

More recently, the pure informal and the pure formal sector have been described as constituting extremes on a continuum of production relationships (Chen 2006), and an alternative view has been emerging which describes formal and informal product markets as inter-linked. This view is backed by a few empirical studies for SSA. Covering a sample of 13 Sub-Saharan African countries, Xaba et al. (2002) detect substantial inter-linkages in the final product market, with each sector being a strong supply as well as demand base of the other sector. Böhme and Thiele (2011) corroborate this finding for six West African capitals. As concerns intermediate demand, the available evidence is less conclusive. Hugon (1990) and Harriss (1990) point to an asymmetry, where the informal sector buys many of its inputs from the formal sector but purchases in the opposite direction are of little importance. By contrast, a case study for Burkina Faso by Grimm and Günther (2006) reveals only minor backward linkages between small informal production units and formal 
enterprises. In the same vein, De Paula and Scheinkman (2007) show that backward linkages of informal firms in Brazil tend to be directed towards the informal sector.

This essay aims to broaden the evidence on the formal-informal backward and forward linkages in African product markets, extending the existing empirical literature in various ways. First, our analysis employs a unique set of internationally comparable data covering informal enterprises from the commercial capitals of six West African Economic and Monetary Union (WAEMU) member states. Second, we at least tentatively account for the observation that the informal sector is characterized by a high degree of heterogeneity. While previous research (e.g. Grimm et al. 2011) has shown that a split of the informal sector into a high-return, upper-tier and a low-return, lower-tier segment along the lines of Ranis and Stewart (1999) does not adequately capture this heterogeneity, we simply assume that linkages to the formal sector vary along the continuum of production relationships. Accordingly, we divide the sample of informal enterprises using (i) registration with official entities such as having a tax number, paying trade tax, being in the trade register and holding a trade certificate, and (ii) capital endowments as alternative categorization criteria. These two criteria are meant to depict the extent to which the informal enterprises are "formalized". Third, while most of the previous literature has been descriptive, we additionally conduct regression analysis in order to identify possible correlates of the observed patterns of formal-informal linkages and to examine whether linkages help explain differences in enterprise performance.

The remainder of the essay is structured as follows. Section 3.2 introduces the dataset used in the empirical analysis and provides descriptive evidence on the linkages of the informal enterprises under consideration. Sections 3.3 and 3.4 present estimates of the main determinants of formalinformal linkages and of their consequences for different indicators of enterprise performance, respectively. Section 3.5 summarizes our main results and draws some conclusions.

\subsection{Nature of backward and forward linkages}

\section{a. Data and enterprise characteristics}

We use data provided by the "Enquêtes 1-2-3". This survey was implemented between 2001 and 2003 in seven economic capitals of the WAEMU and consisted of three integrated phases for a representative set of households (Amegashie et al. 2005). It intended to capture a detailed picture of the main characteristics of the informal sector in the seven cities. Using an identical survey methodology in all sites renders the information comparable across the urban centers of the sample. The employment section of this survey (phase one), which was conducted between 2001 and 2002 with a sample size of 2500 households in each country (3000 in Cotonou), solicited information on 
the enterprises that employed or were managed by household members older than 10 years. In identifying informal activities, the 1-2-3 surveys follow international statistical guidelines, which suggest that informal sector employment should be defined in terms of characteristics of the enterprise or production unit such as size and different legislative criteria (Hussmans 2004). Specifically, the 1-2-3 surveys define informal enterprises as small production units that (a) do not have written formal accounts and/or (b) are not registered with the tax administration.

For the second phase of the survey, a randomized sub-sample of approximately 1000 enterprises in each country was drawn from the production units identified as informal in phase one (Brilleau et al. 2005). The focus of this phase was on characteristics of the entrepreneurs and their production units. It also contains information on input use, capital stocks, sales, profit as well as the unit's forward and backward linkages and therefore provides the basis for the subsequent analysis. Since disaggregated data are not available for Niamey (Niger), we work with a total sample of 5785 enterprises from Cotonou, Ouagadougou, Abidjan, Bamako, Dakar and Lomé.

Based on Chen's (2006) notion of a continuum of production relationships, we account for the heterogeneity of the informal sector by dividing it into different segments. First, we lump together those enterprises that have any kind of formal link with the public sector, calling them registered informal enterprises as opposed to unregistered informal enterprises. Specifically, we define registered units of production as those who hold a tax number, have an entry in the commercial register or pay business tax or some kind of license tax. ${ }^{14}$ The second approach we apply is to leave registration aside and to use the mean capital stock of the whole sample (240 000 CFA) as a threshold to divide the sample into low capital informal enterprises ( $<240000$ CFA) and high capital informal enterprises (>240 000 CFA).

Table 3.1 shows the distribution of the 5785 enterprises across the six cities and the sub-groups defined above. Applying registration or higher-than-average capital stocks as cut-off criteria leads to roughly the same size of the segments of the informal sector. The share of registered and high capital enterprises in the overall sample amounts to 18.5 and 17.2 percent, respectively. The most notable difference between the distributions implied by the two definitions occurs in the trade sector: while about 17 percent of the enterprises involved in trading activities are registered, less than 10 percent own a capital stock exceeding the average value of 240000 CFA. This reflects a general pattern of markedly lower capital endowments in the trade sector as compared to the industry and services sector.

\footnotetext{
${ }^{14}$ Note that while these production units do not fulfill part (b) of the above definition of informality they still count as informal enterprises because part (a) applies to them.
} 
Table 3.1 - Distribution of Sample

\begin{tabular}{|c|c|c|c|c|}
\hline & Industry & Trade & Services & Total \\
\hline Benin - Cotonou & 14.33 & 15.54 & 19.15 & 937 \\
\hline Burkina Faso - Ouaga & 19.35 & 16.92 & 13.89 & 974 \\
\hline Côte d'Ivoire - Abidjan & 15.32 & 16.74 & 19.98 & 996 \\
\hline Mali - Bamako & 19.56 & 16.46 & 14.89 & 985 \\
\hline Sénégal - Dakar & 18.04 & 18.02 & 15.72 & 1,004 \\
\hline Togo - Lomé & 13.39 & 16.32 & 16.37 & 889 \\
\hline REGISTERED & 16.74 & 17.06 & 22.46 & 1,072 \\
\hline UNREGISTERED & 83.26 & 82.94 & 77.54 & 4,713 \\
\hline Low Capital & 82.64 & 90.33 & 73.23 & 4,789 \\
\hline High Capital & 17.36 & 9.67 & 26.77 & 996 \\
\hline Total & 1,912 & 2,181 & 1,692 & - \\
\hline
\end{tabular}

Note: Authors' calculation based on 1-2-3 survey.

Taking a closer look at the sectoral distribution of informal activities (Table 3.2) reveals that petty trade is the predominant activity in the trade sector. This is particularly true at the lower end of the continuum. About 30 percent of all unregistered and low capital informal enterprises in the sample are classified as petty traders. Construction is another sector where these two groups are more strongly represented than registered and high capital enterprises. The latter, in turn, have a much higher probability of offering repair and transport services than the former. Overall, the sectoral pattern of activities across sub-groups turns out to be fairly similar for the two classifications we apply.

Table 3.2 - Sectoral Distribution of UPIs

\begin{tabular}{|c|c|c|c|c|c|c|c|}
\hline & REG & UNREG & Low Capital & High Capital & Industry & Trade & Services \\
\hline Clothing and apparel & 11.85 & 10.95 & 10.54 & 13.86 & 33.63 & - & - \\
\hline Other manufacturing & 14.09 & 14.22 & 14.12 & 14.56 & 42.94 & - & - \\
\hline Construction & 3.92 & 8.61 & 8.33 & 4.92 & 23.43 & - & - \\
\hline Wholesale/retail shops & 19.78 & 8.47 & 10.19 & 12.35 & - & 28.01 & - \\
\hline Petty trading & 14.93 & 29.92 & 30.95 & 8.84 & - & 71.99 & - \\
\hline Hotels and restaurants & 6.06 & 7.09 & 6.89 & 6.93 & - & - & 23.58 \\
\hline Repair services & 10.07 & 4.86 & 5.22 & 8.73 & - & - & 19.92 \\
\hline Transport & 10.26 & 3.46 & 1.98 & 17.87 & - & - & 16.13 \\
\hline Other services & 9.05 & 12.43 & 11.78 & 11.95 & - & - & 40.37 \\
\hline Total & 1,072 & 4,713 & 4,789 & 996 & 1,912 & 2,181 & 1,692 \\
\hline
\end{tabular}

Note: Authors' calculation based on 1-2-3 survey.

Table 3.3 reports further characteristics of the different groups of informal enterprises. Starting with production factors, the number of employees is only moderately higher in the high capital/registered segment of the informal sector, whereas differences in capital stocks and the use 
of electricity and telephones are much more pronounced. Enterprise owners were also asked if they were members of professional associations or received help from professional associations. Membership is generally low but more common among registered and high capital informal enterprises. Assistance is granted more frequently and only slightly biased in favor of these two groups. The last three rows of Table 3.3 display characteristics of the owners or managers of the enterprises. Most notably, registered and high capital enterprises are much less likely to be managed by women than unregistered and low capital enterprises, which is mainly driven by a very strong presence of women in petty trade. Furthermore, owners or managers of enterprises belonging to the upper end of the informal sector have more years of schooling and a somewhat higher age than their lower-end counterparts. Again, the pattern that emerges applies irrespective of whether enterprises are sorted with respect to capital stocks or registration.

Table 3.3 - Characteristics of UPIs

\begin{tabular}{|c|c|c|c|c|c|c|c|}
\hline & REG & UNREG & Low Capital & High Capital & Industry & Trade & Services \\
\hline Age of Company in Years & 10.81 & 9.72 & 9.95 & 9.81 & 10.47 & 9.73 & 9.55 \\
\hline Capital in 1000CFA & 692.15 & 139.46 & 37.36 & 1223.59 & 243.25 & 124.05 & 390.54 \\
\hline Number of Employees & 2.44 & 1.52 & 1.49 & 2.63 & 1.97 & 1.31 & 1.86 \\
\hline Water & 0.10 & 0.08 & 0.07 & 0.17 & 0.08 & 0.06 & 0.12 \\
\hline Electricity & 0.46 & 0.18 & 0.17 & 0.51 & 0.27 & 0.16 & 0.26 \\
\hline Telephone & 0.17 & 0.07 & 0.06 & 0.22 & 0.09 & 0.06 & 0.12 \\
\hline Member of Association & 0.13 & 0.03 & 0.04 & 0.10 & 0.06 & 0.04 & 0.05 \\
\hline Support from Association & 0.46 & 0.35 & 0.36 & 0.44 & 0.39 & 0.36 & 0.37 \\
\hline Sales per worker & 260.35 & 129.68 & 136.46 & 237.37 & 106.40 & 204.15 & 143.03 \\
\hline Profit per worker & 87.67 & 47.44 & 47.99 & 88.46 & 56.08 & 48.41 & 62.05 \\
\hline Return to capital & 343.00 & 490.28 & 567.01 & 22.71 & 367.45 & 632.88 & 363.48 \\
\hline Asset turnover & 10.23 & 13.51 & 15.86 & 0.68 & 7.18 & 23.78 & 6.53 \\
\hline Sex $($ male $=1)$ & 0.75 & 0.44 & 0.45 & 0.74 & 0.62 & 0.30 & 0.61 \\
\hline Age & 37.72 & 35.6 & 35.70 & 37.39 & 35.74 & 36.63 & 35.47 \\
\hline Years of Schooling & 4.84 & 3.71 & 3.57 & 5.60 & 3.97 & 3.27 & 4.69 \\
\hline
\end{tabular}

Note: Authors' calculation based on 1-2-3 survey.

A final aspect that substantiates our typology is the kind of business setup. Enterprises were asked about the locality of their activities. As can be seen from Table 3.4, more than 60 percent of registered and high capital informal businesses have either access to permanent business setups (permanent booths on markets, workshops, shops, or restaurants) or use vehicles. Unregistered and low capital enterprises, by contrast, most frequently work at home without equipment or as ambulant traders and street vendors.

Taken together, the analysis so far has shown that our classification captures important aspects of the heterogeneity of the informal enterprises in the sample. In the following, it will be used to test whether the segments of the informal sector differ with respect to their linkages to the formal sector. 
Table 3.4 - Business Setup of UPIs

\begin{tabular}{|c|c|c|c|c|c|c|c|}
\hline & REG & UNREG & Low Capital & High Capital & Industry & Trade & Services \\
\hline Ambulant & 3.73 & 15.17 & 14.49 & 6.12 & 9.31 & 18.84 & 9.81 \\
\hline Improvised booth on street & 5.32 & 11.18 & 11.13 & 5.12 & 8.21 & 10.77 & 11.35 \\
\hline Permanent booth on street & 8.77 & 10.76 & 10.96 & 7.63 & 6.85 & 11.23 & 13.3 \\
\hline Vehicle & 5.22 & 1.27 & 0.33 & 10.04 & 0.1 & 0.18 & 6.5 \\
\hline At customers ${ }^{6}$ home & 2.89 & 9.99 & 9.79 & 3.31 & 16 & 3.21 & 7.45 \\
\hline At home without equip. & 2.15 & 20.52 & 19.52 & 5.52 & 22.49 & 13.53 & 15.66 \\
\hline At home with equip. & 4.38 & 6.54 & 5.7 & 8.23 & 7.95 & 4.68 & 5.97 \\
\hline Improvised booth on market & 7.18 & 9.76 & 10.77 & 2.11 & 4.92 & 16.74 & 4.61 \\
\hline Permanent booth on market & 25.56 & 6.05 & 8.29 & 16.27 & 7.58 & 12.93 & 7.8 \\
\hline Workshop, shop, restaurant & 33.3 & 7.89 & 8.14 & 34.04 & 16.16 & 6.97 & 15.84 \\
\hline Other & 1.4 & 0.87 & 0.86 & 1.51 & 0.42 & 0.87 & 1.71 \\
\hline Total & 1,072 & 4,713 & 4789 & 996 & 1,912 & 2,181 & 1,692 \\
\hline
\end{tabular}

Note: Authors' calculation based on 1-2-3 survey.

\section{b. Linkages}

Following Hirschmann (1958), we differentiate consumption and production linkages. While the former only concerns sales to final demand, the latter can be split up into forward and backward linkages. Forward linkages refer to the use of an enterprise's output as an input in other productive activities, while backward linkages comprise the enterprise's purchases of intermediate inputs. Our analysis focuses on the existence rather than the size or the share of specific linkages. The reason is that only 168 enterprises have both formal and informal backward linkages and only 16 have both formal and informal forward linkages, which would render a comparison of shares meaningless.

The questionnaire gathered detailed information about the inputs and outputs of all enterprises with respect to the type of services or products involved as well as their destination and origin. Possible destinations and origins include the public sector, big private enterprises, small enterprises, households, imports and exports. This allows us to define the formal sector as being represented by the public sector and big enterprises and the informal sector as being composed of small enterprises. Additionally, we use the type of service or product purchased by the enterprises to define the sector they maintain backward linkages with. In doing so, we distinguish four different sectors: agriculture, industry, trade and services. As concerns forward linkages, the data does not allow us to determine the destination sector given that the type of product sold only characterizes the production unit itself. Even though we can differentiate exports and imports, it is important to recognize that out of the 5785 enterprises only 60 report imports and 13 report exports. 
The use of informal enterprises' output is clearly dominated by final demand, i.e. sales to households. Only 683 enterprises do not sell any of their goods or services to households. As shown in Tables 3.5 and 3.6, the share of sales directed towards final demand generally exceeds 80 percent. The only exceptions are trade-related activities by registered enterprises (Table 3.5) and by high capital informal enterprises (Table 3.6). Mostly as wholesalers, these enterprises cater more strongly to other enterprises, in particular small ones in the informal sector.

The structure of formal-informal linkages exhibits two interesting regularities. First, even for registered and high capital informal enterprises, sales to the formal sector are less important than those to the informal sector. Second, with a share of slightly above 2 percent, the formal sector plays a negligible role as a buyer of goods and services from unregistered and low capital informal enterprises, which is in accordance with Ranis and Stewart's (1999) assumption that enterprises belonging to the lower tier of the informal sector have no production links with the formal sector. As shown in the lower panels of Table 3.5, respectively, the formal forward linkages of these enterprises in the industrial and trade sector are significantly lower than those of their registered and high capital counterparts. The most important formal forward linkage (with a share of 7.5 percent) exists for registered enterprises towards the industrial sector (Table 3.5). This may at least partly reflect subcontracting agreements with large domestic firms and the government. ${ }^{15}$

According to the self-stated business perspectives of the entrepreneurs contained in the questionnaire, the dominance of consumption linkages over (formal) forward linkages tends to be viewed as a constraint for informal enterprises. While finding customers in general is viewed as a problem by the majority of the informal enterprises in the sample (more than 60 percent), a sizeable minority emphasizes the specific importance of forward links to big enterprises. In the industrial sector, the share of entrepreneurs who stress that formalization would allow them to sell to big enterprises (15 percent) is almost as large as the share of entrepreneurs who point to the availability of credit as the main advantage of formalization (19 percent).

\footnotetext{
${ }^{15}$ In a case study for Nigeria, Arimah (2001) shows that subcontracting accounts for a substantial share of existing forward linkages.
} 
Table 3.5 - Forward Linkages of UPIs, Registered vs Unregistered

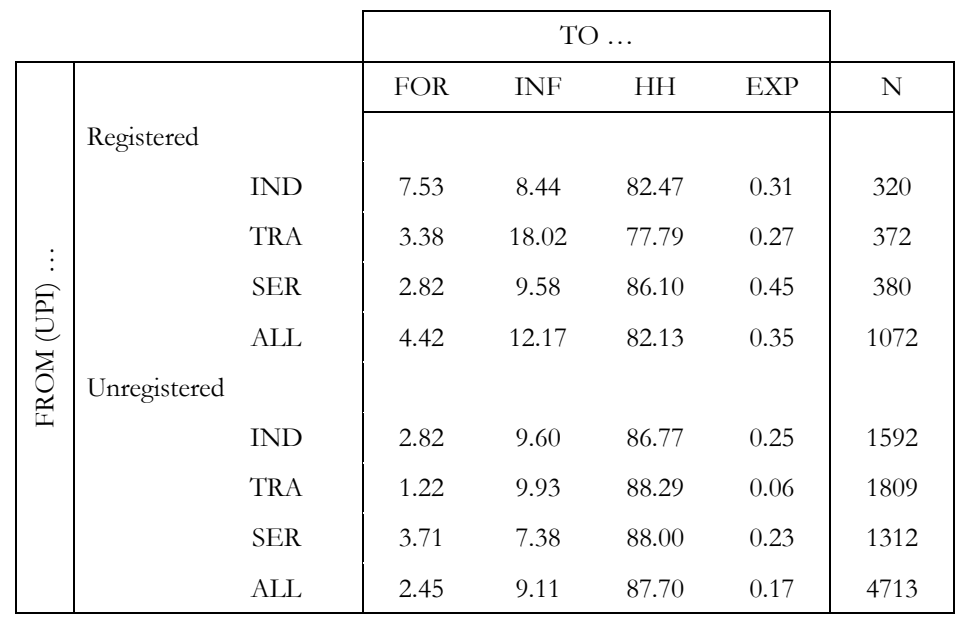

\begin{tabular}{ll|llll}
\hline $\operatorname{Pr}(|\mathrm{T}|>|\mathrm{t}|)$ & & & & & \\
& IND & 0.00 & 0.50 & 0.04 & 0.84 \\
& TRA & 0.00 & 0.00 & 0.00 & 0.22 \\
SER & 0.39 & 0.15 & 0.31 & 0.46 \\
& ALL & 0.00 & 0.00 & 0.00 & 0.23 \\
\hline
\end{tabular}

Note: Authors' calculation based on 1-2-3 survey.

Table 3.6 - Forward Linkages of UPIs, Low Capital Informal vs High Capital Informal

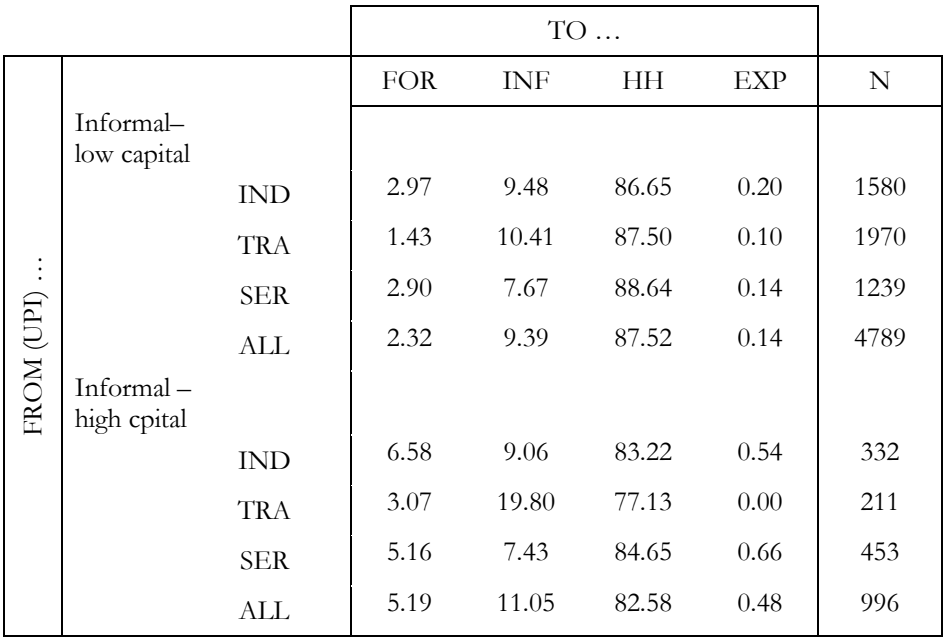

\begin{tabular}{cc|cccc}
\hline $\operatorname{Pr}(|\mathrm{T}|>|\mathrm{t}|)$ & & & & & \\
& IND & 0.00 & 0.81 & 0.92 & 0.26 \\
& TRA & 0.06 & 0.00 & 0.00 & 0.64 \\
SER & 0.21 & 0.60 & 0.02 & 0.06 \\
ALL & 0.00 & 0.10 & 0.00 & 0.03 \\
\hline
\end{tabular}

Note: Authors' calculation based on 1-2-3 survey. 
Table 3.7 - Backward Linkages of UPIs, Registered vs Unregistered

\begin{tabular}{|c|c|c|c|c|c|c|c|c|c|}
\hline & & & & & $\mathrm{OM}$ & CTOR) & & & \\
\hline & & & AG & & & & & IMP & \\
\hline & & & & IND & SER & IND & SER & & $\mathrm{N}$ \\
\hline & Registered & & & & & & & & \\
\hline & & IND & 1.77 & 8.81 & 2.69 & 52.37 & 9.36 & 0.00 & 320 \\
\hline & & TRA & 8.58 & 13.20 & 7.74 & 26.53 & 24.64 & 5.38 & 372 \\
\hline$\vdots$ & & SER & 3.62 & 7.30 & 4.93 & 24.15 & 12.10 & 0.26 & 380 \\
\hline$\widehat{\overrightarrow{\mathrm{e}}}$ & & ALL & 4.79 & 11.19 & 5.24 & 33.40 & 15.63 & 1.96 & 1072 \\
\hline & & IND & 5.28 & 3.57 & 1.16 & 39.43 & 11.14 & 0.22 & 1592 \\
\hline & & TRA & 23.58 & 8.54 & 3.32 & 36.44 & 16.47 & 1.70 & 1809 \\
\hline & & SER & 8.33 & 3.25 & 1.91 & 25.53 & 9.31 & 0.08 & 1312 \\
\hline & & ALL & 13.16 & 5.39 & 2.20 & 34.41 & 12.68 & 0.75 & 4713 \\
\hline & $\operatorname{Pr}(|\mathrm{T}|>|\mathrm{t}|)$ & & & & & & & & \\
\hline & & IND & 0.00 & 0.00 & 0.03 & 0.00 & 0.34 & 0.38 & \\
\hline & & TRA & 0.00 & 0.00 & 0.00 & 0.00 & 0.00 & 0.00 & \\
\hline & & SER & 0.00 & 0.00 & 0.00 & 0.55 & 0.10 & 0.35 & \\
\hline & & ALL & 0.00 & 0.00 & 0.00 & 0.50 & 0.01 & 0.00 & \\
\hline
\end{tabular}

Note: Authors' calculation based on 1-2-3 survey.

Table 3.8 - Backward Linkages of UPIs, Low Capital Informal vs High Capital Informal

\begin{tabular}{|c|c|c|c|c|c|c|c|c|c|}
\hline & & & & & $\mathrm{ROM}(s$ & CTOR) & & & \\
\hline & & & $\mathrm{AG}$ & & & & & IMP & \\
\hline & & & & IND & SER & IND & SER & & $\mathrm{N}$ \\
\hline & $\begin{array}{l}\text { Intormal- } \\
\text { low capital }\end{array}$ & IND & 5.26 & 3.08 & 1.30 & 40.29 & 11.19 & 0.22 & 1580 \\
\hline & & TRA & 22.34 & 9.09 & 3.11 & 35.04 & 18.35 & 1.76 & 1970 \\
\hline$\vdots$ & & SER & 8.64 & 2.53 & 1.86 & 27.25 & 10.15 & 0.08 & 1239 \\
\hline$\widehat{\hat{\mathrm{e}}}$ & & ALL & 13.16 & 5.41 & 2.19 & 34.76 & 13.87 & 0.82 & 4789 \\
\hline & & IND & 2.01 & 10.98 & 1.95 & 47.84 & 9.21 & 0.00 & 332 \\
\hline & & TRA & 8.76 & 18.69 & 13.04 & 32.00 & 13.28 & 7.58 & 211 \\
\hline & & SER & 3.51 & 8.61 & 4.57 & 19.66 & 9.35 & 0.22 & 453 \\
\hline & & ALL & 4.12 & 11.54 & 5.49 & 31.67 & 10.13 & 1.71 & 996 \\
\hline & $\operatorname{Pr}(|\mathrm{T}|>|\mathrm{t}|)$ & & & & & & & & \\
\hline & & IND & 0.00 & 0.00 & 0.34 & 0.01 & 0.28 & 0.37 & \\
\hline & & TRA & 0.00 & 0.00 & 0.00 & 0.35 & 0.06 & 0.00 & \\
\hline & & SER & 0.00 & 0.00 & 0.00 & 0.00 & 0.61 & 0.46 & \\
\hline & & ALL & 0.00 & 0.00 & 0.00 & 0.05 & 0.00 & 0.01 & \\
\hline
\end{tabular}

Note: Authors' calculation based on 1-2-3 survey. 
When comparing the backward linkages shown in Tables 3.5 to 3.8 to the forward linkages, it turns out that informal enterprises are much more likely to buy intermediate goods and services from the formal sector than vice versa, which corroborates the notion of an asymmetric formalinformal relationship in intermediate product markets (Hugon 1990). The frequency of formal backward linkages is by far highest in the trade sector. About 19 percent of the high capital trading companies in our sample, for instance, purchase goods from the formal industrial sector (Table 3.8).

The pattern of backward linkages is in several respects similar to that of forward linkages. Again, linkages to the informal sector are considerably more frequent than linkages to the formal sector for all sub-groups of enterprises, and again formal linkages are of minor significance for unregistered and low capital informal enterprises. The latter is particularly pronounced for purchases of formal services, which only account for around 2 percent of overall expenditures. Irrespective of how we define them, informal enterprises at the higher end of the continuum are more than twice as likely as those at the lower end to buy goods and services originating from the formal sector, the difference being significant at the one percent level for purchases from the industrial, trade and services sector alike (Tables 3.7 and 3.8). Unregistered and low capital informal enterprises, and especially the traders among them, have fairly strong backward linkages to the agricultural sector, from which they mainly buy food items.

\subsection{Correlates of backward linkages}

Based on the descriptive statistics presented above, we construct a simple Probit model to investigate whether it is possible to identify some of the major factors associated with the choice of informal enterprises to enter formal-informal linkages. ${ }^{16}$ In doing so, we focus on backward linkages which in our descriptive analysis above have been shown to be quantitatively much more important than forward linkages. We distinguish six different types of correlates:

(i) Primary production factors (capital stocks, employees), infrastructure (electricity, telephone), and credit. The expectation is that enterprises with higher endowments are in a better position to establish formal linkages.

(ii) Experience as measured by the age of the enterprise. The expectation is that it takes time to build up business relationships.

(iii) Characteristics of the owner/manager of the enterprise (age, schooling, sex). We expect that male as well as older and more educated owners are more likely to establish formal linkages.

\footnotetext{
${ }^{16}$ Since consumptive linkages, i.e. final demand, allow no formal-informal categorization we exclude them from the analysis in the following sections.
} 
(iv) Membership of or help from professional associations. Contact with associations may facilitate networking and thereby raise the likelihood of formal business relationships.

(v) Dummies indicating whether the enterprise is registered or has higher-than-average capital. The evidence in Tables 3.5 to 3.8 clearly suggests that registered and high capital enterprises exhibit stronger formal backward linkages.

(vi) Dummies indicating whether a formal forward linkage exists. This is to test whether an enterprise with formal forward linkages is more likely to engage in formal backward linkages.

In addition to these control variables, the estimations include a set of country and industry dummies.

Table 3.9 - Correlates of Backward Linkages, Probit

\begin{tabular}{|c|c|c|c|c|c|}
\hline & (1) & (2) & (3) & (4) & (5) \\
\hline & \multicolumn{5}{|c|}{ Formal Backward Linkage } \\
\hline formFORW & & & & $0.0819 * * *$ & $0.0789 * * *$ \\
\hline informFORW & & & & 0.0022 & 0.0022 \\
\hline EXP & & & & 0.0231 & 0.0373 \\
\hline UNREG & & $-0.0464 * * *$ & & $-0.0453 * * *$ & \\
\hline LOWCAP & & & $-0.0589 * * *$ & & $-0.0564 * * *$ \\
\hline $\log \mathrm{VAL}$ & $0.0035^{* * *}$ & $0.0027 * *$ & 0.0012 & $0.0028^{* *}$ & 0.0013 \\
\hline totalemployees & $0.0104 * * *$ & $0.0084 * * *$ & $0.0079 * * *$ & $0.0077 * * *$ & $0.0073^{* * *}$ \\
\hline credit & $0.0328^{*}$ & $0.0324^{*}$ & $0.0308^{*}$ & $0.0299 *$ & $0.0285^{*}$ \\
\hline sex & $0.0650 * * *$ & $0.0583^{* * *}$ & $0.0605^{* * *}$ & $0.0564 * * *$ & $0.0585^{* * *}$ \\
\hline age & 0.0002 & 0.0001 & 0.0001 & 0.0001 & 0.0001 \\
\hline scol & $0.0047 * * *$ & $0.0045^{* * *}$ & $0.0043^{* * *}$ & $0.0041 * * *$ & $0.0039 * * *$ \\
\hline firmage & $-0.0014^{* *}$ & $-0.0014 * *$ & $-0.0013^{* *}$ & $-0.0014 * *$ & $-0.0014^{* *}$ \\
\hline telephone & $0.0474 * * *$ & $0.0416^{* *}$ & $0.0419 * *$ & $0.0366^{* *}$ & $0.0368^{* *}$ \\
\hline association & -0.0109 & -0.0179 & -0.0117 & -0.0157 & -0.0096 \\
\hline support & 0.0059 & 0.0040 & 0.0054 & 0.0045 & 0.0058 \\
\hline Obs & 5717 & 5717 & 5717 & 5717 & 5717 \\
\hline$\chi^{2}$ & 337.03 & 349.88 & 345.84 & 358.18 & 356.28 \\
\hline
\end{tabular}

Notes: The dependent variable equals one if the enterprise has formal backward linkages. Included country and sector dummies are not reported. Coefficients are reported as marginal effects. Figures in parenthesis are cluster robust standard error; ${ }^{* * *} \mathrm{p}<0.01,{ }^{* *} \mathrm{p}<0.05,{ }^{*} \mathrm{p}<0.1$. Authors' estimations based on 1-2-3 survey.

The results of the Probit analysis are reported in Table 3.9. We start with a baseline specification that only includes enterprise characteristics as explanatory variables (column 1). It turns out that several of these characteristics are statistically significant and have the expected sign. Backward linkages to the formal sector are more likely to exist for enterprises with a higher number of employees as well as better access to credit and telephone services, and where the owner is male and has more years of schooling. The existence of backward linkages to the formal sector is also 
positively related to the size of the capital stock. For two other firm characteristics, expectations are not corroborated by the empirical evidence: a higher age of the enterprise as well as membership in (or help from) professional associations are not associated with more frequent linkages to the formal sector. Membership in associations rather appears to be favorable for the establishment of informal forward linkages, suggesting that networks may be more easily built among similar firms. ${ }^{17}$

In the next two regressions, we additionally include the registration dummy (column 2) and the lower-than-average capital dummy (column 3). The dummies (UNREG and LOWCAP) are both significant at the one percent level, suggesting that the probability of engaging with the formal sector is higher for registered and high capital informal enterprises. The impact of all other control variables remains the same as before, with one exception: when entering the regression jointly with the high capital dummy, the capital stock variable is still positive but turns insignificant as the former captures part of its impact. Finally, as indicated by the respective dummy variable, which is significant at the one percent level, formal forward and backward linkages are positively associated with each other. By contrast, our regression results do not point to a similar relationship between informal forward linkages and formal backward linkages.

\subsection{Backward linkages and enterprise performance}

Having established that formal backward linkages are correlated with various enterprise characteristics and that their existence varies with the different classifications of informal enterprises, we now examine whether the linkages matter for enterprise performance. There has been extensive theoretical work on the question of whether inputs should be produced by the firm itself or whether they should be procured by independent suppliers (e.g. Williamson 1971). Market failures and the associated transaction costs bring about internalization, i.e. the decision to produce inputs that could be provided more efficiently by suppliers in the absence of transaction costs. Focusing on vertical linkages, Lall (1980) and Mead (1984) argue that this internalization can lead to lower productivity because independent suppliers would benefit from economies of scale for a particular intermediate good and because the internalization limits the gains from specialization. In addition, if enterprises are not able to procure intermediate goods from an independent supplier and lack the physical or human capital to produce the goods themselves, they will be restricted in their ability to introduce innovations to their production. More generally, it can be assumed that linkages facilitate the dispersion of technical innovation. Based on these considerations we expect backward

\footnotetext{
${ }^{17}$ Results for informal linkages are not shown here given that our focus is on the links of informal enterprises with the formal sector, but they are available from the authors on request.
} 
linkages and especially formal backward linkages to exert a positive influence on the productivity of enterprises in the informal sector.

When estimating the effects of backward linkages on firm performance, the main problem that may arise is endogeneity (e.g. Griliches and Maitresse 1995). First, it is very likely that linkages and other potential right-hand-side variables such as primary inputs are determined simultaneously. Second, it is not clear a priori whether an exceptional performance would allow firms to engage in the formal intermediate input market or whether it rather is improved access to formal supply channels that would trigger higher performance. Hence, reverse causality could also be a serious issue.

Before turning to a strategy of how to deal with endogeneity, we first present OLS regressions as a baseline. Our performance indicators are sales per worker and profit per worker. We also employ return on capital as a proxy for profitability and asset turnover as a proxy for the degree of activity of the informal enterprises, defining the return on capital as the ratio of profit to capital and asset turnover as the ratio of sales to capital. As shown in Table 3.3 above, all indicators differ markedly between the different categories. Registered and high capital informal enterprises tend to have higher sales per worker and also generate higher profits per worker compared to their counterparts. Their returns to capital are lower and they turn less of their capital over. Control variables include the same enterprise characteristics as before as well as the registration and high capital dummy, the latter being employed alternatively.

The OLS results are reported in Table 3.10. The most important finding is the significantly positive effect of formal backward linkages on all indicators under consideration. Even though there are few enterprises in the sample with imports we find that these import linkages also tend to be associated with higher performance. Most of the enterprise characteristics (capital, employment, firm age, sex and schooling of the owner, telephones, membership of associations in the full sample) are significant and have the expected sign. Somewhat surprisingly, we find no robust positive effect of credit availability on firm performance and in some cases even a negative impact of professional support from associations. The latter may well reflect reverse causality in the sense that underperforming firms are more likely to be eligible for professional support. Finally, there is evidence that the degree of informality is important for the performance of enterprises. While the registration dummy is always negative and significant at least at the 5 percent level (Table 3.10), a low capital endowment is shown to decrease sales per worker and profit per worker but to have no discernable impact on return on capital and asset turnover. 
Table 3.10 - Effects of Linkages on UPI Performance, OLS

\begin{tabular}{|c|c|c|c|c|c|c|c|c|}
\hline & (1) & (2) & (3) & (4) & \multirow{2}{*}{\multicolumn{2}{|c|}{\begin{tabular}{c|r}
$(5)$ & $(6)$ \\
PROFITABILITY
\end{tabular}}} & \multirow{2}{*}{\multicolumn{2}{|c|}{\begin{tabular}{|r|r|}
$(7)$ & $(8)$ \\
\multicolumn{2}{|c|}{ ACTIVITY RATIO }
\end{tabular}}} \\
\hline & \multicolumn{4}{|c|}{ PERFORMANCE } & & & & \\
\hline & $\log$ sale & worker & $\log$ profi & worker & \multicolumn{2}{|c|}{ log return on capital } & \multicolumn{2}{|c|}{$\log$ asset turnover } \\
\hline formBACKW & $0.75^{* * *}$ & $0.76^{* * *}$ & $0.21 * * *$ & $0.21 * * *$ & $0.20 * * *$ & $0.21 * * *$ & $0.67 * * *$ & $0.70^{* * *}$ \\
\hline informBACKW & $0.25^{* * *}$ & $0.27^{* * *}$ & $-0.20^{* * *}$ & $-0.19 * * *$ & $-0.19 * * *$ & $-0.18^{* * *}$ & $0.24^{* * *}$ & $0.25^{* * *}$ \\
\hline IMP & $1.13^{* * *}$ & $1.17^{* * *}$ & $0.58^{* * *}$ & $0.59 * * *$ & $0.57 * *$ & $0.59 * *$ & $1.12^{* * *}$ & $1.16^{* * *}$ \\
\hline UNREG & $-0.34 * * *$ & & $-0.15^{* * *}$ & & $-0.13^{* *}$ & & $-0.27 * * *$ & \\
\hline LOWCAP & & $-0.30^{* * *}$ & & $-0.20^{* * *}$ & & 0.04 & & 0.05 \\
\hline $\log \mathrm{VAL}$ & $0.05^{* * *}$ & $0.04 * * *$ & $0.04 * * *$ & $0.03 * * *$ & $-0.87 * * *$ & $-0.85^{* * *}$ & $-0.83 * * *$ & $-0.81 * * *$ \\
\hline totalemployees & $-0.10 * * *$ & $-0.10 * * *$ & $-0.15^{* * *}$ & $-0.15^{* * *}$ & $0.20 * * *$ & $0.20 * * *$ & $0.24 * * *$ & $0.25^{* * *}$ \\
\hline credit & $0.28^{* * *}$ & $0.27^{* * *}$ & 0.08 & 0.07 & 0.02 & 0.01 & $0.19^{* * *}$ & $0.18^{* * *}$ \\
\hline $\operatorname{sex}$ & $0.32^{* * *}$ & $0.35^{* * *}$ & $0.46^{* * *}$ & $0.47 * * *$ & $0.35^{* * *}$ & $0.36^{* * *}$ & $0.16^{* * *}$ & $0.19^{* * *}$ \\
\hline age & $0.00 * * *$ & $0.00 * * *$ & 0.00 & 0.00 & -0.00 & -0.00 & $0.00 *$ & $0.00^{*}$ \\
\hline scol & $0.02 * * *$ & $0.02 * * *$ & $0.03 * * *$ & $0.03^{* * *} *$ & $0.02 * * *$ & $0.02 * * *$ & $0.01 * *$ & $0.01 * *$ \\
\hline firmage & $0.01^{* * *}$ & $0.01^{* * *}$ & $0.01 * * *$ & $0.01^{* * *}$ & $0.01 * * *$ & $0.01 * * *$ & $0.01 * * *$ & $0.01 * * *$ \\
\hline telephone & $0.41 * * *$ & $0.42^{* * *}$ & $0.30^{* * *}$ & $0.30^{* * *}$ & $0.26 * * *$ & $0.28^{* * *}$ & $0.35^{* * *}$ & $0.37 * * *$ \\
\hline association & $0.23 * * *$ & $0.28 * * *$ & $0.27 * * *$ & $0.29 * * *$ & $0.20 *$ & $0.22^{* *}$ & $0.16^{* *}$ & $0.22^{* * *}$ \\
\hline support & $-0.08^{* *}$ & $-0.07^{*}$ & $-0.11 * * *$ & $-0.11^{* * *}$ & $-0.10^{* * *}$ & $-0.10^{* *}$ & $-0.06^{*}$ & -0.05 \\
\hline Observations & 5717 & 5717 & 5317 & 5317 & 4649 & 4649 & 4983 & 4983 \\
\hline $\mathrm{R}^{2}$ & 0.25 & 0.25 & 0.20 & 0.20 & 0.64 & 0.64 & 0.69 & 0.69 \\
\hline
\end{tabular}

Notes: Included country and sector dummies are not reported. Figures in parenthesis are cluster robust standard error; ${ }^{* * *} \mathrm{p}<0.01, * * \mathrm{p}<0.05, *$ $\mathrm{p}<0.1$; Authors' estimations based on 1-2-3 survey.

While being suggestive, the OLS estimates are likely to be biased: the Durban-Wu-Hausman test points to the endogeneity of formal backward linkages in almost all specifications. As an attempt to overcome the endogeneity problem, we depart from the theoretical argument made by Hirschmann (1977) that firms will only engage in backward linkages if markets exist to which they can sell their products, reflecting a demand-led growth perspective. Accordingly, we assume that forward linkages come logically before backward linkages. Furthermore, firms in the informal sector consider a lack of demand from big enterprises in the formal sector as one of their major constraints. This leads us to use the existence of formal forward and export linkages as instrumental variables for incurring formal backward linkages.

Causality could also run from backward to forward linkages, or both could be jointly determined by third factors, which would render the theory-based instrument invalid. We therefore employ the informal share of a given sector of origin as a second instrument to evaluate the robustness of our findings. The underlying idea is that the bigger the informal share the less likely it is that (informal) enterprises will have formal linkages to this sector. The first phase of the 1-2-3 survey asked household members about their employment status as well as the sector, size and legal status of the company they worked for. This allowed us to derive the informal share of the sectors listed in Table 
3.2 for each city in the survey. ${ }^{18}$ Since the second phase of the questionnaire comprises a random sub-sample of the first phase we can be confident that the calculated shares are not systematically biased and that they serve as exogenous instruments.

The fact that our theory-based instrumental variables are binary would call for a local average treatment approach (Imbens and Angrist 1994). Yet, given that this Maximum Likelihood method does not allow us to assess the quality of the instruments we opt for a 2 SLS approach instead. ${ }^{19}$ The 2SLS is less efficient but consistent in the present setting (Wooldridge 2002). A disadvantage of the $2 \mathrm{SLS}$ procedure is that the size of the coefficients of the fitted values in the second stage cannot be interpreted in a meaningful way. Hence, we have to rely on the sign and the statistical significance of the coefficients when comparing IV and OLS estimates.

As for the quality of our instruments, we have already shown in Table 3.9 that formal forward linkages are closely related to the formal backward linkages of informal enterprises. As a formal test of the strength of the instruments we report the Cragg-Donald F-statistics. Their critical value for the present IV estimations is $\mathbf{7 . 2 5}$ for the theory-based instrument and 5.53 for the informal sector share instrument according to Stock and Yogo (2002). Both instruments appear to be strong in the two performance equations, whereas values of the Cragg-Donald test are close to the thresholds in the profitability and activity equation. Furthermore, we test the orthogonality assumption of the 2SLS approach, employing the standard Sargan statistic of overidentifying restrictions. This can only be done for the theory-based instruments as there is only one informal sector share instrument. Results are mixed: in half of the cases the null of endogeneity is clearly rejected, pointing to the validity of the instruments, whereas in the other half Sargan p-values between 0.3 and 0.4 suggest the opposite.

\footnotetext{
${ }^{18}$ Since company size is only reported on a scale with non-linear intervals, the calculated shares are not valid point estimates. Nevertheless, they do represent the relative size of the informal sector in each city.

${ }^{19}$ Our overall results are not affected by this choice as they point in the same direction under a local average treatment approach. The results of the local average treatment regressions are available from the authors upon request.
} 
Table 3.11 - Effects of Linkages on UPI Performance, IV Using Forward Linkages as Instrument

\begin{tabular}{|c|c|c|c|c|c|c|c|c|}
\hline & (1) & (2) & (3) & (4) & (5) & (6) & \multicolumn{2}{|l|}{$(7)$} \\
\hline & \multicolumn{4}{|c|}{ PERFORMANCE } & \multirow{2}{*}{\multicolumn{2}{|c|}{$\begin{array}{l}\text { PROFITABILITY } \\
\text { log return on capital }\end{array}$}} & \multirow{2}{*}{\multicolumn{2}{|c|}{$\begin{array}{l}\text { ACTIVITY RATIO } \\
\text { log asset turnover }\end{array}$}} \\
\hline & \multicolumn{2}{|c|}{ log sales per worker } & \multicolumn{2}{|c|}{ log profit per worker } & & & & \\
\hline formBACKW & $6.34^{* * *}$ & $6.42^{* * *}$ & $6.91 * * *$ & $6.94^{* * *}$ & $7.09^{* *}$ & $7.14^{* *}$ & $5.62^{* * *}$ & $5.73^{* * *}$ \\
\hline UNREG & 0.01 & & 0.24 & & 0.14 & & -0.05 & \\
\hline LOWCAP & & 0.10 & & 0.20 & & 0.22 & & $0.24 *$ \\
\hline $\log \mathrm{VAL}$ & $0.03^{* * *}$ & $0.03 * * *$ & $0.02 *$ & $0.02^{* *}$ & $-0.97 * * *$ & $-0.95^{* * *}$ & $-0.91 * * *$ & $-0.87^{* * *}$ \\
\hline totalemployees & $-0.16^{* * *}$ & $-0.16^{* * *}$ & $-0.23^{* * *}$ & $-0.23^{* * *}$ & $0.14^{* * *}$ & $0.14^{* * *}$ & $0.20^{* * *}$ & $0.20^{* * *}$ \\
\hline credit & -0.00 & -0.00 & -0.31 & -0.30 & $-0.42^{*}$ & $-0.42^{*}$ & -0.08 & -0.09 \\
\hline $\operatorname{sex}$ & -0.00 & -0.00 & 0.20 & 0.18 & 0.15 & 0.13 & -0.09 & -0.09 \\
\hline age & 0.00 & 0.00 & -0.00 & -0.00 & -0.00 & -0.00 & -0.00 & -0.00 \\
\hline scol & -0.00 & -0.00 & -0.00 & -0.00 & -0.01 & -0.01 & -0.01 & -0.01 \\
\hline firmage & $0.02 * * *$ & $0.02^{* * *}$ & $0.02 * * *$ & $0.02^{* * *}$ & $0.03^{* * *}$ & $0.03^{* * *}$ & $0.02 * * *$ & $0.02 * * *$ \\
\hline telephone & 0.13 & 0.13 & 0.02 & 0.01 & 0.05 & 0.04 & 0.15 & 0.16 \\
\hline association & $0.42^{* * *}$ & $0.43^{* * *}$ & $0.41 * *$ & $0.37^{* *}$ & $0.39 *$ & $0.37^{*}$ & $0.37^{* *}$ & $0.39 * *$ \\
\hline support & -0.08 & -0.09 & -0.11 & -0.11 & -0.06 & -0.06 & -0.04 & -0.04 \\
\hline Observations & 5717 & 5717 & 5317 & 5317 & 4649 & 4649 & 4983 & 4983 \\
\hline F-statistic & 26.34 & 25.25 & 23.38 & 23.05 & 109.06 & 107.93 & 190.33 & 184.37 \\
\hline CD F-statistic & 9.62 & 9.25 & 10.47 & 10.08 & 6.01 & 5.99 & 6.80 & 6.68 \\
\hline Sargan p-value & 0.05 & 0.06 & 0.28 & 0.30 & 0.40 & 0.41 & 0.04 & 0.04 \\
\hline
\end{tabular}

Notes: Included country and sector dummies are not reported. Figures in parenthesis are cluster robust standard error; $* * * \mathrm{p}<0.01, * * \mathrm{p}<0.05, *$ $\mathrm{p}<0.1$; Authors' estimations based on 1-2-3 survey.

Table 3.12 - Effects of Linkages on UPI Performance, IV Using Informal Market Share as Instrument

\begin{tabular}{|c|c|c|c|c|c|c|c|c|}
\hline & (1) & (2) & (3) & (4) & \multirow{3}{*}{\multicolumn{2}{|c|}{\begin{tabular}{c|r}
$(5)$ & $(6)$ \\
PROFITABILITY \\
log return on capital
\end{tabular}}} & \multirow{3}{*}{\multicolumn{2}{|c|}{\begin{tabular}{l|r}
$(7)$ & $(8)$ \\
ACTIVITY RATIO \\
log asset turnover \\
\end{tabular}}} \\
\hline & \multicolumn{4}{|c|}{ PERFORMANCE } & & & & \\
\hline & \multicolumn{2}{|c|}{ log sales per worker } & \multicolumn{2}{|c|}{ log profit per worker } & & & & \\
\hline formBACKW & $9.71 * * *$ & $10.00^{* * *}$ & $5.94^{* *}$ & \multirow[t]{2}{*}{$5.87^{* *}$} & \multirow{2}{*}{\multicolumn{2}{|c|}{$\begin{array}{l}3.37 \\
-0.00\end{array}$}} & $8.15^{* *}$ & \multirow[t]{2}{*}{$8.49^{* *}$} \\
\hline UNREG & 0.24 & & 0.18 & & & & 0.07 & \\
\hline LOWCAP & & 0.35 & & 0.14 & & 0.12 & & $0.33^{*}$ \\
\hline $\log \mathrm{VAL}$ & 0.02 & $0.03 *$ & $0.02 * *$ & $0.03^{* * *}$ & $-0.91 * * *$ & $-0.90 * * *$ & $-0.95^{* * *}$ & $-0.91 * * *$ \\
\hline totalemployees & $-0.19 * * *$ & $-0.19 * * *$ & $-0.22^{* * *}$ & $-0.22^{* * *}$ & $0.17^{* * *}$ & $0.17^{* * *}$ & $0.18^{* * *}$ & $0.18^{* * *}$ \\
\hline credit & -0.18 & -0.19 & -0.25 & -0.25 & -0.19 & -0.20 & -0.23 & -0.25 \\
\hline $\operatorname{sex}$ & -0.16 & -0.18 & $0.25^{*}$ & 0.24 & $0.29 * * *$ & $0.28^{* * *}$ & -0.18 & -0.21 \\
\hline age & -0.00 & -0.00 & -0.00 & -0.00 & -0.00 & -0.00 & -0.00 & -0.00 \\
\hline scol & -0.02 & -0.02 & 0.00 & 0.00 & 0.01 & 0.00 & -0.02 & -0.02 \\
\hline firmage & $0.03^{* * *}$ & $0.03^{* * *}$ & $0.02 * * *$ & $0.02^{* * *}$ & $0.02^{* * *}$ & $0.02^{* * *}$ & $0.03^{* * *}$ & $0.03^{* * *}$ \\
\hline telephone & -0.04 & -0.05 & 0.06 & 0.06 & 0.18 & 0.17 & 0.05 & 0.04 \\
\hline association & $0.53^{* *}$ & $0.51^{* *}$ & $0.39 * *$ & $0.36^{* *}$ & $0.28^{* *}$ & $0.29 * *$ & $0.47^{* *}$ & $0.47^{* *}$ \\
\hline support & -0.09 & -0.10 & -0.11 & -0.11 & -0.08 & -0.08 & -0.03 & -0.03 \\
\hline Observations & 5717 & 5717 & 5317 & 5317 & 4649 & 4649 & 4983 & 4983 \\
\hline F-statistic & 12.69 & 11.77 & 26.02 & 25.82 & 264.29 & 252.42 & 103.86 & 96.29 \\
\hline CD F-statistic & 8.767 & 8.524 & 9.216 & 8.643 & 5.684 & 6.353 & 6.221 & 7.210 \\
\hline
\end{tabular}

Notes: Included country and sector dummies are not reported. Figures in parenthesis are cluster robust standard error; ${ }^{* * *} \mathrm{p}<0.01, * * \mathrm{p}<0.05, *$ $\mathrm{p}<0.1$; Authors' estimations based on 1-2-3 survey. 
The IV results are displayed in Table 3.11 for the theory-based instrument and in Table 3.12 for the informal sector share instrument. In accordance with our OLS results, we find that - irrespective of the instrumentation strategy - formal backward linkages have a positive and significant impact on the performance, profitability and activity variables. The only exception is the profitability equation in Table 10, where the respective coefficient is only marginally significant but still positive. The negative effect of being unregistered and having a lower-than average capital stock we found in the OLS estimations vanishes in most cases. This suggests that the degree of informality of the enterprises in our sample mainly affects firm performance through their linkages to the formal sector. By contrast, several other control variables (capital stocks, employees, firm age, and membership in associations) retain their independent impact on most of the indicators under the IV specification.

\subsection{Summary and Conclusions}

Along the lines of Hirschmann's linkage methodology, this essay has analyzed to what extent informal enterprises in six West African urban centers are engaged with the formal sector. We have shown that formal-informal linkages do exist, that backward linkages to the formal sector are much more prevalent than forward linkages, and that linkages vary with the degree of informality, occurring less frequently if firms are unregistered or have low capital stocks. Another important finding is that various measures of firm performance are strongly improved by the existence of formal backward linkages, whereas the degree of informality of the enterprises seems to affect firm performance only indirectly through their linkages to the formal sector.

Taken together these results lead us to conclude that the pessimistic view on the prospects of the informal sector implied by standard dual economy models is not justified. Yet, it has to be recognized that the unregistered and low-capital enterprises of our sample are rather weakly integrated with the formal sector, which in turn impairs their development prospects. These enterprises are most likely in need of public support, be it in the form of microcredit, investments in infrastructure or legal reforms that facilitate transactions among firms.

As concerns future research, the important role that linkages play according to our findings would call for a more detailed analysis of how business relationships between enterprises come about and are sustained. Such an analysis could, for example, build on the growing literature on social networks in developing countries, or it could take a closer look at the spatial distribution of formal and informal activities. A deeper knowledge of the conditions under which formal-informal linkages are successfully established might enable governments to provide support that more effectively removes existing bottlenecks. 


\title{
Essay 4
}

\section{Is the Informal Sector constrained from the demand side? Evidence for six West African capitals*}

with Rainer Thiele

\begin{abstract}
Employing a unique dataset that covers households from six West African capitals, this essay provides new evidence on the demand for informal sector products and services. We first investigate whether demand linkages exist between formal and informal products and distribution channels. In a second step, we estimate demand elasticities based on Engel curves. We find strong demand-side linkages between the formal and informal sector, with the exception that informal goods are hardly bought through formal distribution channels. The estimated demand elasticities tend to show that rising incomes are associated with a lower propensity to consume informal sector goods and to use informal distribution channels.
\end{abstract}

Keywords: Informal sector; formal-informal linkages; Engel curves; Africa; West African capitals

JEL codes: D12; 017

* Published in World Development 40(7): 1369-1381. 


\subsection{Introduction}

In urban Sub-Saharan Africa (SSA), formal employment covered by labor legislation and social protection schemes is the exception rather than the rule. By far the largest part of urban employment is generated by micro and small enterprises, and (self-) employment in those enterprises can be considered informal by almost any definition one might want to apply. The informal sector is characterized by a high degree of heterogeneity comprising both low and high return activities. If markets fail to equalize returns, this can imply substantial welfare losses where poor urban households are prevented from escaping the lower tier of informal employment. Among the constraints that may bring about persistent differentials in returns, supply side factors such as capital market failures and entry barriers have received considerable attention in the literature (e.g. de Mel et al. 2008; Grimm et al. 2011).

It has been less well recognized that the evolution of the informal sector is also shaped by the demand side, in particular by the structure of final demand as well as linkages to the formal sector. The literature on the structure of demand has mainly been descriptive. It has not only distinguished informal and formal products and services, but also formal and informal customers or households, typically identified by the (main) sector of occupation of the household head (formal or informal). A core proposition of this literature has been that informal and formal products will often have an overlapping customer base (Sethuraman 1997). Such overlaps may reflect complementary or competitive product markets. The most common example of a complementary market occurs when the informal sector sells formal sector products. In competitive markets, the two sectors compete within the same product market, and the informal sector may for example retain market shares by charging lower prices. The rather limited evidence for Sub-Saharan Africa tends to confirm the notion of an overlapping customer base. Covering a sample of 13 Sub-Saharan African countries, Xaba et al. (2002) find rather strong inter-linkages in the final product market, with each sector being a strong supply as well as demand base of the other sector. Similar results are obtained by Grimm and Günther (2006) for the case of Burkina Faso.

By contrast, Fortin et al. (2000) suggest various reasons why working in the informal sector will raise the probability of buying products in the informal market, thereby limiting the demand overlap. For instance, those working in the informal sector may have an informational advantage about how and where to obtain informal goods and services. In accordance with this reasoning, Livingstone (1991) finds that in Kenya informal goods target mainly low-income consumers, while Reilly et al. (2006) obtain an inverse relationship between purchases from informal markets and income. For a sample of 24 African countries, La Porta and Shleifer (2011) show that informal firms mostly sell to 
informal clients for cash, which they attribute to differences in quality between formal and informal firms.

Of crucial importance for the economic prospects of informal entrepreneurs is the elasticity of demand for their products, which in turn depends on the strength of formal-informal linkages. Again, evidence on this issue is scarce. The only exception in the African context is Lachaud (1990) who shows that rising wages lead to a lower propensity to consume informal sector goods. In a similar vein, D'Haese and Van Huylenbroeck (2005) find evidence that supermarkets create fierce competition with local agricultural sales in South Africa. With rising income households tend to purchase their goods at supermarkets because they are able to offer a broader variety and a higher quality at lower prices. Even though D'Haese and Van Huylenbroeck do not address the informal sector directly it can be assumed that local agricultural sales are often informal.

This essay aims to broaden the evidence on the characteristics of demand for informal sector products and services in Africa. We extend the literature in various ways. First, by using fully comparable data for a sample of six West African countries, we provide a comprehensive set of demand elasticities based on Engel curves. Second, in contrast to previous papers, our dataset allows us to consider imported goods in addition to domestically produced formal and informal goods, and to account for informal and formal distribution channels. Hence, we are able to categorize goods along two dimensions - their origin (formal, informal, imported) and their point of sale. For example, a good such as industrial bread, which is produced by the formal sector, may either be sold formally in a supermarket or informally by a market hawker. Third, we address methodological challenges such as the potential endogeneity of income and the nonlinearity of Engel curves. This has been done before (e.g. Gibson 2002; Kedir and Girma 2007), but not in the context of the informal sector.

The overall objective of the essay is to investigate the extent to which the informal sector is constrained from the demand side in the sense that the demand for informal goods and distribution channels is income-inelastic. In combination with supply side factors such as credit constraints, inelastic demand would severely limit the prospects of those working in the informal sector. If informal goods are mainly bought by poor informal households via informal distribution channels, due to lower information costs or quality differences, one would expect low demand elasticities throughout. If, by contrast, formal-informal linkages play a significant role, for instance because formal customers value certain characteristics of the informal sector such as higher flexibility in terms of longer opening hours, the picture could be much more nuanced, with certain segments of the informal sector benefiting from strong demand by richer households who earn their income in the formal sector. 
The remainder of the essay is structured as follows. Section 4.2 introduces the dataset employed in the empirical analysis and presents descriptive evidence on whether there are demand-side linkages between the formal and informal sector. Section 4.3 derives some hypotheses concerning the demand elasticities and describes the Engel curve methodology, while Section 4.4 discusses the estimated elasticities. Section 4.5 summarizes our main results and provides some concluding remarks.

\subsection{Data and Descriptive Analysis}

\section{The Dataset}

We use data provided by the "Enquêtes 1-2-3". This survey was carried out between 2001 and 2003 in seven economic capitals of the West African Economic and Monetary Union (WAEMU). It consisted of three integrated phases for a representative set of households. The first phase of the survey was constructed as a general labor force survey, interviewing formal and informal workers and entrepreneurs. It provides detailed information about individual socio-demographic characteristics and employment. In identifying informal activities, the 1-2-3 surveys follow international statistical guidelines, which suggest that informal sector employment should be defined in terms of characteristics of the enterprise or production unit such as size and different legislative criteria (Hussmans 2004). Specifically, the 1-2-3 surveys define informal enterprises as small production units that (a) do not have written formal accounts and/or (b) are not registered with the tax administration.

The second phase of the survey interviewed a sub-sample of the informal production units identified in phase one. The focus of this phase was on characteristics of the entrepreneurs and their production units. It also contains information on input use, investment, sales, profit as well as the unit's forward and backward linkages.

The third phase, on which the subsequent analysis will mainly rely, collected data on household expenditure including the point of sale. Expenditures were recorded based on a classification of 315 different products and services. The technique of registration varied according to the periodicity of the purchase. While food expenditures were registered on a daily basis for 15 days, for other types of expenditure such as clothing, housing, health, transport and education a retrospective module was used. All expenditure aggregates are recorded at the household level, annualized and given in local currency units. A two-stage random sample design was applied based on an updated general population census of each country (Amegashie et al. 2005). Area codes were used as the primary 
sampling unit, of which 125 were selected for each city. Households were the secondary sampling unit, of which 20 (24 in Benin) were drawn from each primary unit. Data was then collected for each household member. The 4200 households included in phase three constitute a representative subsample drawn from the 15300 households of phase one.

The data collected in phase one permitted an additional stratification based on income and sector of activity of the household head in phase three. This constitutes one major advantage of using the integrated 1-2-3 survey, because it allows us to distinguish formal and informal households and thus to test whether these two groups differ in their demand patterns as suggested by Fortin et al. (2000). A further strength of the 1-2-3-surveys is that they used exactly the same questionnaire and were conducted more or less simultaneously in the seven economic capitals of the WAEMU, rendering the datasets fully comparable. Finally, being coordinated by AFRISTAT and DIAL and financially supported by the European Commission, the French Ministry of Foreign Affairs and the World Bank, the surveys were elevated into the status of official data, which should add to the credibility of the results based on them.

Table 4.1 shows summary statistics of selected socio-demographic household characteristics for the six West African capitals under consideration. Most interestingly in the context of this essay, between 40 percent and 60 percent of the household heads receive their primary income from informal sector activities, classifying the respective households as informal. The share is lowest in Dakar, the capital of Senegal, the richest country in the sample. The primary wage income of informal households is on average roughly 70 percent of the income of formal households. At the country level, informal households have throughout less income than formal households; this difference is significant (except for Mali) but varies in size across countries.

The other major household characteristics listed in Table 1 also exhibit a considerable degree of variation across countries. Average household size, for instance, is by far highest in Dakar due to a strikingly large number of adult members. ${ }^{20}$ The mainly Christian capitals of Togo and Benin are characterized by high rates of primary school completion among household heads and a rather high share of female-headed households, whereas the opposite is true for the mainly Muslim capitals of Burkina Faso, Mali and Niger.

\footnotetext{
${ }^{20}$ The large number of adults may partly reflect polygamy. We thank an anonymous referee for pointing us to this possible explanation.
} 
Table 4.1 - Summary Statistics of Sample Households by Country

\begin{tabular}{|c|c|c|c|c|c|c|}
\hline Country & $\begin{array}{l}\text { Benin - } \\
\text { Cotonou }\end{array}$ & $\begin{array}{c}\text { Burkina } \\
\text { Faso - } \\
\text { Ouaga }\end{array}$ & $\begin{array}{l}\text { Mali - } \\
\text { Bamako }\end{array}$ & $\begin{array}{l}\text { Niger - } \\
\text { Niamey }\end{array}$ & $\begin{array}{c}\text { Senegal - } \\
\text { Dakar }\end{array}$ & $\begin{array}{l}\text { Togo - } \\
\text { Lomé }\end{array}$ \\
\hline Category & coastal & sahel & sahel & sahel & coastal & coastal \\
\hline \multicolumn{7}{|l|}{ Mean number of household members } \\
\hline Infants $(<6)$ & 0.4 & 0.6 & 0.8 & 0.8 & 0.4 & 0.4 \\
\hline Children (6-15) & 0.7 & 1.3 & 1.2 & 1.5 & 1.2 & 0.7 \\
\hline Adults $(>15)$ & 3.0 & 4.0 & 3.6 & 3.9 & 6.1 & 3.0 \\
\hline Mean age of household head & 42.5 & 43.2 & 43.8 & 44.5 & 50.5 & 39.6 \\
\hline Sex of household head (male $=1$ ) & $72.9 \%$ & $87.0 \%$ & $88.6 \%$ & $86.3 \%$ & $73.0 \%$ & $72.1 \%$ \\
\hline $\begin{array}{l}\text { Completed primary education of household head } \\
(\%)\end{array}$ & $83.9 \%$ & $54.2 \%$ & $53.1 \%$ & $48.0 \%$ & $58.7 \%$ & $83.3 \%$ \\
\hline Primary wage income source is public sector $(\%)$ & $12.6 \%$ & $19.0 \% \%$ & $13.1 \%$ & $18.9 \%$ & $13.4 \%$ & $10.9 \%$ \\
\hline Primary wage income source is private sector $(\%)$ & $75.4 \%$ & $71.7 \%$ & $77.6 \%$ & $68.0 \%$ & $75.1 \%$ & $79.9 \%$ \\
\hline $\begin{array}{l}\text { Household head earns primary income in the } \\
\text { informal sector }(\%)\end{array}$ & $54.1 \%$ & $46.8 \%$ & $50.1 \%$ & $47.1 \%$ & $38.2 \%$ & $61.3 \%$ \\
\hline Observations & 573 & 936 & 956 & 575 & 567 & 569 \\
\hline
\end{tabular}

Note: Authors' calculation based on 1-2-3 Surveys.

\section{Structure of Demand}

To analyze the structure of demand for goods and services, we aggregate annual expenditures in two different ways. First, we apply a conventional sectoral classification, where expenditures are allocated to eleven different categories. ${ }^{21}$ This classification has the advantage that it can directly be matched with the survey information and closely resembles what has been done in previous studies, allowing a comparison of our results. This has to be weighed against one important disadvantage, namely that the sectors only roughly correspond with the distinction between formal and informal goods we are interested in. One can argue, for instance, that Food and Non-Alcoholic Beverages includes mainly informal products, whereas Transportation and Communication supplies mainly formal goods and services, but at the same time one has to acknowledge that within categories there are notable exceptions such as informal taxi services.

Second, we distinguish four types of expenditures: on domestically produced formal goods, domestically produced informal goods, imported goods and services. In principle, this option is

\footnotetext{
${ }^{21}$ These categories are: (1) Food and Non-Alcoholic Beverages, (2) Alcoholic Beverages and Tobacco, (3) Clothing and Shoes, (4) Housing, (5) Gas, Electricity and Water, (6) Furniture and Household Maintenance, (7) Health and Education, (8) Transport and Communication, (9) Leisure and Culture, (10) Hotels and Restaurants and (11) Diverse Goods and Services.
} 
superior to the sectoral classification as it directly captures the distinction between formal and informal goods. However, the households in the survey were not asked whether they bought any specific product from the formal or informal sector. The best available alternative was to use certain characteristics of the products that households purchase to sort them into the two different categories. Specifically, agricultural, artisan and traditional products were assumed to be produced informally, whereas capital intensive, technologically advanced and industrial products were assumed to be produced formally. The first category mainly comprises food products such as traditionally made bread, while the second category consists mainly of electricity, fuel, construction materials, household articles, clothing and footwear, as well as certain food products such as industrially produced bread or canned meat. With this procedure, we cannot rule out that specific products are sorted into the wrong categories, but are confident that the aggregates constitute a meaningful representation of informal and formal goods. Still, findings based on this categorization have to be interpreted cautiously.

In contrast to domestic formal and informal goods, demand for imports and services can readily be identified from the survey. Households can with an acceptable margin of error name the country of origin of goods purchased due to the packing and labeling. One central characteristic of services is the quasi-concurrence of production and purchase. Hence, knowing the distribution channel is sufficient to distinguish between formal and informal services. The questionnaire asked consumers about the location of their purchases such as explicitly formal enterprises, supermarkets and the public sector, which are assumed to be formal points of sale, and household production, mobile traders and public markets, which are assumed to be informal points of sale. This allows us to distinguish purchases via formal and informal distribution channels for each of the demand categories defined above.

As can be seen in Table 4.2, food products and non-alcoholic beverages account for roughly 30 percent of annual household expenditures throughout the sample. If non-frequent purchases are excluded, i.e. only monthly expenditures are used this share rises to over 70 percent for all West African capitals. Housing and Transport and Communication constitute the next-biggest positions, accounting for 10-18 percent and 10-16 percent of total expenditures respectively. The structure of demand does not seem to vary in a systematic way across the sample countries. We do, for example, not find higher shares of food expenditures in poorer countries such as Mali and Niger than in richer countries such as Senegal and Benin. While one might argue that this finding works against Engel's law, our interpretation is that even the richer countries in the sample are still too poor to exhibit significantly lower food expenditure shares. 
Table 4.2 - National Annual Household Expenditure Shares by Sector (percent)

\begin{tabular}{|c|c|c|c|c|c|c|}
\hline Country & $\begin{array}{l}\text { Benin - } \\
\text { Cotonou }\end{array}$ & $\begin{array}{c}\text { Burkina } \\
\text { Faso - } \\
\text { Ouaga }\end{array}$ & $\begin{array}{c}\text { Mali - } \\
\text { Bamako }\end{array}$ & $\begin{array}{l}\text { Niger - } \\
\text { Niamey }\end{array}$ & $\begin{array}{c}\text { Senegal - } \\
\text { Dakar }\end{array}$ & $\begin{array}{l}\text { Togo - } \\
\text { Lomé }\end{array}$ \\
\hline Food and Non-Alcoholic Beverages & 29.0 & 29.6 & 35.0 & 36.2 & 36.4 & 33.4 \\
\hline Alcoholic Beverages and Tobacco & 1.7 & 2.9 & 0.5 & 1.1 & 0.8 & 1.8 \\
\hline Clothing and Shoes & 6.1 & 6.6 & 7.2 & 7.1 & 5.2 & 8.5 \\
\hline Housing & 14.4 & 11.2 & 15.9 & 13.2 & 17.8 & 9.8 \\
\hline Gas, Electricity and Water & 6.9 & 6.7 & 9.6 & 7.6 & 8.3 & 5.4 \\
\hline Furniture and Household Maintenance & 3.8 & 4.6 & 5.3 & 5.7 & 6.0 & 4.4 \\
\hline Health and Education & 8.5 & 9.4 & 5.3 & 5.7 & 6.4 & 7.9 \\
\hline Transport and Communication & 14.7 & 16.3 & 13.5 & 12.4 & 9.8 & 10.8 \\
\hline Leisure and Culture & 3.1 & 3.8 & 1.7 & 2.7 & 2.9 & 2.5 \\
\hline Hotels and Restaurants & 7.0 & 4.9 & 1.7 & 4.6 & 2.2 & 9.3 \\
\hline Diverse Goods and Services & 4.8 & 4.0 & 4.3 & 3.6 & 4.1 & 6.2 \\
\hline
\end{tabular}

Note: Authors' calculation based on 1-2-3 Surveys.

This interpretation is also in accordance with our within-country finding that the expenditure share of food and non-alcoholic beverages even rises slightly from the first to the second income quintile and only then starts to drop in accordance with Engel's law (Table 4.3). ${ }^{22}$ In all countries, expenditure shares tend to fall across quintiles for Housing ${ }^{23}$ as well as Hotels and Restaurants, while they tend to rise substantially for Health and Education as well as Transport and Communication.

From Table 4.4 it appears that the informal sector is the dominant point of sale. ${ }^{24}$ The only notable exception is Health and Education where services are almost exclusively distributed through formal channels. For Gas, Electricity and Water and Transport and Communication we see a rather balanced relationship between formal and informal expenditure shares. Households turn to the formal sector for purchases of capital intensive products such as private vehicles and for the use of public transportation, and to the informal sector for rather inexpensive transportation-related goods such as bicycles and spare parts. In the food and beverages sector, formal outlets such as supermarkets appear to be virtually non-existent.

\footnotetext{
${ }^{22}$ For Togo, we find no evidence pointing to an Engel curve.

${ }^{23}$ Housing expenditures include imputed rents for owner-occupied housing.

${ }^{24}$ The results of Table 4.4 remain comparable or become even more pronounced when we focus on the frequency of purchases.
} 
Table 4.3 - Average Annual Household Expenditure Shares by Sector and Quintile (percent)

\begin{tabular}{|c|c|c|c|c|c|c|c|c|c|c|c|c|c|c|c|}
\hline \multirow{2}{*}{$\begin{array}{l}\text { Country } \\
\text { Quintile (Total Expenditure) }\end{array}$} & \multicolumn{5}{|c|}{ Benin - Cotonou } & \multicolumn{5}{|c|}{ Burkina Faso - Ouaga } & \multicolumn{5}{|c|}{ Mali - Bamako } \\
\hline & 1 & 2 & 3 & 4 & 5 & 1 & 2 & 3 & 4 & 5 & 1 & 2 & 3 & 4 & 5 \\
\hline Food and Non-Alcoholic Beverages & 34.7 & 34.8 & 33.6 & 31.9 & 26.6 & 37.6 & 40.7 & 37.2 & 34.5 & 24.1 & 39.7 & 43.3 & 41.5 & 38.2 & 29.7 \\
\hline Alcoholic Beverages and Tobacco & 4.5 & 3.2 & 3.3 & 3.7 & 4.4 & 7.6 & 4.6 & 5.2 & 5.5 & 4.7 & 4.6 & 3.8 & 2.2 & 1.4 & 1.6 \\
\hline Clothing and Shoes & 6.9 & 7.2 & 7.3 & 7.1 & 6.5 & 6.9 & 6.6 & 7.0 & 7.0 & 7.7 & 7.6 & 6.9 & 8.5 & 8.2 & 8.5 \\
\hline Gas, Electricity and Water & 6.7 & 7.0 & 7.3 & 7.4 & 6.2 & 6.5 & 6.7 & 7.5 & 7.1 & 6.8 & 6.0 & 6.3 & 7.7 & 9.4 & 12.0 \\
\hline Furniture and Household Maintenance & 3.4 & 4.0 & 3.5 & 3.6 & 4.2 & 4.1 & 3.6 & 3.7 & 4.2 & 5.7 & 4.2 & 4.7 & 4.5 & 5.5 & 7.3 \\
\hline Health and Education & 4.4 & 5.9 & 8.4 & 8.5 & 10.6 & 5.8 & 7.0 & 8.6 & 9.6 & 10.7 & 4.6 & 4.2 & 4.6 & 4.7 & 6.9 \\
\hline Transport and Communication & 9.2 & 10.5 & 10.3 & 11.9 & 17.1 & 6.7 & 8.4 & 9.7 & 11.7 & 19.9 & 8.3 & 10.0 & 10.2 & 10.9 & 16.5 \\
\hline Leisure and Culture & 3.3 & 2.8 & 3.1 & 3.8 & 4.0 & 3.1 & 2.8 & 3.8 & 3.9 & 4.4 & 1.4 & 1.6 & 1.7 & 1.5 & 2.3 \\
\hline Hotels and Restaurants & 12.2 & 9.3 & 9.4 & 7.5 & 5.7 & 14.6 & 8.2 & 6.7 & 5.9 & 3.6 & 11.8 & 6.1 & 3.6 & 4.5 & 2.7 \\
\hline Divers Goods and Services & 4.9 & 5.5 & 5.5 & 4.6 & 4.4 & 4.3 & 3.8 & 3.8 & 4.2 & 4.4 & 4.4 & 4.3 & 4.4 & 4.6 & 5.0 \\
\hline
\end{tabular}


(Table 4.3 continued)

\begin{tabular}{|c|c|c|c|c|c|c|c|c|c|c|c|c|c|c|c|}
\hline \multirow{2}{*}{$\begin{array}{l}\text { Country } \\
\text { Quintile (Total Expenditure) }\end{array}$} & \multicolumn{5}{|c|}{ Niger - Niamey } & \multicolumn{5}{|c|}{ Senegal - Dakar } & \multicolumn{5}{|c|}{ Togo - Lomé } \\
\hline & 1 & 2 & 3 & 4 & 5 & 1 & 2 & 3 & 4 & 5 & 1 & 2 & 3 & 4 & 5 \\
\hline Food and Non-Alcoholic Beverages & 41.3 & 48.9 & 44.9 & 40.6 & 29.9 & 40.1 & 43.3 & 42.3 & 40.1 & 30.0 & 28.7 & 33.2 & 34.7 & 33.1 & 29.9 \\
\hline Alcoholic Beverages and Tobacco & 7.3 & 3.7 & 4.2 & 2.2 & 3.4 & 4.4 & 1.2 & 2.9 & 1.7 & 1.4 & 6.9 & 6.6 & 4.0 & 4.8 & 4.0 \\
\hline Clothing and Shoes & 5.9 & 6.8 & 8.1 & 8.4 & 7.9 & 5.5 & 5.6 & 5.2 & 5.1 & 6.0 & 7.6 & 7.6 & 9.1 & 8.7 & 9.5 \\
\hline Gas, Electricity and Water & 8.5 & 7.5 & 6.1 & 7.6 & 8.4 & 10.2 & 9.4 & 9.6 & 8.6 & 7.5 & 5.9 & 5.7 & 4.8 & 5.9 & 5.6 \\
\hline Furniture and Household Maintenance & 3.9 & 4.6 & 6.1 & 5.6 & 7.2 & 5.3 & 4.4 & 5.4 & 5.9 & 7.2 & 4.5 & 4.3 & 3.8 & 4.2 & 5.0 \\
\hline Health and Education & 3.5 & 3.4 & 4.9 & 5.4 & 7.1 & 3.6 & 4.6 & 4.7 & 5.7 & 8.8 & 5.3 & 5.9 & 7.3 & 7.0 & 10.2 \\
\hline Transport and Communication & 6.1 & 5.8 & 5.8 & 7.8 & 16.8 & 5.3 & 4.7 & 4.7 & 7.6 & 13.8 & 9.4 & 7.9 & 8.7 & 10.0 & 13.4 \\
\hline Leisure and Culture & 2.1 & 1.8 & 2.5 & 2.9 & 3.6 & 2.3 & 2.9 & 2.4 & 2.6 & 3.9 & 2.9 & 2.9 & 2.8 & 2.7 & 3.3 \\
\hline Hotels and Restaurants & 13.6 & 7.0 & 7.3 & 6.8 & 4.0 & 10.8 & 6.1 & 2.7 & 2.4 & 2.2 & 13.2 & 13.1 & 11.0 & 10.2 & 7.7 \\
\hline Divers Goods and Services & 3.8 & 3.4 & 4.4 & 4.0 & 4.2 & 4.0 & 4.2 & 3.8 & 4.8 & 4.3 & 7.5 & 6.2 & 6.9 & 7.2 & 5.8 \\
\hline
\end{tabular}

Note: Authors' calculation based on 1-2-3 Surveys. 
Table 4.4 - National Annual Household Expenditure Shares by Sector and Distribution Channel (percent)

\begin{tabular}{|c|c|c|c|c|c|c|c|c|c|c|c|c|}
\hline \multirow{2}{*}{$\begin{array}{l}\text { Country } \\
\text { Distribution Channel }\end{array}$} & \multicolumn{2}{|c|}{ Benin - Cotonou } & \multicolumn{2}{|c|}{ Burkina Faso - Ouaga } & \multicolumn{2}{|c|}{ Mali - Bamako } & \multicolumn{2}{|c|}{ Niger - Niamey } & \multicolumn{2}{|c|}{ Senegal - Dakar } & \multicolumn{2}{|c|}{ Togo - Lomé } \\
\hline & formal & informal & formal & informal & formal & informal & Formal & informal & formal & informal & formal & informal \\
\hline Food and Non-Alcoholic Beverages & 2.0 & 27.0 & 1.1 & 28.5 & 0.4 & 34.5 & 0.5 & 35.8 & 1.0 & 35.4 & 0.3 & 33.0 \\
\hline Alcoholic Beverages and Tobacco & 0.2 & 1.5 & 0.1 & 2.7 & 0.0 & 0.5 & 0.0 & 1.1 & 0.0 & 0.7 & 0.1 & 1.8 \\
\hline Clothing and Shoes & 1.4 & 4.7 & 0.8 & 5.8 & 1.0 & 6.2 & 1.1 & 6.1 & 0.9 & 4.3 & 0.2 & 8.3 \\
\hline Housing & 0.5 & 13.9 & 0.7 & 10.5 & 0.9 & 15.0 & 0.4 & 12.8 & 1.7 & 16.0 & 0.1 & 9.7 \\
\hline Gas, Electricity and Water & 4.0 & 2.9 & 4.3 & 2.4 & 6.0 & 3.6 & 4.3 & 3.3 & 5.0 & 3.3 & 3.0 & 2.4 \\
\hline Furniture and Household Maintenance & 0.8 & 3.1 & 0.5 & 4.1 & 0.4 & 4.9 & 0.6 & 5.1 & 0.7 & 5.3 & 0.2 & 4.3 \\
\hline Health and Education & 7.6 & 0.9 & 7.7 & 1.7 & 3.7 & 1.6 & 4.5 & 1.3 & 5.3 & 1.1 & 6.3 & 1.5 \\
\hline Transport and Communication & 6.4 & 8.3 & 8.3 & 8.0 & 5.4 & 8.0 & 6.7 & 5.7 & 6.5 & 3.4 & 3.0 & 7.8 \\
\hline Leisure and Culture & 1.4 & 1.7 & 1.3 & 2.5 & 0.4 & 1.3 & 0.8 & 1.9 & 1.3 & 1.6 & 1.0 & 1.5 \\
\hline Hotels and Restaurants & 0.5 & 6.5 & 0.4 & 4.5 & 0.2 & 1.5 & 0.6 & 4.0 & 0.4 & 1.9 & 0.4 & 8.9 \\
\hline Divers Goods and Services & 1.0 & 3.7 & 0.6 & 3.5 & 0.7 & 3.5 & 0.6 & 3.0 & 0.8 & 3.3 & 0.4 & 5.8 \\
\hline
\end{tabular}

Note: Authors' calculation based on 1-2-3 Surveys. 
Turning to the classification by expenditure categories, a clear pattern emerges where the informal distribution channel predominates for all four types of expenditures (Table 4.5). This is most obviously the case for informal goods, which are hardly ever sold via formal distribution channels. Comparing the six capitals, demand for formal goods is found to be highest in Dakar, but even there the bulk of products are distributed informally. Overall, formal-informal demand relationships do not appear to vary systematically with income per capita. For example, the demand share for informal goods is lower in the poorest country, Niger (15 percent), than in the richest country, Senegal (18 percent). This lack of a clear relationship may reflect that cross-country differences in per capita income are not sufficiently pronounced. Strikingly, Togo has the lowest expenditure shares on both formal goods and goods distributed via formal distribution channels and at the same time exhibits by far the worst governance indicators among the countries under consideration. Import shares vary considerably across countries, ranging from 15 percent in Dakar to 38 percent in Niamey. Around 30 percent of all imported goods in Cotonou, Ouagadougou and Bamako are produced in other (mainly neighboring) African countries, while this figure is substantially higher in Niamey (46 percent) and substantially lower in Dakar (9 percent).

Table 4.5 - National Annual Household Expenditure Shares by Product Category (percent)

\begin{tabular}{|c|c|c|c|c|c|c|}
\hline Country & $\begin{array}{l}\text { Benin - } \\
\text { Cotonou }\end{array}$ & $\begin{array}{c}\text { Burkina } \\
\text { Faso - } \\
\text { Ouaga }\end{array}$ & $\begin{array}{c}\text { Mali - } \\
\text { Bamako }\end{array}$ & $\begin{array}{l}\text { Niger - } \\
\text { Niamey }\end{array}$ & $\begin{array}{c}\text { Senegal - } \\
\text { Dakar }\end{array}$ & $\begin{array}{l}\text { Togo - } \\
\text { Lomé }\end{array}$ \\
\hline \multicolumn{7}{|l|}{ Budget share formal goods } \\
\hline Formal distribution channel & 4.3 & 5.5 & 7.2 & 4.5 & 8.3 & 0.4 \\
\hline Informal distribution channel & 9.5 & 11.9 & 15.1 & 9.3 & 22.2 & 7.2 \\
\hline \multicolumn{7}{|l|}{ Budget share informal goods } \\
\hline Formal distribution channel & 0.7 & 0.5 & 0.3 & 0.1 & 0.5 & 0.1 \\
\hline Informal distribution channel & 17.1 & 17.3 & 25.5 & 15.0 & 17.7 & 21.7 \\
\hline \multicolumn{7}{|l|}{ Budget share imported goods } \\
\hline Formal distribution channel & 10.0 & 10.1 & 5.2 & 6.7 & 4.1 & 8.8 \\
\hline Informal distribution channel & 18.3 & 21.9 & 16.5 & 31.6 & 11.3 & 24.5 \\
\hline \multicolumn{7}{|l|}{ Budget share services } \\
\hline Formal distribution channel & 10.7 & 9.5 & 6.4 & 8.6 & 10.7 & 6.1 \\
\hline Informal distribution channel & 29.4 & 23.2 & 23.7 & 24.1 & 25.1 & 31.3 \\
\hline
\end{tabular}


Table 4.6 reveals that expenditures by informal households as defined above are by no means restricted to informal goods and informal distribution channels. In Cotonou, for example, these households account for more than a third of total expenditures on formally distributed formal goods (36.8 percent) and formally distributed imports (34.6 percent). Irrespective of product category, distribution channel and city, their expenditure share is in no case lower than 20 percent. Conversely, the fact that the expenditure share of informal households in no case exceeds 60 percent implies that formal households are important buyers of informal goods and goods distributed through informal channels, which points to a strong overlapping customer base.

Overall, this section has shown that significant formal-informal linkages exist in the six West African capitals. They may well be strong enough to affect the pattern of estimated demand elasticities, to which we will turn in the next section, in a way that eludes the notion of a simple formal-informal sector dichotomy.

Table 4.6 - National Shares of Informal Households in Overall Expenditures (percent)

\begin{tabular}{|c|c|c|c|c|c|c|}
\hline Country & $\begin{array}{l}\text { Benin - } \\
\text { Cotonou }\end{array}$ & $\begin{array}{c}\text { Burkina Faso } \\
\text { - Ouaga }\end{array}$ & $\begin{array}{c}\text { Mali- } \\
\text { Bamako }\end{array}$ & $\begin{array}{l}\text { Niger - } \\
\text { Niamey }\end{array}$ & $\begin{array}{c}\text { Senegal - } \\
\text { Dakar }\end{array}$ & Togo - Lomé \\
\hline \multicolumn{7}{|l|}{ Goods } \\
\hline \multicolumn{7}{|l|}{ Formal goods } \\
\hline Formal distribution channel & 36.8 & 24.1 & 31.0 & 48.1 & 26.2 & 35.5 \\
\hline Informal distribution channel & 50.0 & 39.7 & 43.7 & 50.5 & 34.6 & 56.3 \\
\hline \multicolumn{7}{|l|}{ Informal goods } \\
\hline Formal distribution channel & 27.0 & 37.4 & 24.3 & 56.2 & 33.8 & 55.4 \\
\hline Informal distribution channel & 49.6 & 42.1 & 46.1 & 49.1 & 35.2 & 57.5 \\
\hline \multicolumn{7}{|l|}{ Imported goods } \\
\hline Formal distribution channel & 34.6 & 24.3 & 31.5 & 35.2 & 24.5 & 48.0 \\
\hline Informal distribution channel & 48.5 & 38.2 & 41.8 & 51.8 & 34.5 & 56.7 \\
\hline \multicolumn{7}{|l|}{ Services } \\
\hline Formal distribution channel & 36.0 & 24.8 & 34.3 & 43.2 & 20.8 & 48.6 \\
\hline Informal distribution channel & 35.5 & 26.9 & 28.3 & 37.1 & 18.4 & 48.4 \\
\hline
\end{tabular}

Note: Informal Households are defined as those for whom the informal sector is the primary income source. From each cell, expenditure shares of formal households can be calculated as 100 percent minus the expenditure share of informal households. The expenditure share of formal households on formal goods distributed through formal distribution channels in Benin, for example, is $100-36.8=63.2$; Authors' calculation based on 1-2-3 Surveys. 


\subsection{Estimation of Engel Curves}

\section{Hypotheses}

While demand estimation is often primarily concerned with quantities, consumers also face a quality choice (Deaton 1988, Blundell and Stoker 2005). Consequently the observed expenditure patterns will be conditioned by price, quantity and quality of the available products. Merella (2006) has shown that Engel Curves depend on the assumption of constant quality. With increasing quality of a product the marginal utility of this same product would not decline. Based on this assumption the author asserts that increasing income will first affect the quantity of products bought and only thereafter the shift between products due to quality differences. More generally, poor households will be concerned primarily with subsistence and therefore quantity while rich households' consumption is driven by quality differences in goods. This theory has implicitly been corroborated in prior studies (e.g. Wan 1996) where food and shelter - which are necessities and are expected to show an elasticity coefficient that is greater than zero but less then unity - have been found to be treated as a luxury by extremely poor households.

Recently, Banerji and Jain (2007) introduced a new perspective by arguing that the dynamics of the informal sector are also driven by changes in consumer demand. At the core of their argument stands the observation that there is a marked quality difference between formal and informal goods and services. Accordingly, the informal sector caters to a consumer base that is not able to pay high prices for high quality.

From these theoretical considerations a testable hypothesis can be derived. If Banerji and Jain (2007) are correct and formal and informal goods and services differ markedly in their quality, we have to expect significantly different income elasticities for the same goods produced or sold by formal and informal enterprises. If, in addition, Merella (2006) is right then we should observe smaller income elasticities for low quality products, i.e. informal sector products. To obtain a rough indication of whether quality differences exist, we compared the unit prices between informal and formal points of sale following the trade literature (e.g. Fontagne et al. 2006). Out of the product and service categories we were able to compare on a disaggregated level, 46 percent showed significantly different unit prices, and in 96 percent of these cases the mean unit price was found to be lower for the informal point of sale. While these results are suggestive of quality differences, we have to interpret them cautiously given that the aggregation and the enormous variance in prices could drive the differences. In addition, the fairly strong formal-informal linkages we find suggest that demand for informal goods and distribution channels is not exclusively driven by quality dualism, but may also reflect positive characteristics of the informal sector such as flexibility in terms 
of longer opening hours or less paperwork that are valued by formal consumers. The existing linkages may lead to a more nuanced picture of elasticity estimates.

\section{Methodology}

To answer the question of whether customers behave differently vis-á-vis formal and informal products and distribution channels we estimate demand elasticities for different aggregated production sectors and different types of expenditures as defined above. As predicted by neoclassical consumer theory private demand for goods and services is a function of disposable income and prices. Since the data we work with is cross-sectional, estimations have to be simplified assuming prices to be constant across observations. The corresponding specifications, known as Engel curves, represent the evolution of Marshallian demand functions for a particular good or service category as income varies, holding the prices for all goods constant.

Deciding on whether to estimate the Engel curves by means of a simultaneous equation approach or equation by equation involves a trade-off. On the one hand, estimating a demand system would allow us to account for the restrictions required by utility-based demand theory such as the adding-up criterion. A Breusch and Pagan test in a number of cases rejects the null hypothesis of no correlation among the error terms of different equations, pointing to interdependencies between demand categories. On the other hand, the equation-by-equation approach has the advantage that mis-specified equations do not affect overall results, which we consider to be especially relevant given the strong indications of differences in functional forms between demand categories (see below). We therefore decided to present estimates equation by equation as our preferred approach, but also estimated demand systems for both sectors and expenditure categories. The results of these estimations are shown in the Appendix; a brief comparison of the two sets of results is given below.

Since non-parametric Kernel density regressions as well as formal Ramsey RESET tests point to the absence of non-linearities in all but two cases (see below), we adopt a simple linear doublelogarithmic model as our base specification. ${ }^{25}$ The equation fitted takes the following form:

$x_{i j}=\beta_{0 j}+\beta_{1 i j} x_{i}+\beta_{2 i j} H_{i}+\beta_{3 i j} D_{i}+\sum_{k=1}^{L} \gamma_{k i j}\left(m_{i}\right)+u_{i j} \quad i=1, \ldots M$ and $j=1, \ldots N$

with: $\quad x_{i}=\sum_{j=1}^{N} x_{i j}$

\footnotetext{
${ }^{25}$ See Blundell and Duncan (1998) for a detailed discussion of household expenditure and non-parametric kernel regressions.
} 
where $x_{i j}$ is the log of expenditure of household $i$ on product category $j, x_{i}$ is the log of household income, $H_{i}$ is the log of household size in adult equivalents, $m_{i}$ are $L$ different household characteristics including age, sex and religion of the household head, household composition variables such as a dummy for elderly members, an indicator of primary school completion of the household head, and sector of employment of the household head, and $D_{i}$ are district dummies.

While we include the additional control variables primarily to account for household heterogeneity, the occupation variable also allows us to test the hypothesis (e.g. Fortin et al. 2000) that being employed in the informal sector raises the likelihood of consuming informal goods and services. Concerning household size, we performed robustness checks using simple household size instead of equivalence scales as predictor variables, which hardly affected our results. Likewise, results do not change when we employ years of schooling rather than primary completion as an indicator of education.

When estimating the Engel curves, several challenges arise. One problem is that observed income might not be the main driver of expenditure behavior. More specifically, we have to consider the possible seasonal volatility of employment and earnings which casts doubt on the appropriateness of monthly income as a representation of disposable annual income. Thus, we use total expenditure as a proxy of income, even though our data contains information about declared monthly income from primary and secondary employment as well as income from other sources such as remittances and assets for all household members. A further justification for using total expenditure instead of total income is based on the permanent-income hypothesis. Accordingly, expenditure will be conditional upon long-run income rather than transitory income, even though it has to be conceded that consumption smoothing in West Africa is likely to be far from perfect as a result of liquidity constraints. ${ }^{26}$ While the use of total expenditure can lead to biased or even inconsistent estimation results given that it is only a proxy of income, various authors (e.g. Lewbel 1996, Gibson 2002) have argued that this bias tends to be small compared to the bias introduced by using transitory income.

Using total expenditure does, however, introduce an econometric complication, namely the possible correlation of the independent variable with the error term since by definition our dependent variable, the expenditure on different product categories and types, will always be part of the explanatory variable. This possible simultaneity bias calls for the use of instrumental variables. In addition, measurement error in household survey data is a well-known problem in demand estimation (Liviatan 1961, Griliches 1974, Theil 1979, Keen 1986, Lewbel 1996, Hausman 2001). This

\footnotetext{
${ }^{26}$ For a general discussion of whether income or expenditure constitutes the preferred welfare indicator in the context of developing countries, see for example Deaton (1997).
} 
problem can also be mitigated by using instrumental variables. Based on the classical errors-in variables assumption that presumes a correlation between the observed variable and the error term one would expect the OLS estimator to be closer to zero than the true estimator represented by a valid IV coefficient. Several authors have pointed to exceptions to this rule in the context of demand analysis (e.g. Keen 1986; Liviatan 1961). Most recently, Gibson and Bonggeun (2007: 479) have asserted that "[...] only some form of correlated error could cause" the coefficient "to be biased downwards".

In the context of consumer behavior most of the previous studies have instrumented total expenditure by monthly income (e.g. Lewbel 1996, Kedir and Girma 2007). We also did so, but additionally employed a wealth index, given that it seems plausible to assume that household wealth will also influence the observed expenditure patterns, perhaps even more so than current income. We constructed a wealth index, using a principal components analysis along the lines of, for example, McKenzie (2005) and Filmer and Pritchett (2001). In doing so, we converted all available wealth and asset variables (housing characteristics, access to infrastructure and durable assets) into binary ones, except for the number of rooms in the household. One of the main advantages of such an index is that it reduces measurement error. Since reporting errors in household income and household wealth cannot be ruled out, we additionally considered an instrumentation strategy using variables that describe the activity portfolio of the household (number of fixed-contract wage earners in the household; share of wages/salaries from public sector, primary sector, industrial sector, commercial sector and service sector) as well as job characteristics (sector of occupation; type of job; type of contract; type of wage payment; hours worked) of the household head and the main wage earner in the household. ${ }^{27}$

We started our empirical analysis by employing ordinary least-squares (OLS) estimation techniques. The explanatory power of this simple model is rather good; in almost all cases up to one half of the observed variation can be explained. As already noted above, a non-parametric analysis of the data pointed to a non-linear relationship in some cases, which was confirmed by a formal Ramsey RESET test. Specifically, we had to reject the null hypothesis of no omitted variables and therefore our linear specification for food and non-alcoholic beverages at the 1 percent level and for transport and communication at the 5 percent level for all countries in favour of a more flexible specification. To account for these test results we included a quadratic term of the log of total expenditure for these two categories.

\footnotetext{
${ }^{27}$ We thank an anonymous referee for pointing us to this option.
} 
Using a Hausman test we can reject the null hypothesis of endogeneity of the log of total expenditure for all sectors apart from Food and Non-alcoholic Beverages as well as Electricity, Gas and Water. By contrast, the Hausman test points to potential endogeneity for all four expenditure categories (formal goods, informal goods, imports, services) at least in some of the countries. Accordingly, we performed two-stage least-squares (2SLS) estimations for our linear specifications when this was suggested by the test results. We found no evidence of endogeneity in the non-linear specifications for Food and Transport and therefore did not employ the 2SLS approach for this setup.

To evaluate the strength of our proposed instrumental variables we applied the test suggested by Staiger and Stock (1997) and Stock and Yogo (2002). According to this test, income and the wealth index are strong instruments, The $\mathrm{F}$ value of the wealth index being somewhat higher throughout, whereas the indicators of activity portfolio and job characteristics generally turn out to be weak instruments.

\subsection{Estimation Results}

Our OLS estimates at the sectoral level displayed in Table 4.7 are in line with the findings of prior studies for East Africa (Massel and Heyer 1969, Ostby and Gulilat 1969, Humphrey and Oxley 1976, Okunade 1985, Teklu 1996) and for other developing countries such as India and China (e.g. Tiwari and Goel 2002, Chern and Wang 1994). In particular, we find Food and Non-alcoholic Beverages as well as Alcoholic Beverages and Tobacco to be necessary goods as suggested by Engel's law. An increase of one percent in disposable income would on average lead to an increase of expenditure on food and non-alcoholic beverages of 0.77 percent in the six countries. ${ }^{28}$ Clothing and Shoes, Furniture, Health and Education, Transport and Communication as well as Leisure and Culture turn out to be luxury goods in all countries under consideration. The low demand elasticities for hotels and restaurants may appear somewhat surprising, but the previous literature is inconclusive as to whether food-away-from home - for hotels, there is no comparable evidence - constitutes a necessity or a luxury good (Byrne et al. 1996, Min et al. 2000).

\footnotetext{
${ }^{28}$ We get virtually the same result when pooling the data from the six capitals (see last column of Table 4.7).
} 
Table 4.7 - Budget Elasticities for Sectors (OLS)

\begin{tabular}{|c|c|c|c|c|c|c|c|c|}
\hline Country & $\begin{array}{l}\text { Benin - } \\
\text { Cotonou }\end{array}$ & $\begin{array}{c}\text { Burkina } \\
\text { Faso - } \\
\text { Ouaga }\end{array}$ & $\begin{array}{c}\text { Mali - } \\
\text { Bamako }\end{array}$ & $\begin{array}{l}\text { Niger - } \\
\text { Niamey }\end{array}$ & $\begin{array}{c}\text { Senegal - } \\
\text { Dakar }\end{array}$ & $\begin{array}{l}\text { Togo - } \\
\text { Lomé }\end{array}$ & Pooled $^{a}$ & $\begin{array}{c}\text { Pooled } \\
\text { Obs }\end{array}$ \\
\hline \multicolumn{9}{|l|}{ Elasticities by Sector } \\
\hline Food and Non-Alcoholic Beverages & $0.80^{* * *}$ & $0.76^{* * *}$ & $0.77^{* * *}$ & $0.74^{* * *}$ & $0.80^{* * *}$ & $0.95^{* * *}$ & $0.80^{* * *}$ & 4160 \\
\hline Alcoholic Beverages and Tobacco & $0.87 * * *$ & $0.84^{* * *}$ & $0.51^{* * *}$ & 0.28 & 0.16 & $0.74^{* * *}$ & $0.57^{* * *}$ & 1601 \\
\hline Clothing and Shoes & $1.07^{* * *}$ & $1.14^{* * *}$ & $1.19^{* * *}$ & $1.17^{* * *}$ & $1.24^{* * *}$ & $1.27^{* * *}$ & $1.14^{* * *}$ & 3696 \\
\hline Housing & $0.68^{* * *}$ & $0.64^{* * *}$ & $0.48^{* * *}$ & $0.59^{* * *}$ & $0.81^{* * *}$ & $0.42^{* * *}$ & $0.70^{* * *}$ & 4159 \\
\hline Gas, Electricity and Water & $0.87^{* * *}$ & $0.86^{* * *}$ & $1.18^{* * *}$ & $0.90^{* * *}$ & $0.79 * * *$ & $0.86^{* * *}$ & $0.97^{* * *}$ & 4138 \\
\hline Furniture and Household Maintenance & $1.23^{* * *}$ & $1.19 * * *$ & $1.24 * * *$ & $1.27^{* * *}$ & $1.36^{* * *}$ & $1.15^{* * *}$ & $1.21 * * *$ & 3868 \\
\hline Health and Education & $1.24^{* * *}$ & $1.32^{* * *}$ & $1.26^{* * *}$ & $1.28^{* * *}$ & $1.48^{* * *}$ & $1.33^{* * *}$ & $1.25^{* * *}$ & 3948 \\
\hline Transport and Communication & $1.36^{* * *}$ & $1.75^{* * *}$ & $1.68^{* * *}$ & $1.71^{* * *}$ & $1.85^{* * *}$ & $1.38^{* * *}$ & $1.57^{* * *}$ & 3962 \\
\hline Leisure and Culture & $1.11^{* * *}$ & $1.18^{* * *}$ & $1.27^{* * *}$ & $1.32^{* * *}$ & $1.39^{* * *}$ & $1.22^{* * *}$ & $1.15^{* * *}$ & 3416 \\
\hline Hotels and Restaurants & $0.55^{* * *}$ & $0.39 * * *$ & $0.42^{* * *}$ & $0.50^{* * *}$ & $0.41^{* * *}$ & $0.58^{* * *}$ & $0.42^{* * *}$ & 3198 \\
\hline Diverse Goods and Services & $0.84^{* * *}$ & $1.07^{* * *}$ & $1.12^{* * *}$ & $1.01 * * *$ & $1.16^{* * *}$ & $0.86^{* * *}$ & $1.01 * * *$ & 3888 \\
\hline \multicolumn{9}{|l|}{ Elasticities by Sector (2SLS) } \\
\hline Food and Non-Alcoholic Beverages & $0.59^{* * *}$ & $0.52^{* * *}$ & $0.49^{* * *}$ & $0.34^{* * *}$ & $0.52^{* * *}$ & $0.49^{* * *}$ & $0.51^{* * *}$ & 4160 \\
\hline Gas, Electricity and Water & $1.04^{* * *}$ & $1.29 * * *$ & $1.55^{* * *}$ & $1.37 * * *$ & $1.04 * * *$ & $1.56^{* * *}$ & $1.30^{* * *}$ & 4138 \\
\hline
\end{tabular}

Note: Dependent Variable is $\log$ of total household expenditure on a specific product group; Independent Variable is log of total household expenditure; Included Control Variables are district dummies, log number of household members (OECD-modified Adult Equivalent Scale), share of adult women in the household, elderly in the household, type of family structure, gender of household head, age of household head, completed primary education of household head, religion of household head (Muslim or Catholic Christian) and informal sector is source of household head's primary income; ${ }^{* * *} \mathrm{p}<0.01,{ }^{* *} \mathrm{p}<0.05,{ }^{*} \mathrm{p}<0.1$ based on robust standard errors; a includes country dummies; Authors' calculation based on 1-2-3 Surveys.

When comparing these results with the demand system estimation shown in the Appendix, it turns out that the pattern of elasticities is very similar, even though in a number of cases the point estimates differ quite substantially between the two approaches. Both approaches suggest that Clothing and Shoes, Furniture, Health and Education, Transport and Communication as well as Culture and Leisure are luxuries, whereas Food and Non-alcoholic Beverages, Housing as well as Hotels and Restaurants tend to be necessities. 
In the lower part of Table 4.7 we report selected results for the 2SLS estimations using the wealth index as an instrumental variable. ${ }^{29}$ According to the tests performed, Food and Non-alcoholic Beverages, as well as Electricity, Gas and Water are the only sectors where we are advised to perform an instrumental variable estimation. For these sectors, differences between OLS and 2SLS estimates turn out to be substantial. Food and Non-alcoholic Beverages are shown to follow Engel's law even more clearly when using 2SLS as indicated by lower budget elasticities in all countries under consideration, while Electricity, Gas and Water switches from being a necessity to being a luxury good.

Among the additional control variables, household size uniformly has a positive and significant influence on food expenditures. Its impact on expenditures is significantly negative throughout for Transport and Communication and in some countries also for Shoes and Clothing as well as Furniture and Household Maintenance. These findings are in line with economies of scale concerning these commodities. In several cases, the gender of the household head turns out to be another important determinant of expenditures, pointing to gender-specific preferences and intra-household bargaining. All else being equal, households headed by a male tend to spend less on Food as well as Health and Education, and more on Transport and Communication as well as Leisure and Culture. We also find that being Catholic or Muslim has a significantly negative effect on alcohol and tobacco expenditures in all countries except Mali.

The quadratic OLS estimations are shown in Table 4.8. Recall that the RESET test points to a nonlinear specification only in the case of Food and Beverages as well as Transport and Communication. We find that the elasticity function for Food and Beverages is concave, which is in line with the saturation hypothesis. We also observe that the turning point (the maximum) is located in the $10^{\text {th }}$ expenditure decile in all countries; it is comparatively higher in Benin and Senegal than in the other countries. Given that the turning point is located very close to the maximum of the income range of households, our finding arguably does not invalidate Engel's law. For Transport and Communication the elasticity function is first falling with income and after a certain threshold point increasing again. ${ }^{30}$ In this case the turning point is a minimum, which is lowest in Benin and Togo and highest in Niger, but practically irrelevant as it is located outside the observable income range.

\footnotetext{
${ }^{29}$ Robustness checks using the other two instrumentations (not shown; available upon request) left results qualitatively unaffected.

${ }^{30}$ See Diaz et al. (2008) for a survey of transport expenditures in Sub-Saharan Africa.
} 
Table 4.8 - Budget Elasticities for Sectors, Quadratic Specification (OLS)

\begin{tabular}{|c|c|c|c|c|c|c|c|c|c|c|c|c|}
\hline \multirow{2}{*}{$\begin{array}{l}\text { Country } \\
\text { Elasticities by Sector }\end{array}$} & \multicolumn{2}{|c|}{ Benin - Cotonou } & \multicolumn{2}{|c|}{ Burkina Faso - Ouaga } & \multicolumn{2}{|c|}{ Mali - Bamako } & \multicolumn{2}{|c|}{ Niger - Niamey } & \multicolumn{2}{|c|}{ Senegal - Dakar } & \multicolumn{2}{|c|}{ Togo - Lomé } \\
\hline & EXP & EXP2 & EXP & EXP2 & EXP & $E X P^{2}$ & EXP & EXP2 & EXP & EXP2 & EXP & $E X P^{2}$ \\
\hline Food and Non-Alcoholic Beverages & $4.47^{* * *}$ & $-0.13^{* * *}$ & $7.11 * * *$ & $-0.23 * * *$ & $8.03^{* * *}$ & $-0.25^{* * *}$ & $7.67^{* * *}$ & $-0.25^{* * *}$ & $6.06^{* * *}$ & $-0.18^{* *}$ & $5.098^{* * *}$ & $-0.19^{* * *}$ \\
\hline Marginal Effects & \multicolumn{2}{|c|}{0.84} & \multicolumn{2}{|c|}{0.81} & \multicolumn{2}{|c|}{0.80} & \multicolumn{2}{|c|}{0.81} & \multicolumn{2}{|c|}{0.79} & \multicolumn{2}{|c|}{0.98} \\
\hline Standard Errors & \multicolumn{2}{|c|}{0.04} & \multicolumn{2}{|c|}{0.02} & \multicolumn{2}{|c|}{0.03} & \multicolumn{2}{|c|}{0.05} & \multicolumn{2}{|c|}{0.04} & \multicolumn{2}{|c|}{0.05} \\
\hline Observations & \multicolumn{2}{|c|}{568} & \multicolumn{2}{|c|}{933} & \multicolumn{2}{|c|}{953} & \multicolumn{2}{|c|}{571} & \multicolumn{2}{|c|}{567} & \multicolumn{2}{|c|}{568} \\
\hline $\mathrm{R}^{2}$ & \multicolumn{2}{|c|}{0.69} & \multicolumn{2}{|c|}{0.68} & \multicolumn{2}{|c|}{0.66} & \multicolumn{2}{|c|}{0.54} & \multicolumn{2}{|c|}{0.65} & \multicolumn{2}{|c|}{0.60} \\
\hline Transport and Communication & $-2.89 *$ & $0.15^{* *}$ & 0.47 & 0.05 & $-4.88^{* *}$ & $0.23^{* * *}$ & $-9.57^{* * *}$ & $0.40^{* * *}$ & $-6.44 * * *$ & $0.29 * * *$ & $-3.37 * *$ & $0.18^{* * *}$ \\
\hline Marginal Effects & \multicolumn{2}{|c|}{1.31} & \multicolumn{2}{|c|}{1.74} & \multicolumn{2}{|c|}{1.65} & \multicolumn{2}{|c|}{1.62} & \multicolumn{2}{|c|}{1.86} & \multicolumn{2}{|c|}{1.35} \\
\hline Standard Errors & & 07 & & 0.05 & & 08 & & .08 & & .09 & & .07 \\
\hline Observations & & 60 & & 880 & & 68 & & 531 & & 563 & & 60 \\
\hline $\mathrm{R}^{2}$ & & 66 & & 0.64 & & 46 & & .56 & & .57 & & .50 \\
\hline
\end{tabular}

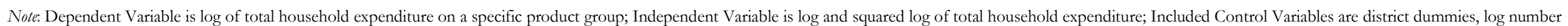
of household members (OECD-modified Adult Equivalent Scale), share of adult women in the household, elderly in the household, type of family structure, gender of household head, age of household head, completed primary education of household head, religion of household head (Muslim or Catholic Christian) and informal sector is source of household head's primary income; ${ }^{* * *} \mathrm{p}<0.01,{ }^{* *} \mathrm{p}<0.05,{ }^{*} \mathrm{p}<0.1$ based on robust standard errors; Authors' calculation based on 1-2-3 Survey. 
The estimates shown in Table 4.9 allow us to assess the hypothesis of quality dualism as they capture the distinction between formal and informal goods and distribution channels. A very clear pattern emerges for formal goods: In all countries the demand elasticity is substantially above unity for formal provision and substantially below unity for informal provision. Imported goods and services are also uniformly seen as luxuries when distributed via formal retailers, and in some countries (Mali, Niger, Senegal) the demand elasticity is above unity even in case of informal distribution. Informal goods exhibit elasticities far below unity across the board if they are distributed via informal distribution channels, whereas the few formal sales appear to be luxuries in Benin, Mali, Senegal and Togo. Aggregated over the two distribution channels, informal goods are in all countries considered necessities, while the opposite is true for services. Overall, our evidence broadly supports the hypothesis of quality dualism, which is also corroborated by the demand system estimates displayed in the Appendix.

Table 4.9 - Budget Elasticities for Expenditure Categories (2SLS)

\begin{tabular}{|c|c|c|c|c|c|c|c|c|}
\hline Country & $\begin{array}{l}\text { Benin - } \\
\text { Cotonou }\end{array}$ & $\begin{array}{c}\text { Burkina } \\
\text { Faso - } \\
\text { Ouaga }\end{array}$ & $\begin{array}{l}\text { Mali - } \\
\text { Bamako }\end{array}$ & $\begin{array}{l}\text { Niger - } \\
\text { Niamey }\end{array}$ & $\begin{array}{l}\text { Senegal - } \\
\text { Dakar }\end{array}$ & $\begin{array}{l}\text { Togo - } \\
\text { Lomé }\end{array}$ & Pooled $^{a}$ & $\begin{array}{c}\text { Pooled } \\
\text { Obs }\end{array}$ \\
\hline \multicolumn{9}{|l|}{$\begin{array}{l}\text { Elasticities by Expenditure Category and } \\
\text { Distribution Channel }\end{array}$} \\
\hline Elasticities of formal goods & $0.85^{* * *}$ & $1.38^{* * *}$ & $1.33^{* * *}$ & $1.22^{* * *}$ & $0.95^{* * *}$ & $0.58^{* * *}$ & $1.22^{* * *}$ & 4165 \\
\hline Formal distribution channel & $1.68^{* * *}$ & $2.26^{* * *}$ & $2.09 * * *$ & $1.87^{* * *}$ & $2.11 * * *$ & $1.79 * * *$ & $2.02^{* * *}$ & 2719 \\
\hline Informal distribution channel & $0.18^{* *}$ & $0.63^{* * *}$ & $0.48^{* * *}$ & $0.29 * * *$ & $0.38^{* * *}$ & $0.45^{* * *}$ & $0.57^{* * *}$ & 4156 \\
\hline & & & & & & & $0.63^{* * *}$ & 4131 \\
\hline Elasticities of informal goods & $0.66^{* * *}$ & $0.56^{* * *}$ & $0.45^{* * *}$ & $0.62^{* * *}$ & $0.92^{* * *}$ & $0.33^{* * *}$ & & \\
\hline Formal distribution channel & $1.28^{* * *}$ & $0.84^{* * *}$ & $1.19 *$ & -0.12 & $1.41 * * *$ & $1.78^{* * *}$ & $1.02 * * *$ & 634 \\
\hline Informal distribution channel & $0.40^{* * *}$ & $0.42^{* * *}$ & $0.33^{* * *}$ & $0.61 * * *$ & $0.63^{* * *}$ & $0.28^{* *}$ & $0.46^{* * *}$ & 4131 \\
\hline Elasticities of imported goods & $1.36 * * *$ & $1.13^{* * *}$ & $1.49 * * *$ & $0.98^{* * *}$ & $0.91^{* * *}$ & $1.55^{* * *}$ & $1.12^{* * *}$ & 4153 \\
\hline Formal distribution channel & $1.95^{* * *}$ & $1.70 * * *$ & $2.04^{* * *}$ & $2.31 * * *$ & $1.65^{* * *}$ & $3.02 * * *$ & $1.96^{* * *}$ & 3031 \\
\hline Informal distribution channel & $0.73 * * *$ & $0.66^{* * *}$ & $1.06^{* * *}$ & $0.42^{* * *}$ & $0.27 *$ & $0.91 * * *$ & $0.59 * * *$ & 4148 \\
\hline Elasticities of services & $1.26 * * *$ & $1.42^{* * *}$ & $1.32^{* * *}$ & $1.54^{* * *}$ & $1.59 * * *$ & $1.25^{* * *}$ & $1.40^{* * *}$ & 4174 \\
\hline Formal distribution channel & $2.00^{* * *}$ & $1.89 * * *$ & $1.81 * * *$ & $2.25^{* * *}$ & $2.11 * * *$ & $2.17^{* * *}$ & $1.98^{* * *}$ & 3066 \\
\hline Informal distribution channel & $0.98^{* * *}$ & $1.00^{* * *}$ & $1.09 * * *$ & $1.20^{* * *}$ & $1.25^{* * *}$ & $0.86^{* * *}$ & $1.06^{* * *}$ & 4170 \\
\hline
\end{tabular}

Note: Dependent Variable is log of total household expenditure on a specific product group; Independent Variable is log of total household expenditure which is instrumented by a wealth index; Included Control Variables are district dummies, log number of household members (OECD-modified Adult Equivalent Scale), share of adult women in the household, elderly in the household, type of family structure, gender of household head, age of household head, completed primary education of household head, religion of household head (Muslim or Catholic Christian) and informal sector is source of household head's primary income; ${ }^{* * *} \mathrm{p}<0.01, * * \mathrm{p}<0.05,{ }^{*} \mathrm{p}<0.1$ based on robust standard errors; ${ }^{\text {a }}$ includes country dummies; Authors' calculation based on 1-2-3 Surveys. 
Graphically these results are illustrated for Benin in Figure 4.1. The steep slope of the fitted values of formal distribution represents clearly the higher elasticity of this distribution channel compared to the informal channel. Using a simple Chow test we find differences in slopes and intercepts between formal and informal distribution channels to be significant throughout, for informal goods at the 10 percent level and for all other categories at the 1 percent level of significance. Regarding the household characteristics, we cannot observe clear tendencies of influence, which may at least partly reflect the high level of aggregation. Most notably, employment of the household head in the informal sector is in almost all cases statistically insignificant. This corroborates the above finding that informal households reveal no particularly strong preference for informal goods and services.

Figure 4.1 - Elasticities by Product Category and Distribution Channel in Benin
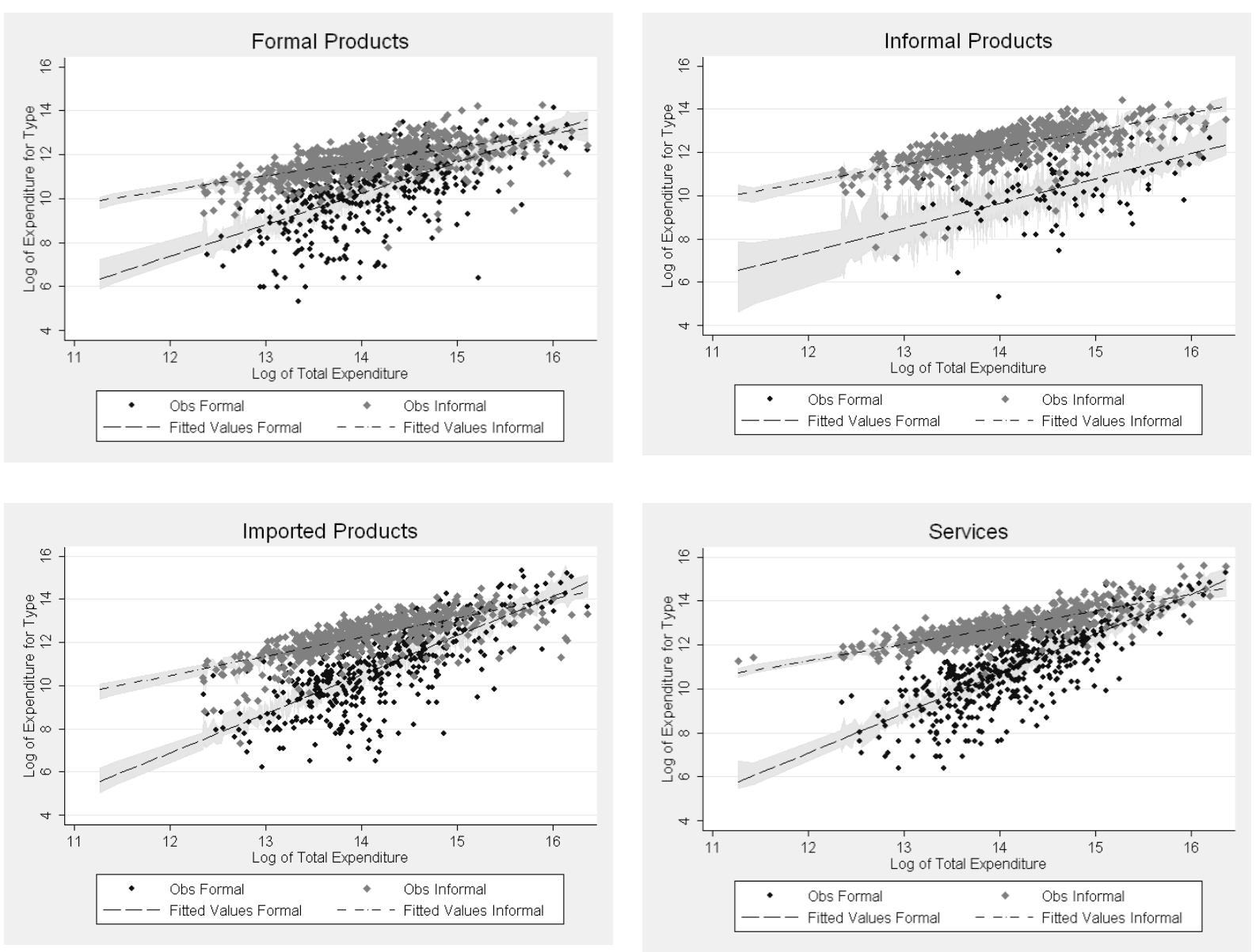

Up to now, we have considered the four expenditure categories only in the aggregate. This is because a further disaggregation dramatically reduces the number of observations. We nonetheless specifically looked at Food and Beverages as well as Transport and Communication, for which the 
number of observations is largest. ${ }^{31}$ But even in these two categories we partly run into data problems. For Food and Non-Alcoholic Beverages, only between 1 percent and 7 percent of all purchases were located in the formal sector, i.e. products that have been distributed by formal vendors. The data restriction becomes even more severe if one focuses on a single expenditure category such as formally produced domestic products. The corresponding results thus have to be interpreted very cautiously. ${ }^{32}$ For all three expenditure categories considered (services are not recorded), the estimated expenditure elasticities for formally distributed food products reveal a very mixed picture, which arguably reflects to a large part the lack of sufficient data. By contrast, a stable pattern of elasticities below unity appears for informal distribution channels, which corroborates the findings obtained at the aggregate level. Aggregated over distribution channels, the three product categories are found to be necessities in all but two cases.

For Transport and Communication, we disentangle different types of products and their distribution channels. While formal and imported goods are composed mainly of capital intensive items such as private vehicles, services are composed of public and private transport modes such as public buses and taxies. Imports and services account for the bulk of expenditures in this category. If significant, estimated demand elasticities at formal points of sale tend to exceed unity. Most notably, formally distributed formal products such as private vehicles turn out to be strong luxuries in the two richest countries, Benin and Senegal. In contrast to Food and Beverages, even the elasticities for informal distribution channels are partly above unity, suggesting that informal sales will not necessarily fall with rising incomes.

\subsection{Concluding Remarks}

In this essay, we have offered a descriptive overview of demand in six capitals of the West African Economic and Monetary Union as well as an analysis of budget elasticities for different sectors and distribution channels. Our main findings are that

(i) there is support for linkages between the formal and informal sector regarding the channels through which goods are distributed, with the exception that informal goods are hardly bought through formal distribution channels;

\footnotetext{
${ }^{31}$ Ideally, one would want to disaggregate even further so as to arrive at fairly homogenous items (e.g. single goods such as maize or millet) where quantity and quality aspects can be disentangled. This would, however, render the distinction between formal and informal distribution channels meaningless as one of them prevails. 32 To save space, we do not report the regression results here. Estimations are available from the authors' upon request.
} 
(ii) there appears to be a strongly overlapping customer base between the formal and informal sector;

(iii) rising incomes tend to lead to a lower propensity to consume informal sector goods and to use informal distribution channels.

We find little systematic variation in demand structures across countries. Most notably, expenditure shares for informal goods and informal distribution channels do not appear to be consistently higher in the richer sample countries. Macro indicators such as government effectiveness or trade openness are also hardly related to cross-country differences in demand. An interesting correlation can only be observed for Togo: it exhibits by far the worst governance indicators and at the same time has the lowest expenditure shares on both formal goods and goods distributed via formal distribution channels.

Our elasticity estimates imply that overall the development of the informal sector in West Africa will most likely be constrained from the demand side, which is in accordance with the hypothesis of quality dualism, with the informal sector being characterized by low quality. However, the pattern is not uniform, underscoring the notion of a heterogeneous informal sector put forward in studies of the supply side. Along expenditure categories, elasticities of the informal distribution channel are much higher - in some cases (e.g. Mali) even above unity - for imports and services than for domestically produced informal as well as formal goods, suggesting that importers and buyers of services tend to value certain characteristics of informal distribution channels and thus do not necessarily turn to the formal sector when their incomes rise.

The overall demand bias against the informal sector suggests that the majority of poor informal households, for example those who produce or sell food, would be affected less than proportionately by recessions. The implications for their welfare in the longer run depend on how easily they can switch to more income responsive activities. As long as the high entry barriers previously identified for West Africa (Grimm et al. 2011) continue to limit the adjustment possibilities of informal entrepreneurs, the growth process of the urban economy is unlikely to be pro-poor. In the food sector, which accounts for a large share of informal activities in all six capitals, future competition by supermarkets may even further reduce the room of maneuvering for informal households.

As concerns future research, the next step would ideally involve a further disentangling of the relation of quality and quantity by using more homogenous goods and panel data. This would allow us to mitigate the well-known difficulties caused by the aggregation of broad product groups. Another interesting area for future research would be to investigate in more detail why formalinformal demand linkages exist. 


\section{References}

Acosta, P., C. Calderón, P. Fajnzylber, and H. Lopez (2008). What is the Impact of International Remittances on Poverty and Inequality in Latin America? World Development 36(1): 89-114.

Adams, R. (1998). Remittances, Investment, and Rural Asset Accumulation in Pakistan. Economic Development and Cultural Change 47(1): 155-173.

Adams, R. H. Jr. and J. Page (2005). Do international migration and remittances reduce poverty in developing countries? World Development 33(10): 1645-1669.

Ahituv, A. and A. Kimhi (2002). Off-farm Work and Capital Accumulation Decisions of Farmers Over the Life-cycle: The Role of Heterogeneity and State Dependence. Journal of Development Economics 68(2): 329-353.

Alexander, K.L. and M.A. Cook (1979). The Motivational Relevance of Educational Plans: Questioning the Conventional Wisdom. Social Psychology Quarterly 42(3): 202-213.

Alexander, K.L., D.R. Entwisle, and S.D. Bedinger (1994). When Expectations Work: Race and Socioeconomic Differences in School Performance. Social Psychology Quarterly 57(4): 283-299.

Amegashie, F., A. Brilleau, S. Coulibaly, O. Koriko, E. Ouedraogo, F. Roubaud, and C. Torelli (2005). La Conception et la Mise en Oeuvre des Enquêtes 1-2-3 en UEMOA, les Enseignements Méthodologiques. Stateco 99: 21-42.

Amemiya, T. (1973). Regression Analysis When the Dependent Variable is Truncated Normal. Econometrica 41 (6): 997-1016.

Angrist, J. (2001). Estimation of Limited-dependent Variable Models with Binary Endogenous Regressors: Simple Strategies for Empirical Practice. Journal of Business and Economic Statistics 19(1): 2-16.

Angrist, J.D., G.W. Imbens, and D.B. Rubin (1996). Identification of Causal Effects Using Instrumental Variables. Journal of the American Statistical Association 91(434): 444-455.

Antman, F.M. (2011). The Intergenerational Effects of Paternal Migration on Schooling and Work: What Can we Learn from Children's Time Allocations? Journal of Development Economics 96(2): 200-208.

Arias, O. and M. Khamis (2008). Comparative Advantage, Segmentation and Informal Earnings: A Marginal Treatment Effects Approach. Institute for the Study of Labor (IZA), Discussion Paper, No. 3916.

Arimah, B.C. (2001). Nature and Determinants of the Linkages between Informal and Formal Sector Enterprises in Nigeria. African Development Review 13: 114-144.

Arslan, A. and J.E. Taylor (2011). Whole Household Migration, Inequality and Poverty in Rural Mexico. Kiel Working Paper 1742, Kiel Institute for the World Economy. 
Attanasio, O.P. (2009). Expectations and Perceptions in Developing Countries: Their Measurement and Their Use. American Economic Review 99 (2): 87-92.

Banerji, A. and S. Jain (2007). Quality Dualism. Journal of Development Economics 84: 234-250.

Barajas, A., R. Chami, C. Fullenkamp, M. Gapen, and P. J. Montiel (2009) Do Workers' Remittances Promote Economic Growth? International Monetary Fund, Working Paper, No. 09/153.

Batista, C. and P.C. Vicente (2011). Do Migrants Improve Governance at Home? Evidence from a Voting Experiment. World Bank Economic Review 25 (1):77-104.

Batista, C., A. Lacuesta, and P.C. Vicente (2012). Testing the 'Brain Gain' Hypothesis: Micro Evidence from Cape Verde. Journal of Development Economics 97(1): 32-45.

Beaman, L., E. Duflo, R. Pande, and P. Topalova (2012). Female Leadership Raises Aspirations and Educational Attainment for Girls: A Policy Experiment in India. Science 335: 582-586.

Beine, M. and K. Sekkat (2012). Skilled migration and the transfer of institutional norms. The Economic Research Forum. Working Paper, No. 675.

Beine, M., F. Docquier, and M. Schiff (2009). International Migration, Transfers of Norms and Home Country Fertility. Policy Research Working Paper 4925, World Bank.

Beine, M., F. Docquier, and H. Rapoport (2001). Brain Drain and Economic Growth: Theory and Evidence. Journal of Development Economics 64(1): 275-89.

Beine, M., F. Docquier, and H. Rapoport(2007). Brain Drain and Human Capital Formation in Developing Countries: Winners and Losers. The Economic Journal 118(528): 631 - 652.

Bernard, T., S. Dercon, and A. Taffesse (2011). Beyond Fatalism - an Empirical Exploration of Selfefficacy and Aspirations Failure in Ethiopia. CSAE Working Paper Series 2011-03.

Bierlen, R. and A.M. Featherstone (1998). Fundamental q, Cash Flow, and Investment: Evidence from Farm Panel Data. Review of Economics and Statistics 80 (3): 427-435.

Blunch, N.-H., S. Canagarajah, and D. Raju (2001). The Informal Sector Revisited: A Synthesis Across Space and Time. World Bank, Social Protection Discussion Paper, No. 0119.

Blundell, R. and A. Duncan (1998). Kernel Regression in Empirical Microeconomics. Journal of Human Resources 33(1): 62-87.

Blundell, R. and T.M. Stoker (2005). Heterogeneity and Aggregation. Journal of Economic Literature 43(2): 347-391.

Böhme, M. and R. Thiele (2011). Is the Informal Sector Constrained from the Demand Side? Evidence for Six West African Capitals. World Development, forthcoming.

Brilleau, A., S. Coulibaly, F. Gubert, O.Koriko, M. Kuepie, and E. Ouedraogo (2005). Le Secteur Informel: Performances, Insertion, Perspectives, Enquête 1-2-3 phase 2. Stateco 99: 65-88.

Bruhn, M. (2013). A tale of two species: Revisiting the effect of registration reform on informal business owners in Mexico. Journal of Development Economics 103: 275-283. 
Byrne, P., O. Capps Jr., and A. Saha (1996). Analysis of Food Away from Home Expenditures for U.S. Households, 1982-89. American Journal of Agricultural Economics 78: 614-627.

Chauvet, L. and M. Merciery (2013). Do return migrants transfer political norms to their origin country? Evidence from Mali. Mimeo.

Cebi, M. (2007). Locus of Control and Human Capital Investment Revisited. Journal of Human Resources 42 (4): 919-932.

Chen, M.A. (2006). Rethinking the Informal Economy: Linkages with the Formal Economy and the Formal Regulatory Environment. In B. Guha-Khasnobis, R. Kanbur, E. Ostrom (eds), Linking the Formal and Informal Economy - Concepts and Policies. Oxford: Oxford University Press, pp. 75-92.

Chern, W. and G. Wang (1994). The Engel Function and Complete Food Demand System for Chinese Urban Households. China Economic Review 5(1): 35-57.

Chiapa, C., J.L. Garrido, and S. Prina (2010). The Effect of Social Programs and Exposure to Professional son the Educational Aspirations of the Poor. Economics of Education Review, forthcoming.

Chiodi, V., E. Jaimovich, and G. Montes-Rojas (2012). Migration, Remittances and Capital Accumulation: Evidence from Rural Mexico. Journal of Development Studies 48(8): 1139-1155.

Ciccone, A. (2002). Input Chains and Industrialization. Review of Economic Studies 69: 565-587.

Coleman, M. and T. DeLeire (2003). An Economic Model of Locus of Control and the Human Capital Investment Decision. Journal of Human Resources 38(3): 701-721.

Dalton, P.S., S. Ghosal, and A. Mani (2010). Poverty and Aspirations Failure. University of Warwick, CAGE Online Working Paper 22.

Damon, A. (2010). Agricultural Land Use and Asset Accumulation in Migrant Households: The Case of El Salvador. Journal of Development Studies 46(1): 162-189.

Davies, S., J. Easaw, and A. Ghoshray (2009). Mental Accounting and Remittances: A Study of Rural Malawian Households. Journal of Economic Psychology 30(3): 321-334.

De Brauw, A. and S. Rozelle (2008). Migration and Household Investment in Rural China. China Economic Review 19(2): 320-335.

De Haas, H. (2010). Migration and Development: A Theoretical Perspective. International Migration Review 44(1): 227-264.

De Mel, S., D. McKenzie, and C. Woodruff (2013). The Demand for, and Consequences of, Formalization among Informal Firms in Sri Lanka. American Economic Journal: Applied Economics 5(2): 122-50.

De Mel, S., D. McKenzie, and C. Woodruff (2008). Returns to Capital in Microenterprises: Evidence from a Field Experiment. Quarterly Journal of Economics 123 (4): 1329-1372.

De Paula, A. and J.A. Scheinkman (2007). The Informal Sector. NBER Working Paper 13486. 
Deaton, A. (1988). Quality, Quantity, and Spatial Variation of Price. The American Economic Review 78(3): 418-430.

Deaton, A. (1997). The Analysis of Household Surveys: A Micro-econometric Approach to Ddevelopment Ppolicy. Baltimore: Johns Hopkins University Press.

Delavande, A., X. Giné, and D. McKenzie (2011). Measuring Subjective Expectations in Developing Countries: A Critical Review and New Evidence. Journal of Development Economics 94(2): 151-163.

Démurger, S. and H. Xu (2011). Return Migrants: The Rise of New Entrepreneurs in Rural China. World Development 39(10): 1847-1861.

Dercon, S. (1998). Wealth, Risk and Activity Choice: Cattle in Western Tanzania. Journal of Development Economics 55(1): 1-42.

D'Haese, M., G. Van Huylenbroeck (2005). The Rise of Supermarkets and Changing Expenditure Patterns of Poor Rural Households Case Study in the Transkei area, South Africa. Food Policy 30(1): 97-113.

Diaz, L., D. Plat, and P. Pochet (2008). Household Transport Expenditure in Sub-Saharan African Cities: Measurement and Analysis. Journal of Transport Geography 16 (1): 1-13.

Dickens, W.T. and K. Lang (1985). A Test of Dual Labor Market Theory. American Economic Review 75(4): 792-805.

Docquier, F., E. Lodigiani, H. Rapoport, and M. Schiff (2011). Emigration and democracy. IZA Discussion Paper, No. 5496.

Dreby, J. and Stutz, L. (2012). Making Something of the Sacrifice: Gender, Migration and Mexican Children's Educational Aspirations. Global Networks 12(1): 71-90.

Dustmann, C. (1997). Return Migration, Uncertainty and Precautionary Savings. Journal of Development Economics 52(2): 295-316.

Dustmann, C. and O. Kirchkamp (2002). The Optimal Migration Duration and Activity Choice after Remigration. Journal of Development Economics 67(2): 351-72.

Elhorst, P.J. (1993). The Estimation of Investment Equations at the Farm Level. European Review of Agricultural Economics 20(2): 167-182.

Fajnzylber, P., W. F. Maloney, and G. V. Montes-Rojas (2011). Does formality improve micro-firm performance? Evidence from the Brazilian SIMPLES program. Journal of Development Economics 94(2): 262-276.

Fazzari, S., Hubbard, G., and Petersen, B. (1988). Financing Constraints and Corporate Investment. Brookings Papers on Economic Activity 1: 141-206.

Fields, G. (1975). Rural-Urban Migration, Urban Unemployment and Underemployment, and Jobsearch Activity in LDCs. Journal of Development Economics 2(2): 165-187.

Filmer, D. and L. Pritchett (2001). Estimating Wealth Effects without Expenditure Data-or tears: An Application to Educational Enrollments in States of India. Demography 38 (1): 115-132. 
Fontagne, L., Freudenberg, M., Gaulier, G. (2006). A systematic Decomposition of World Trade into Horizonal and Vertical IIT. Review of World Economics 142(3): 459-475.

Fortin, B., G. Laxroix and C. Montmarquette (2000). Are Underground Workers More Likely to Be Underground Consumers? The Economic Journal 110(466): 838-860.

Gasparini, L., and L. Tornarolli (2009). Labor Informality in Latin America and the Caribbean: Patterns and Trends from Household Survey Microdata. Desarrollo y Sociedad 63: 13-80.

Gërxhani, K. (2004). The Informal Sector in Developed and Less Developed Countries: A Literature survey. Public Choice 120(3/4): 267-300.

Gibson, J. (2002). Why Does the Engel Method Work? Food Demand, Economies of Size and Household Survey Methods. Oxford Bulletin of Economics and Statistics 64(4): 341-359.

Gibson, J. and K. Bonggeun (2007). Measurement Error in Recall Surveys and the Relationship between Household Size and Food Demand. American Journal of Agricultural Economics 89(2): 473-489.

Gilchrist, S. and C. P. Himmelberg (1995). Evidence on the Role of Cash Flow for Investment. Journal of Monetary Economics 36(3):541-572.

Gollier, C. R. and Zeckhauser (2002). Horizon Length and Portfolio Risk. Journal of Risk and Uncertainty 24(3): 195-212.

Griliches, Z. (1961). A Note on Serial Correlation Bias in Estimates of Distributed Lags. Econometrica 29(1): 65-73.

Griliches, Z. (1974). Errors in variables and other unobservables. Econometrica 42(6): 971-998.

Griliches, Z. and J. Mairesse (2005). Production Functions: The Search for Identification. NBER Working Paper 5067.

Grimm, M. and I. Günther (2006). Inter- and Intra-household Linkages between the Informal and Formal Sector. A Case Study for Urban Burkina Faso. In B. Guha-Khasnobis and R. Kanbur (eds), Informal Labor Markets and Development (pp. 155-179). London: Palgrave Macmillan.

Grimm, M., P. Knorringa, and J. Lay (2012). Constrained Gazelles: High Potentials in West Africa's Informal Economy. World Development 40(7): 1352-1368.

Grimm, M., J. Krüger, and J. Lay (2011). Barriers of Entry and Capital Returns in Informal Activities: Evidence from Sub-Saharan Africa. Review of Income and Wealth 57(s1): s27-s53.

Günther I. and A. Launov (2011). Informal Employment in Developing Countries: Opportunity or Last Resort? Journal of Development Economics 97(1): 88-98.

Harris, J. and M. Todaro (1970). Migration, Unemployment and Development: A Two-Sector Analysis. American Economic Review 60(1): 126-142.

Harriss, J.C. (1990). Linkages between the Formal and Informal Sectors in Developing Countries: A Review of the Literature. World Development Research Working Paper. ILO, Geneva. 
Hart, K. (1973). Informal income opportunities and urban employment in Ghana. Journal of Modern African Studies 11(1): 61-89.

Hartog, J. and Zorlu, A. (2009). How Important is Homeland Education for Refugees' Economic Position in The Netherlands? Journal of Population Economics 22(1): 219-246.

Hausman, J. (2001). Mismeasured Variables in Econometric Analysis: Problems from the Right and Problems from the Left. The Journal of Economic Perspectives 15(4): 57-67.

Heckman, J. (1979). Sample Selection Bias as a Specification Error. Econometrica 47(1): 153-161.

Hirschmann, A.O. (1958). The Strategy of Economic Development. Yale University Press, New Haven.

Hirschmann, A.O. (1977). A Generalized Linkage Approach to Development - with Special Reference to Staples. Economic Development and Cultural Change 25 (Supplement): 67-98.

Holmlund, H., M. Lindahl, and E. Plug (2011). The Causal Effect of Parents' Schooling on Children's Schooling: A Comparison of Estimation Methods. Journal of Economic Literature 49(3): 615-51.

Hubbard, R.G. (1998). Capital-market Imperfections and Investment. Journal of Economic Literature 36(1): 193-225.

Hubbard, R.G. and A.K. Kashyap (1992). Internal Net Worth and the Investment Process: An Application to U.S. Agriculture. Journal of Political Economy 100(3): 506-534.

Hugon, P. (1990). The Informal Sector Revisited (in Africa). In D. Turnham, B. Salome and A. Schwarz (eds), The Informal Sector Revisited. Paris: OECD Publication.

Humphrey, D. and H. Qxley (1976). Expenditure and Household-size Elasticities in Malawi: UrbanRural Comparisons, Demand Projections and a Summary of East African Findings. Journal of Development Studies 12(2): 252-269.

Hussmans, R. (2004). Statistical Definition of Informal Employment: Guidelines Endorsed by 17th ICLS (2003) in Delhi Group on Informal Sector, February. ILO, Geneva.

Ilahi, N. (1999). Return Migration and Occupational Change. Review of Development Economics 3(2): 170-186.

Imbens, G.W. and J.D. Angrist (1994). Identification and Estimation of Local Average Treatment Effects. Econometrica 62(2): 467-475.

Jensen, R. (2012). Do Labor Market Opportunities Affect Young Women's Work and Family Decisions? Experimental Evidence from India. Quarterly Journal of Economics, 127 (2): 753-792.

Kahneman, D. and A. Tversky (1984). Choices, values, and frames. American Psychologist 39(4): 341350.

Kandel, W. and G. Kao (2001). The Impact of Temporary Labor Migration on Mexican Children's Educational Aspirations and Performance. International Migration Review 35(4): 1205-1231.

Kandel, W. and D.S. Massey (2002). The Culture of Mexican Migration: A Theoretical and Empirical Analysis. Social Forces 80(3): 981-1004. 
Kedir, A. and S. Girma (2007). Quadratic Engel Curves with Measurement Error: Evidence from a Budget Survey. Oxford Bulletin of Economics and Statistics 69(1): 123-138.

Keen, M. (1986). Zero Expenditures and the Estimation of Engel Curves. Journal of Applied Econometrics 1(3): 277-286.

Kogszegi, B. and M. Rabin (2006). A Model of Reference-dependent Preferences. Quarterly Journal of Economics 121(4): 1133-1165.

Krishnan, P. and S. Krutikova (2010). Skill Formation in Bombay's Slums. University of Cambridge, Working Paper 1010.

La Porta, R. and A. Shleifer (2011). The Unofficial Economy in Africa. NBER Working Paper 16821.

Lachaud, J. (1990). The Urban Informal Sector and the Labour Market in Sub-Saharan Africa. In D. Turnham, B. Salomé, and A. Schwarz (eds), The Informal Sector Revisited (pp. 111-130). Paris: OECD Publication.

Lall, S. (1980). Vertical Inter-Firm Linkages in LDCs: An Empirical Study. Oxford Bulletin of Economics and Statistics 42(3): 203-226.

Lamb, R. (2003). Fertilizer Use, Risk, and Off-farm Labor Markets in the Semi-arid Tropics of India. American Journal of Agricultural Economics 85(2): 359-371.

Lee, E. S. (1966). A Theory of Migration. Demography 3(1): 47-57.

Leibenstein, H. (1968). Entrepreneurship and Development. American Economic Review 58(2): 72-83.

Lewbel, A. (1996). Demand Estimation with Expenditure Measurement Errors on the Left and Right Hand Side. The Review of Economics and Statistics 78(4): 718-725.

Lewis, W.A. (1954). Economic Development with Unlimited Supplies of Labor. Manchester School 22(2): 139-191.

Liviatan, N. (1961). Errors in Variables and Engel Curve Analysis. Econometrica 29(3): 336-362.

Livingstone, I. (1991). A Reassessment of Kenya's Rural and Urban Informal Sector. World Development 19(6): 651-670.

Lucas, R. (1987) Emigration to South Africa's Mines. American Economic Review 77(3): 313-330.

Macours, K. R. and Vakis (2009). Changing Households Investments and Aspirations Through Social Interactions. World Bank Research Working Paper 5137.

Maloney, W.F. (2004). Informality Revisited. World Development 32(7): 1159-1178.

Mansuri, G. (2006) Migration, School Attainment and Child Labor: Evidence from Rural Pakistan. Policy Research Working Paper 3945, World Bank.

Massell, B. and J. Heyer (1969). Household Expenditure in Nairobi: A Statistical Analysis of Consumer Behavior. Economic Development and Cultural Change 17(2): 212-234. 
Mazumdar, D. (1976). The Rural-Urban Wage Gap, Migration, and the Shadow Wage. Oxford Economic Papers 28(3): 406-425.

Mazumdar, D. (1976). The Urban Informal Sector. World Development 4(8): 655-679.

McCormick, B. and J. Wahba (2003). Return International Migration and Geographical Inequality: The case of Egypt. Journal of African Economics 12(4): 500-532.

McKenzie, D. (2005). Measuring Inequality with Asset Indicators. Journal of Population Economics, 18 (2): 229-260.

McKenzie, D. and H. Rapoport (2006). Can Migration Reduce Educational Attainment? Evidence from Mexico. World Bank, Policy Research Working Paper 3952.

Mckenzie, D. and H. Rapoport (2007). Network Effects and the Dynamics of Migration and Inequality: Theory and Evidence from Mexico. Journal of Development Economics 84(1): 1-24.

McKenzie, D. and H. Rapoport (2010). Self-Selection patterns in Mexico-U.S. migration: The role of migration networks. Review of Economics and Statistics 92(4): 811-821.

McKenzie, D. and Y. S. Sakho (2010). Does It Pay Firms to Register for Taxes? The Impact of Formality on Firm Profitability. Journal of Development Economics 91(1): 15-24.

McKenzie, D. and C. Woodruff (2008). Experimental evidence on returns to capital and access to finance in Mexico. World Bank Economic Review 22(3): 457-482.

McKenzie, D., J. Gibson, and S. Stillman (2012). A land of milk and honey with streets paved with gold: Do emigrants have over-optimistic expectations about incomes abroad? Journal of Development Economcis, 102: 116-127.

Mead, D.C. (1984). Of Contracts and Subcontracts: Small Firms in Vertically Dis-integrated Production/Distribution Systems in LDCs. World Development 12: 1095-1106.

Mendola, M. (2008). Migration and technological change in rural households: Complements or substitutes? Journal of Development Economics 85(1-2): 150-175.

Merella, V. (2006). Engel's Curve and Product Differentiation: A Dynamic Analysis of the Effects of Quality on Consumer's Choice. International Review of Economics 53(2): 157-182.

Mesnard, A. (2004). Temporary migration and capital market imperfections. Oxford Economic Papers 56(2): 242-262.

Min, I., C. Fang C., and Q. Li (2000). Investigation of Patterns in Food-away-from-home Expenditure for China. China Economic Review (15): 457-476.

Mookherjee, D., S. Napel and R. Ray (2010). Aspirations, Segregation, and Occupational Choice. Journal of the European Economic Association 8(1): 139-168.

Mountford, A. (1997). Can a Brain Drain Be Good for Growth in the Source Economy? Journal of Development Economics 53(2): 287-303. 
Munshi, K. (2003). Networks in the Modern Economy: Mexican Migrants in the U. S. Labor Market. Quarterly Journal of Economics 118(2): 549-599.

Okunade, A. (1985). Engel Curves in Developing Nations: The Case of Africa. Eastern Africa Economic Review 1(1): 13-22.

Omar Mahmoud, T., H. Rapoport, A. Steinmayr, and C. Trebsch (2012). Emigration and Political Change, mimeo.

Orrenius, P., M. Zavodny, J. Cañas, and R. Coronado (2010). Do Remittances Boost Economic Development? Evidence from Mexican States. Law and Business Review of the Americas, 16 (4): 803-821.

Ostby, I. and T. Gulilat (1969). A Statistical Study of Household Expenditure in Addis Ababa. Eastern Africa Economic Review 1(2): 63-74.

Perry, G. E., W.F. Maloney, O.S. Arias, P. Fajnzylber, A.D. Mason, and J. Saavedra-Chanduvi (2007). Informality : Exit and Exclusion. World Bank, Washington DC.

Piracha, M.F. and R. Vadean (2010). Return Migration and Occupational Choice: Evidence from Albania. World Development 38 (8): 1141-1155.

Quisumbing, A. and S. McNiven (2010). Moving Forward, Looking Back: The Impact of Migration and Remittances on Assets, Consumption, and Credit Constraints in the Rural Philippines. Journal of Development Studies 46(1): 91-113.

Ranis, G. and F. Stewart (1999). V-Goods and the Role of the Urban Informal Sector in Development. Economic Development and Cultural Change 47(2): 259-281.

Ray, D. (2006). Aspirations, Poverty and Economic Change. In A. Banerjee, R. Benabou, and D. Mookherjee (eds.), Understanding Poverty (pp. 409-422). Oxford University Press.

Reilly, B., G. Krstic and M. Cominetta (2006). Purchasing From Informal Markets: Evidence from Serbia. Applied Economics Quarterly 52 (1): 239-264.

Rodriguez-Clare, A. (1996). Multinationals, Linkages, and Economic Development. American Economic Review 86(4): 852-873.

Rozelle, S., J.E. Taylor, and A. De Brauw (1999). Migration, Remittances, and Agricultural Productivity in China. American Economic Review 89(2): 287-291.

Sanromá, E., Ramos, R., and Simón, H. (2009). Immigrant Wages in the Spanish Labour Market: Does the Origin of Human Capital Matter? IZA Discussion Paper 4157.

Schneider, F., and D. H. Enste (2000). Shadow Economies: Size, Causes, and Consequences. Journal of Economic Literature 38 (1):77-114.

Sethuraman, S. (1997). Urban Poverty and the Informal Sector: A Critical Assessment of Current Strategies. Geneva: International Labour Organization.

Shea, J. (2000). Does Parents' Money Matter? Journal of Public Economics 77(2): 155-184. 
Simon, H. (1959) Theories of Decision-Making in Economics and Behavioral Science. American Economic Review 49(3): 253-283.

Sjaastad, A. H. (1962). The Costs and Returns of Human Migration. Journal of Political Economy 70(S5): 80-93.

Spilimbergo, A. (2009). Democracy and Foreign Education. American Economic Review 99(1): 528-43.

Staiger, D., and Stock, J.H. (1997). Instrumental Variables Regression with Weak Instruments. Econometrica 65(3): 557-586.

Stark, O. and D. Bloom (1985). The New Economics of Labor Migration. American Economic Review 75(2): 173-178.

Stark, O. and J.E Taylor (1989). Relative Depriviation and International Migration. Demography 26(1): 1-14.

Stark, O., C. Helmenstein and A. Prskawetz (1997). A Brain Gain with a Brain Drain. Economics Letters 55(2): 227-234.

Stock, J.H. and M. Yogo (2002). Testing for Weak Instruments in Linear IV Regression. NBER Technical Working Paper 284.

Taylor, J.E. (1999). The New Economics of Labor Migration and the Role of Remittances in the Migration Process. International Migration 37(1): 63-88.

Taylor, J.E. and A. Lopez-Feldman (2010). Does Migration Make Rural Households More Productive? Evidence from Mexico. Journal of Development Studies 46(1): 68-90.

Taylor, J.E., S. Rozelle, and A. De Brauw (2003). Migration and Incomes in Source Communities: A New Economics of Migration Perspective from China. Economic Development and Cultural Change 52(1): 75-101.

Teklu, T. (1996). Food Demand Studies in Sub-Saharan Africa: A Survey of Empirical Evidence. Food Policy 21(6): 479-496.

Theil, H. (1979). The Effect of Measurement Errors in the Estimation of Demand Systems. Economic Letters 3 (4): 373-376.

Tiwari, R.S. and M.S. Goel (2002). Migration Pattern, Poverty Profile and Consumption Pattern: A Study of Unregistered Informal Sector Workers in Cities of Agra and Kanpur in Uttar Pradesh and Puri in Orissa. The Indian Journal of Economics 82(3): 311-335.

Todaro, M.P. (1969). A Model of Labor Migration and Urban Unemployment in Less Developed Countries. American Economic Review 59(1): 138-148.

Vidal, J-P. (1998) The Effect of Emigration on Human Capital Formation. Journal of Population Economics 11(4): 589-600.

Wan, G. (1996). Income Elasticities of Household Demand in Rural China: Estimates from Crosssectional Survey Data. Journal of Economic Studies 23(3): 18-33. 
Williamson, O.E. (1971). The Vertical Integration of Production: Market Failure Considerations. American Economic Review 61(2): 112-123.

Woodruff, C. and R. Zenteno (2007). Migration Networks and Microenterprises in Mexico. Journal of Development Economics 82(2): 509-528.

Wooldridge, J. (2002). Econometric Analysis of Cross Section and Panel Data. MIT Press, Cambridge, MA.

Wouterse, F. and J. Taylor (2008). Migration and Income Diversification: Evidence from Burkina Faso. World Development 36(4): 625-640.

Xaba, J., P. Horn, and S. Motala (2002). The Informal Sector in Sub-Saharan Africa. International Labour Office (ILO), Working Paper, 2002/10.

Yang, D. (2008). International Migration, Remittances, and Household Investment: Evidence from Philippine Migrants' Exchange Rate Shocks. Economic Journal 118(528): 591-630.

Zeldes, S. (1989). Consumption and Liquidity Constraints: An Empirical Investigation. Journal of Political Economy 97(2): 305-346. 
Ich versichere an Eides Statt, dass ich die eingereichte Dissertation

„Essays on International Migration and Informal Markets in Developing Countries"

selbstständig verfasst habe.

Anderer als der von mir angegebenen Hilfsmittel und Schriften habe ich mich nicht bedient. Alle wörtlich oder sinngemäß den Schriften anderer Autorinnen und/oder Autoren entnommenen Stellen habe ich kenntlich gemacht.

Marcus Böhme, Kiel, 17. Juni 2013 